\title{
Environmental Controls, Similitude, and Scaling of Stream Dissolved Oxygen across the Pacific Coast of U.S.A
}

\author{
Filmon Araya
}

Follow this and additional works at: https://researchrepository.wvu.edu/etd

\section{Recommended Citation}

Araya, Filmon, "Environmental Controls, Similitude, and Scaling of Stream Dissolved Oxygen across the Pacific Coast of U.S.A" (2018). Graduate Theses, Dissertations, and Problem Reports. 5117.

https://researchrepository.wvu.edu/etd/5117

This Thesis is protected by copyright and/or related rights. It has been brought to you by the The Research Repository @ WVU with permission from the rights-holder(s). You are free to use this Thesis in any way that is permitted by the copyright and related rights legislation that applies to your use. For other uses you must obtain permission from the rights-holder(s) directly, unless additional rights are indicated by a Creative Commons license in the record and/ or on the work itself. This Thesis has been accepted for inclusion in WVU Graduate Theses, Dissertations, and Problem Reports collection by an authorized administrator of The Research Repository @ WVU. For more information, please contact researchrepository@mail.wvu.edu. 


\title{
Environmental Controls, Similitude, and Scaling of Stream Dissolved Oxygen across the Pacific Coast of U.S.A.
}

\author{
Filmon Araya \\ Thesis Submitted \\ to the Benjamin M. Statler College of Engineering and Mineral Resources \\ at West Virginia University \\ in partial fulfillment of the requirements for the degree of \\ Master of Science in \\ Civil Engineering
}

Dr. Omar I. Abdul-Aziz, Ph.D., Chair

Dr. Seung Ho Hong, Ph.D.

Dr. P.V. Vijay, Ph.D.

Department of Civil and Environmental Engineering

Morgantown, West Virginia

2018

Keywords: Data analytics, coastal streams, dissolved oxygen, relative linkages, similitude, scaling, Pacific coast, United States. 


\section{Abstract \\ Environmental Controls, Similitude, and Scaling of Stream Dissolved Oxygen across the Pacific Coast of USA.}

\section{Filmon Araya}

Dissolved oxygen (DO) is a key indicator for water quality and the general health of stream ecosystems. However, the dynamics of stream DO is controlled by myriad interacting environmental drivers. This thesis investigates the major environmental drivers, emergent similitude (similarity leading to parametric reductions), and scaling of stream DO across the Pacific Coast of U.S.A. The research was conducted by assembling a dataset for 1998-2015 at 35 water quality monitoring stations of U.S. Geological Survey and Environmental Protection Agency. Pearson correlation matrix, principal component analysis, and factor analysis were employed to identify the interrelations and groupings of stream DO and the environmental drivers. Power-law based partial least squares regression (PLSR) models, with a bootstrap Monte Carlo procedure (1000 iterations), were developed to reliably estimate the dominant controls of DO by resolving multi-collinearity among the environmental drivers. In the Pacific Northwest (Washington and Oregon) and southern California, water temperature was the most dominant driver of DO in majority of the streams, suggesting an environmental regime dictated by climatic control. However, in central through northern California, the in-stream DO was controlled by multiple drivers (water temperature, $\mathrm{pH}$, stream flow, and total phosphorus), exhibiting a mixed environmental regime controlled by stream metabolism. Dimensional analysis was then conducted with the dominant variables to investigate any emergent similitude, and formulate mechanistically meaningful dimensionless numbers to represent the collective as well as contrasting environmental controls of stream DO. Plot of the response and predictor dimensionless number was found to collapse observations from diverse streams into a single dimensionless curve, indicating a remarkable emergent pattern along the Pacific Coast. A threshold value of the driver dimensionless number emphasized the existence of two environmental regimes, representing the climatic versus metabolic controls of stream DO. The dimensionless curve was estimated with observed data by using a power-law scaling function, which was then used as a non-linear empirical model to robustly predict stream DO in different environmental regimes along the U.S. Pacific Coast (NashSutcliffe Efficiency, NSE=0.72). The research findings and tools would facilitate a robust prediction and assessment of stream water quality and ecosystem health across the Pacific Coast of U.S.A. and beyond. 


\section{Dedication}

I dedicate this thesis to my lovely mother, Mnya Bahre Nayzgi, who inspires me and reminds me that education is a privilege. 


\section{Acknowledgements}

First and foremost, praises and thanks to the Almighty God for his showers of blessings throughout my research work to complete it successfully.

Then I would like to express my deep and sincere gratitude to my advisor and committee chair, Dr. Omar I. Abdul-Aziz, for providing the research opportunity and giving excellent guidance throughout this project. His dynamism, vision, sincerity, and motivation have deeply inspired me. The guidance, advice, encouragement, and support from my advisor have been indispensable in completion of this work. I would also like to thank my committee members, Dr. Seung Ho Hong and Dr. P.V. Vijay, for their advice and providing their time to give insightful comments. This research is funded by a CAREER Award to Dr. Omar I. Abdul-Aziz from the U.S. National Science Foundation (NSF) Environmental Sustainability Program. I also acknowledge funding support from the WVU Faculty Start-up grant, given to Dr. Omar I. Abdul-Aziz.

I would like to express my deepest thanks to Shakil Ahmed (Ph.D. student) for his effort, valuable guidance, and suggestions for my research. I would also like to express my gratitude to all Ecological and Water Resources Engineering Lab (EWREL) members of 2017.

I am extremely grateful to my loving mother, Mnya, for her prayer, caring, and sacrifice for educating and preparing me for my future. Words cannot express the gratefulness I have for her; she has been always loving, patient, and supportive mother throughout my studies. Also I express my thanks to my sister, Rahel, and all my family members for their support, encouragement, and for having faith in me.

Finally, I would like to thank all my friends for all the love and support that I have received without which I could not have achieved this target. 


\section{Table of Contents}

Chapter $\quad$ Page

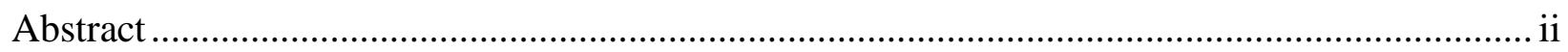

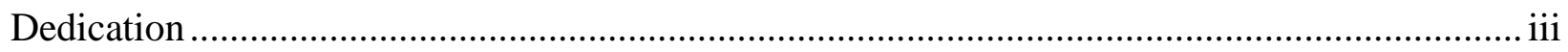

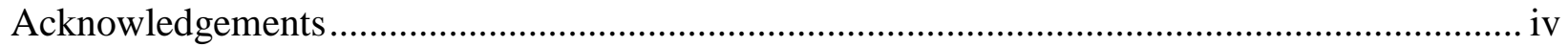

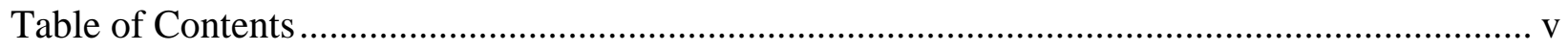

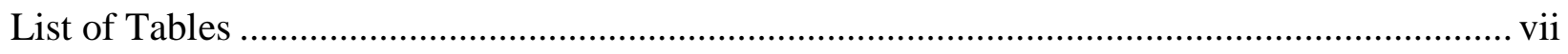

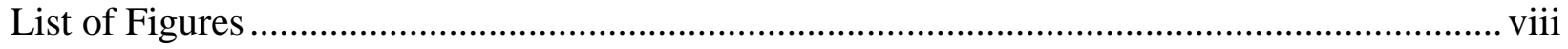

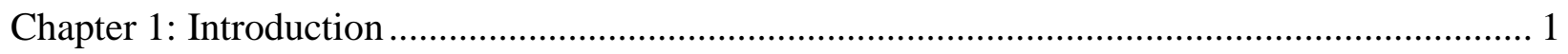

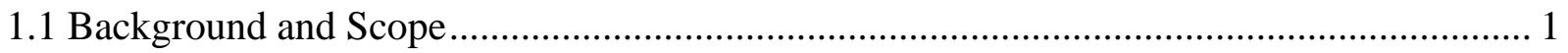

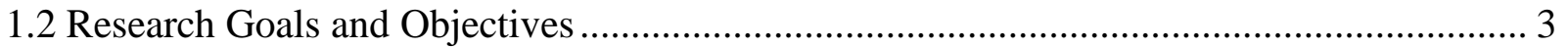

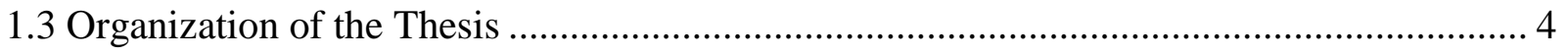

Chapter 2: Dynamic Environmental Controls of Stream Dissolved Oxygen across the Pacific

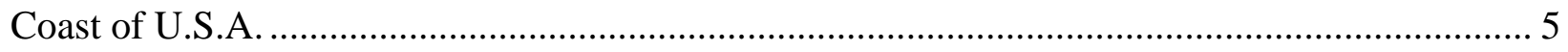

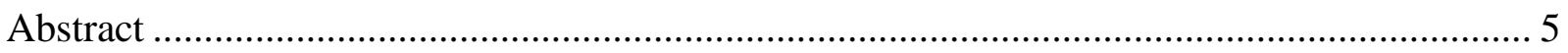

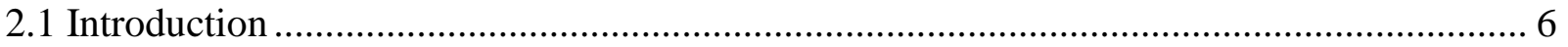

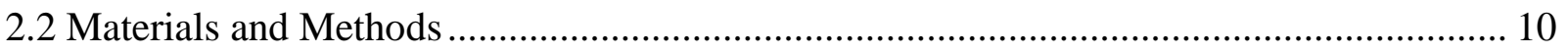

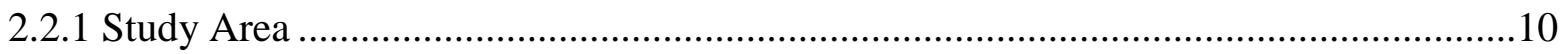

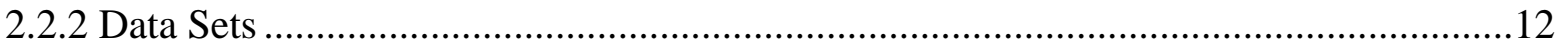

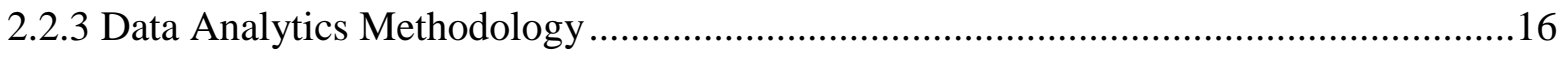

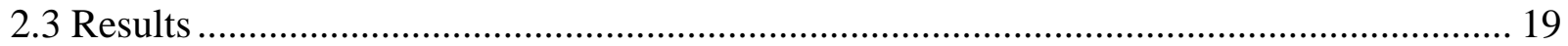

2.3.1 Mutual Correspondences of the Dynamic Environmental Drivers.............................19

2.3.2 Relative Orientations and Interrelations of Stream DO with Environmental Drivers ...21

2.3.3 Major Water Quality Drivers based on Independent Latent Factors ..........................24

2.3.4 Estimations of the Relative Linkages of Stream DO with the Drivers........................25

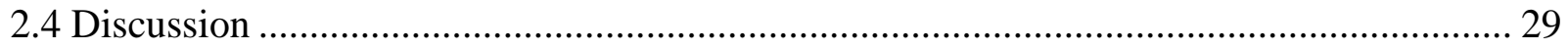

2.4.1 Relative Controls of Environmental Drivers on Stream DO ....................................29

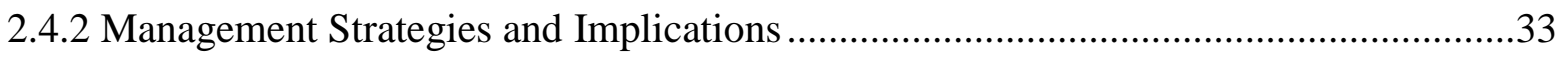

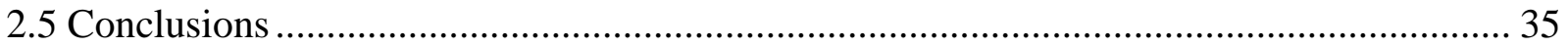

Chapter 3: Similitude and Scaling of Stream Dissolved Oxygen across the Pacific Coast of

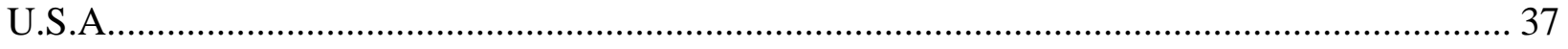

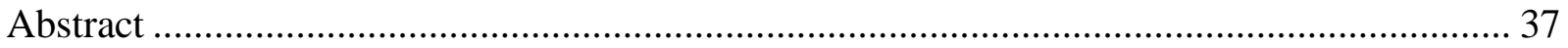

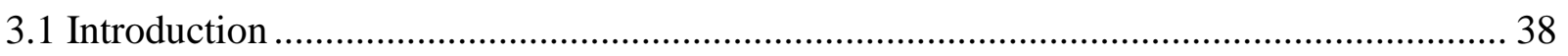

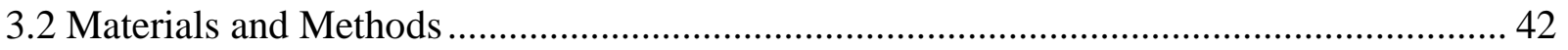

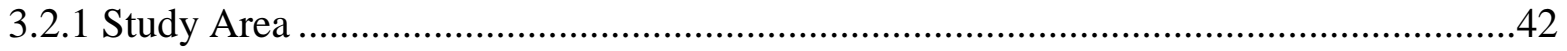

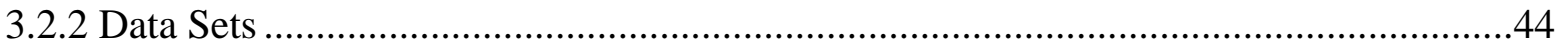




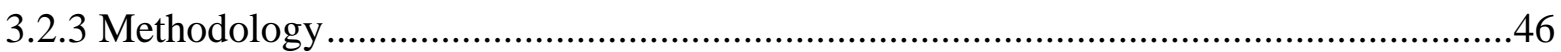

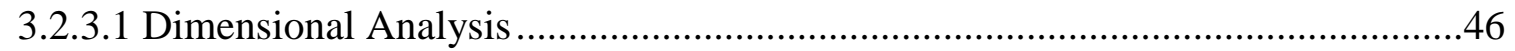

3.2.3.2 Investigating Similitude and Environmental Regimes .......................................50

3.2.3.3 Determination of the Regimes-specific Environmental Linkages.........................51

3.2.3.4 Development of Scaling Relationships and Predictive Models...........................52

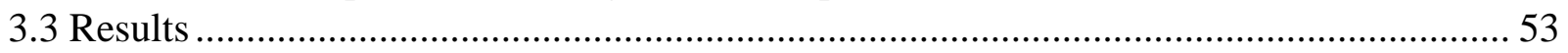

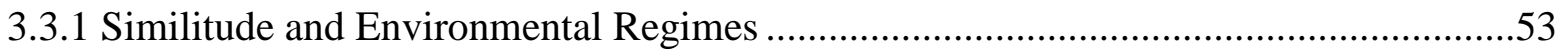

3.3.2 Regime-Specific Relative Linkages of the Environmental Drivers ..............................55

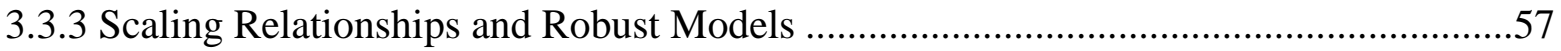

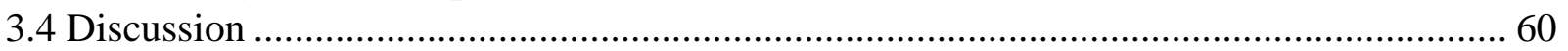

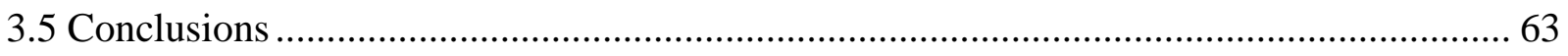

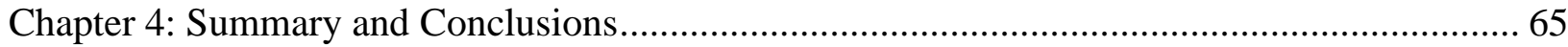

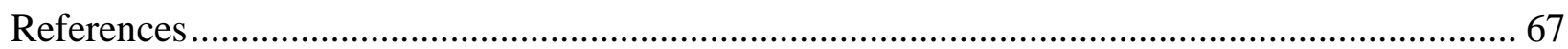

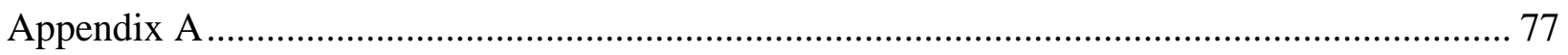

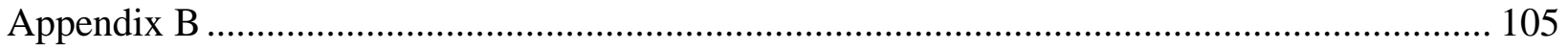




\section{List of Tables}

Table 2.1: Ensemble mean and standard deviations (in parenthesis) of the observed stream DO and the dynamic environmental drivers across the Pacific Coast of U.S.A

Table 2.2: Ensemble mean Pearson correlation coefficients (r) between stream DO and the dynamic environmental drivers

Table 2.3: Major latent factors with their optimized loadings on the participatory variables for selected sites from four types of environmental regimes.

Table 2.4: Mean coefficients $(\beta)$ (and standard deviations in parenthesis) of the Z-score PLSR models after 1000 Monte-Carlo simulations for the four environmental regimes...... 26

Table 2.5: Ensemble mean of the aggregated model coefficients $(\beta)$ along with standard deviations (in parenthesis) with four environmental process components in different environmental regimes

Table 3.1: Summary of water quality and hydro-geometric variables.

Table 3.2: Variables used in dimensionless analysis and their corresponding units and dimensions

Table 3.3: Estimated coefficients $(\beta)$ of the Z-score PLSR models for the two environmental regimes

Table 3.4: The estimated model parameters and model fitting efficiency (with validation in parenthesis) for predicting stream DO 


\section{List of Figures}

Figure 1.1: Schematic diagram of sources and sinks of stream DO

Figure 2.1: Study area and the incorporated water quality monitoring stations across the Pacific

Coast of U.S.A

Figure 2.2: The data analytics framework to determine the relative linkages of stream DO with the dynamic environmental drivers

Figure 2.3: Biplots from principal component (PC) analysis, showing the relative orientations and interrelations of stream DO with the environmental drivers for the selected sites from four types of environmental regimes: (a) Type I, (b) Type II, (c) Type III, and (d) Type IV. Percent variance explained by each PC is shown in parenthesis

Figure 2.4: Plot of cross-validated (a) Nash-Sutcliffe efficiency (NSE), (b) normalized AIC, and (c) Eigenvalue with the number of partial least squares components for all sites 27

Figure 3.1: Study area and the water quality monitoring stations with hydro-geometric data across the Pacific Coast of U.S.A

Figure 3.2: Plot of the predictor dimensionless group $\left(\Pi_{\mathrm{r}}\right)$ with the response dimensionless group (DO*): collapse of (a) all original data and (b) bin-based averaged data from different streams across different environmental regimes 54

Figure 3.3: Plot of cross-validated (a) normalized AIC and (b) Nash-Sutcliffe efficiency (NSE) with the number of partial least square components for all sites 56

Figure 3.4: Plot of observed vs. predicted stream dissolved oxygen across the Pacific Coast of

U.S.A. 59 


\section{Chapter 1: Introduction}

\subsection{Background and Scope}

The Federal Clean Water Act (CWA) has been the backbone of surface water quality protection in the United States since 1972 [Lyon and Stein, 2008]. However, water quality has been continuously deteriorating due to increasing pressure on the environment. Dissolved oxygen (DO) is a key indicator of surface water quality and ecosystem health [Brown and Power, 2011; Moore et al., 2009; Rajwa-Kuligiewicz et al., 2015]. Subject to the variation of environmental drivers in relation to climate, hydrology, and land use/cover, DO concentration tends to vary in time (hours, days, years) and space in the same as well as in different streams. Understanding the dominant controls and predicting the dynamics of stream DO is, therefore, crucial to ensure clean water under a changing climate and environment. However, existing literature lacks large-scale investigations of stream DO dynamics in relation to the environmental drivers, particularly in the context of coastal urban/natural environments across the U.S. Pacific Coast.

The major environmental process components of stream DO are shown with a simple schematic diagram (Figure 1.1). The major sinks of stream DO are autotrophic and heterotrophic respiration [Cai et al., 2011; $\mathrm{Xu}$ and $\mathrm{Xu}, 2016$ ] following eutrophication due to nutrient (e.g., nitrogen and phosphorous) enrichment in water [Diaz and Rosenberg, 2008; Hondzo and Wang, 2002]. In contrast, major sources of stream DO are reaeration (i.e., air-water exchange) and photosynthesis by the aquatic autotrophs. Stream DO can also be reduced due to increase in stream temperature [Shrestha and Kazama, 2007]. Higher temperature reduces DO by increasing the metabolic rate of aquatic organisms and the rate of chemical reactions, as well as by reducing the density and dissolution capacity of water [Chapra, 2008; Conley et al., 2011; Meire et al., 2013]. 
Further, flow rate, salinity, and atmospheric pressure are also among the environmental drivers that can affect the solubility of DO in water [Chapra, 2008]. Stream discharge (flow rate) can increase stream DO by aeration through turbulence and minimize DO consumption by diluting nutrients. However, it may also affect DO negatively by bringing sediments and particulate nutrients, enhancing turbidity and/or eutrophication in the streams.

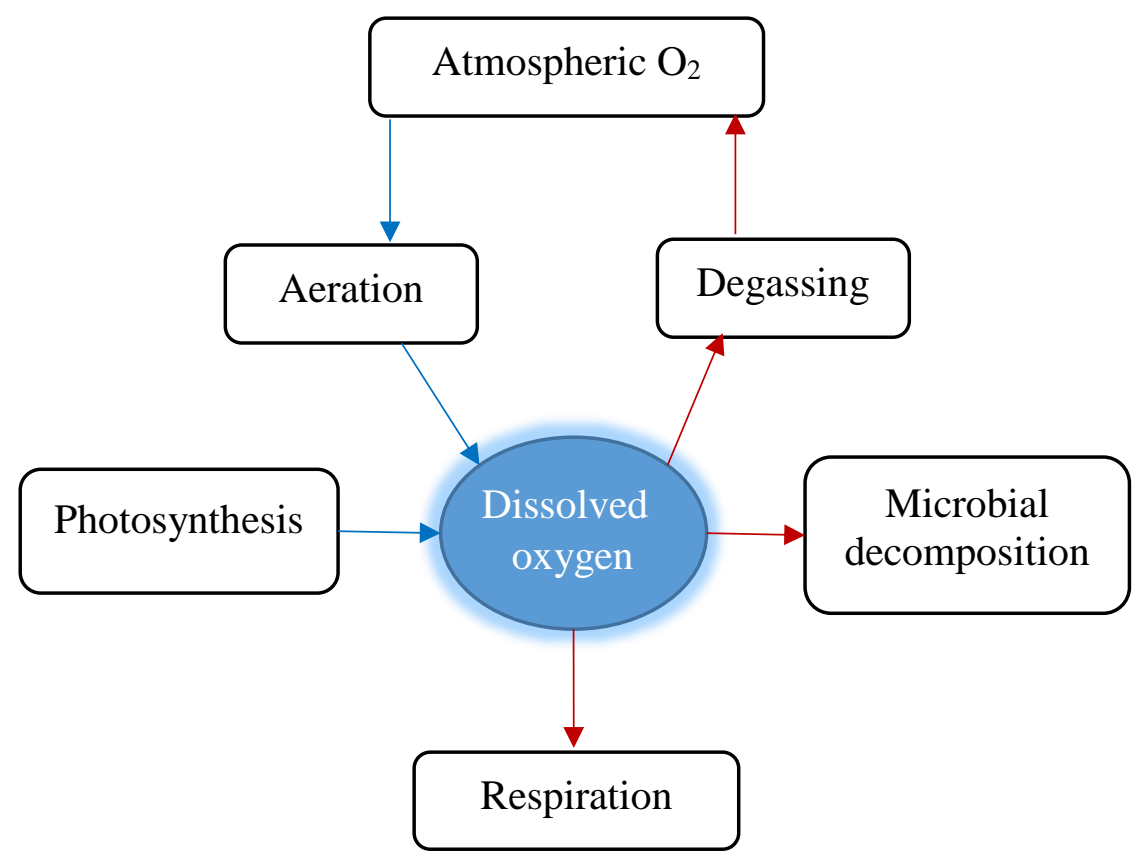

Figure 1.1: Schematic diagram of major sources and sinks of stream DO.

Much research has investigated the links and predictions of stream DO dynamics with the environmental drivers. For example, Prasad et al. [2011] predicted dissolved oxygen as a function of water temperature, salinity and dissolved nutrient concentrations in the Chesapeake Bay. Ji et al. [2017] predicted DO concentration in the hypoxic Wen-Ruin Tang River, China. Rabalais et al. [2002] found DO depletion through eutrophication in the Gulf of Mexico. Cai et al. [2011] reported a strong positive link of stream DO with $\mathrm{pH}$ in the northern Gulf of Mexico. However, the existing studies often used regression-based modeling approaches to estimate the links of 
stream DO with the drivers in a small spatial scale without resolution of multi-collinearity (mutual correlations) among the interacting drivers. The findings were, therefore, likely impacted by the spurious correlations of the corresponding environmental data matrices.

The environmental drivers of stream DO are interconnected to each other and their complex interactions shape the stream water quality. Understanding and estimating the relative linkages of stream DO with the dynamic environmental drivers by resolving multi-collinearity can provide relatively unbiased information and useful insights into the stream water quality dynamics [AbdulAziz and Ahmed, 2017]. Application of similitude and dimensional analysis in stream water quality dynamics can further help through parametric reductions and unravelling emergent patterns to develop a general understanding in various environmental conditions [Miragliotta, 2011; Warnaars et al., 2007]. Meaningful and dominant dimensionless numbers can then be utilized to robustly model and predict DO in diverse streams. On this backdrop, this study focuses to identify the dominant environmental drivers and leverage the knowledge to investigate similitude and scaling of DO in diverse streams across the Pacific Coast of U.S.A.

\subsection{Research Goals and Objectives}

The overall research goal of this thesis is to unravel major environmental drivers, emergent similitude (parametric reductions), and scaling of stream DO across the Pacific Coast of U.S.A.

The specific research objectives are as follows:

1. To quantify the relative linkages of coastal stream DO with the environmental drivers by employing a systematic data analytics framework across the Pacific Coast of U.S.A.

2. To investigate emergent similitude and scaling of coastal stream DO by formulating meaningful dimensionless numbers. 
3. To leverage the knowledge of the dominant environmental drivers, similitude, and scaling in the development of generalized model to predict stream DO across the Pacific Coast of U.S.A.

The research findings and tools are expected to provide new information and insights into the dynamic environmental process components that controls DO in coastal streams. Knowledge of the dominant drivers, emergent similitude, and scaling can then lead to robust modeling and predictions of coastal stream DO. The research outcomes would help set priority for management of stream ecosystems across the U.S. Pacific Coast and around the world.

\subsection{Organization of the Thesis}

This thesis is presented in four distinct chapters. The current chapter provides a brief introduction and overview of the overall thesis, including background and scope, research goal and objectives along with the organization of the thesis. Chapter 2 employs a systematic data analytics framework to examine the interrelations and quantify the relative linkages of the coastal stream DO with the dynamic environmental drivers across the large spatial scale of U.S. Pacific Coast. Chapter 3 presents the investigation of biogeochemical-ecological similitude, environmental regimes, and scaling relationships of stream DO using dimensional analysis. The scaling relationships were finally leveraged to develop a generalized model predict DO in streams across the Pacific Coast. Chapter 4 summarizes the overall findings and conclusions of this research and thesis. 


\title{
Chapter 2: Dynamic Environmental Controls of Stream Dissolved Oxygen across the Pacific Coast of U.S.A.
}

\begin{abstract}
Dissolved oxygen (DO) is one of the limiting factors for stream metabolism, and a key indicator to assess the health of aquatic ecosystem and pollution status. However, the dynamics of stream DO is controlled by a multitude of interacting environmental drivers. Therefore, a systematic data analytics approach was utilized to determine the relative linkages of stream DO with the dynamic environmental drivers across the large spatial scale of U.S. Pacific Coast. Multivariate statistical techniques of Pearson correlation matrix, principal component analysis, and factor analysis were applied to a complex water quality dataset (1998-2015) incorporating 35 stream water quality monitoring stations of USGS NWIS and EPA STORET. Power-law based partial least squares regression (PLSR) models with a bootstrap Monte Carlo procedure (1000 iterations) were developed to reliably estimate the relative linkages by resolving multi-collinearity (Nash-Sutcliffe Efficiency, NSE $=0.50-0.94)$. Based on the dominant controls of DO, the data analytics categorized the streams into four distinct environmental regimes across the Pacific Coast of U.S.A. In the Pacific Northwest (Washington and Oregon) and southern California, water temperature was the most dominant driver of DO in majority of the streams, suggesting an environmental regime controlled by climate. However, in central and northern California, stream DO was controlled by multiple drivers (i.e., water temperature, $\mathrm{pH}$, stream flow, and total phosphorus), exhibiting a mixed environmental regime dictated by stream metabolism. Further, total phosphorus (TP) appeared to be the limiting nutrient for most streams. The estimated linkages and insights would be useful to identify management priorities to achieve healthy coastal stream ecosystems across the Pacific Coast of U.S.A. and similar regions around the world.
\end{abstract}




\subsection{Introduction}

Surface water quality has been a matter of serious concern with the development of economy, rapid industrialization, and urban sprawl across the Globe. Natural processes (e.g., photosynthesis and respiration, reaeration and atmospheric diffusion) and anthropogenic pollutions adversely affects stream water quality [Abdul-Aziz and Ishtiaq, 2014]. Dissolved oxygen (DO) is a key indicator for water quality and the general health of stream ecosystems. DO is vital for aquatic lives as it impacts the biological as well as the biogeochemical processes [Brown and Power, 2011; Moore et al., 2009]. Subject to the variations in hydro-climatic and biogeochemical drivers (e.g., stream flow, water temperature, and organic waste), DO concentration tends to vary at different streams or at the same site in different days. Coastal stream DO depletion is a widespread phenomenon that appears to be growing globally and has become one of the most serious environmental problems [Meier et al., 2011; Rabalais et al., 2002; Vaquer-Sunyer and Duarte, 2008]. So, it is crucial to investigate and understand the relative linkages of stream DO with the relevant environmental drivers in coastal streams so that appropriate management can be undertaken to control pollutions in coastal waters [Simeonov et al., 2003; Singh et al., 2004]. Although linking stream water quality with the environmental drivers has been a focus of much research [Shrestha and Kazama, 2007; Y Wan et al., 2014], the relative linkages of stream DO with the hydro-climatic and biogeochemical drivers are yet to be understood well in the context of growing coastal urban/natural environments across a large spatial scale. The knowledge gap motivates further research to understand and manage changes in DO in coastal streams.

Temporal variations of coastal stream DO are the result of complex interactions of physical and biogeochemical factors [Kemp et al., 2009; Meire et al., 2013]. Photosynthesis and reaeration from the atmosphere (air-water exchange) are the oxygen-producing processes (sources) of stream 
DO [Odum, 1956]. In contrast, nutrient enrichment (eutrophication) and climate change impacting the biological, chemical, and physical characteristics — are the two major oxygen consuming processes (sinks) of stream DO [Meire et al., 2013]. For example, water temperature can affect the solubility of compounds in water, metabolic rates of aquatic organisms, and density of water [Chapra, 2008]. Further, stream discharge (flow rate) has a positive effect on stream DO, likely due to an increase in the renewal rate (reaeration) [Iriarte et al., 2014] and a minimization of DO consumption by diluting nutrients (e.g., nitrogen, phosphorus). However, stream flow can also affect negatively by increasing turbidity and/or bringing in nutrients that can cause eutrophication. In addition, specific conductance (surrogate of salinity) is also an another driver that affects the solubility of DO by creating stress on the photosynthetic organisms, reducing the photosynthesis rate of phytoplankton [Cloern, 1996].

The dynamics of DO in coastal waters and estuaries has been a topic of much research. For example, Iriarte et al. [2014] reported the influence of hydro-climatic factors and eutrophication on stream DO in small estuary Urdaibai (inner Bay of Biscay). Prasad et al. [2011] predicted DO as a function of water temperature, salinity and dissolved nutrient concentrations as well as it's implication in the Chesapeake Bay. Ficklin et al. [2013] reported the effects of climate change on stream temperature, DO, and sediment concentration in Sierra Nevada, California. Ji et al. [2017] predicted DO concentrations in the hypoxic Wen-Ruin Tang River, China. Rabalais et al. [2002] found DO depletion through eutrophication in the Gulf of Mexico. Cai et al. [2011] also reported a strong positive linkage of DO with $\mathrm{pH}$ in the northern Gulf of Mexico located near the tropical zone. Shrestha and Kazama [2007] found a strong negative relationship between water temperature and DO in Fuji river basin, Japan. Overall, most of the previous studies on stream DO focused on identifying the sources and sinks in site-specific scale. However, a large spatial scale study is vital 
to achieve greater insights, and its inference could help scientists as well as policy makers to assess and manage the environmental health and ecological status of coastal streams.

For effective pollution control and water resource management, it is indispensable to interpret complex water quality data. However, interrelationships among parameters (physical, chemical, biological, and microbiological properties) in a large and complex data matrix are difficult to analyze and interpret meaningfully [Chapman, 1992; Zhou et al., 2007]. For a complete understanding of surface water quality, which often involves multi-collinear data sets (high mutual correlations among the drivers), the application of multivariate statistical techniques is inevitable. Multivariate statistical techniques have been widely applied in environmental data reduction and in interpretation of multi-constituent physicochemical and biochemical measurements [Wenning and Erickson, 1994]. The most commonly used multivariate statistical techniques in empirical investigations of stream water quality are principal component analysis (PCA), factor analysis (FA), cluster analysis (CA), and multiple regression modeling. They can facilitate in identifying important components or factors related to surface water quality while accounting for most of the variances of the system [Ouyang et al., 2006; Shrestha and Kazama, 2007].

Multivariate pattern recognition techniques reduce the number of variables to a small number of indices and also attempt to preserve the intrinsic relationships in the original dataset [Filik Iscen et al., 2008]. For example, Koklu et al. [2009] employed PCA, FA, and multiple regression techniques to assess the water quality of the Melen River System, Turkey. Y Wan et al. [2014] provided a comprehensive account of studies, involving multivariate techniques to link stream water quality indicators mainly with their land use and hydrologic drivers. Shrestha and Kazama [2007] employed PCA and FA for the evaluation of spatio-temporal variations by assembling a large water quality data set for the Fuji River Basin, Japan. Simeonov et al. [2003] 
employed cluster analysis (CA), principal component analysis (PCA), and multiple regression analysis in Northern Greece. Ouyang et al. [2006] assessed the seasonal changes in surface water quality of the Lower Saint John River (Florida, USA) through implementing PCA. Li et al. [2009] implemented CA, PCA, FA, and discriminant analysis (DA) for evaluating the temporal and spatial variations in large water quality data for the Songhua River Basin, China. Huang et al. [2011] employed CA, DA, and PCA for the assessment of temporal and spatial variation of coastal water quality and source identification along Macau Peninsula.

Clearly, the previous studies provided valuable insights into the applications of PCA, FA, and multiple regression techniques to infer the linkages between the water quality indicators and their potential drivers for environmental management and protection. But those traditional regression modeling can lead to biased results due to multi-collinearity of data matrix. Partial least squares regression (PLSR) can resolve multi-collinearity by performing the model fitting on the transformed orthogonal planes [Ishtiaq and Abdul-Aziz, 2015]. PLSR differs from the conventional multiple linear regression technique (MLR) mainly in that it can provide stable predictions even when there is significant multi-collinearity among the predictor variables [Singh et al., 2007]. Some previous studies used PLSR modeling for surface water quality [Abdul-Aziz and Ahmed, 2017; Aulinger et al., 2004; Singh et al., 2007; Wold, 2001]. However, a comprehensive application of those multivariate techniques for coastal water quality assessment across the Pacific Coast of U.S.A has not yet been conducted.

This paper aims to quantify the relative linkages of stream DO with the dynamic environmental drivers across the large spatial gradient of the U.S Pacific Coast. The research is conducted by integrating four complementary layers (correlation matrix, PCA, FA, and PLSR) of data analytics into a single systematic framework. Based on the dominant stream water quality 
processes, the relative linkage patterns in different streams were compared to investigate potential environmental regimes across the U.S. Pacific Coast. The research provides an objective empirical framework to achieve crucial insights and useful information for managing coastal stream water quality across the Pacific Coast of U.S.A. and around the world.

\subsection{Materials and Methods}

\subsubsection{Study Area}

The study includes 35 stream water quality monitoring sites of coastal watershed across the Pacific Coast of U.S.A. The study area, located between $33^{\circ} 0^{\prime} 0^{\prime \prime}$ and $49^{\circ} 0^{\prime} 0^{\prime \prime} \mathrm{N}$ and between $114^{\circ} 02^{\prime} 0^{\prime \prime}$ and $124^{\circ} 08^{\prime} 0^{\prime \prime} \mathrm{W}$, encompasses three U.S. states: California, Oregon, and Washington, representing a reasonable spatial distribution along the Pacific Coast (Figure 2.1). The study area consisted of three climatic regions [Gleason et al., 2011]: (i) Pacific Northwest (Oregon and Washington), (ii) central and northern California, and (iii) southern California. However, the entire Pacific Coast of U.S.A is located in the temperate zone [Peel et al., 2007]. It has an oceanic climate in its northern edge towards the Canada-U.S. border, warm to cold climate in central and northern California, and Mediterranean climate in southern California towards the Mexico-US border.

There are numerous rivers such as the Columbia, Klamath, and Sacramento Rivers that drain to the Pacific Coast. Columbia River is the largest in the region, draining through 259,000 square miles of the Pacific Northwest. The coastal watersheds were identified using the ArcGIS shape file of National Oceanic and Atmospheric Administration (NOAA) coastal watersheds [Percy Pacheco, personal communications, 2016]. Overall, the coastal counties of U.S.A. are home for more than $53 \%$ of total U.S. population, representing $25 \%$ of the total land area [Crossett et al., 2004; Culliton, 1998]. NOAA defined a coastal county as follows: (1) a county with at least 15\% 
of its total land area located within the nation's coastal watershed; or (2) a county with a portion of its land that accounts for at least $15 \%$ of a coastal catalogue unit [Culliton, 1998].

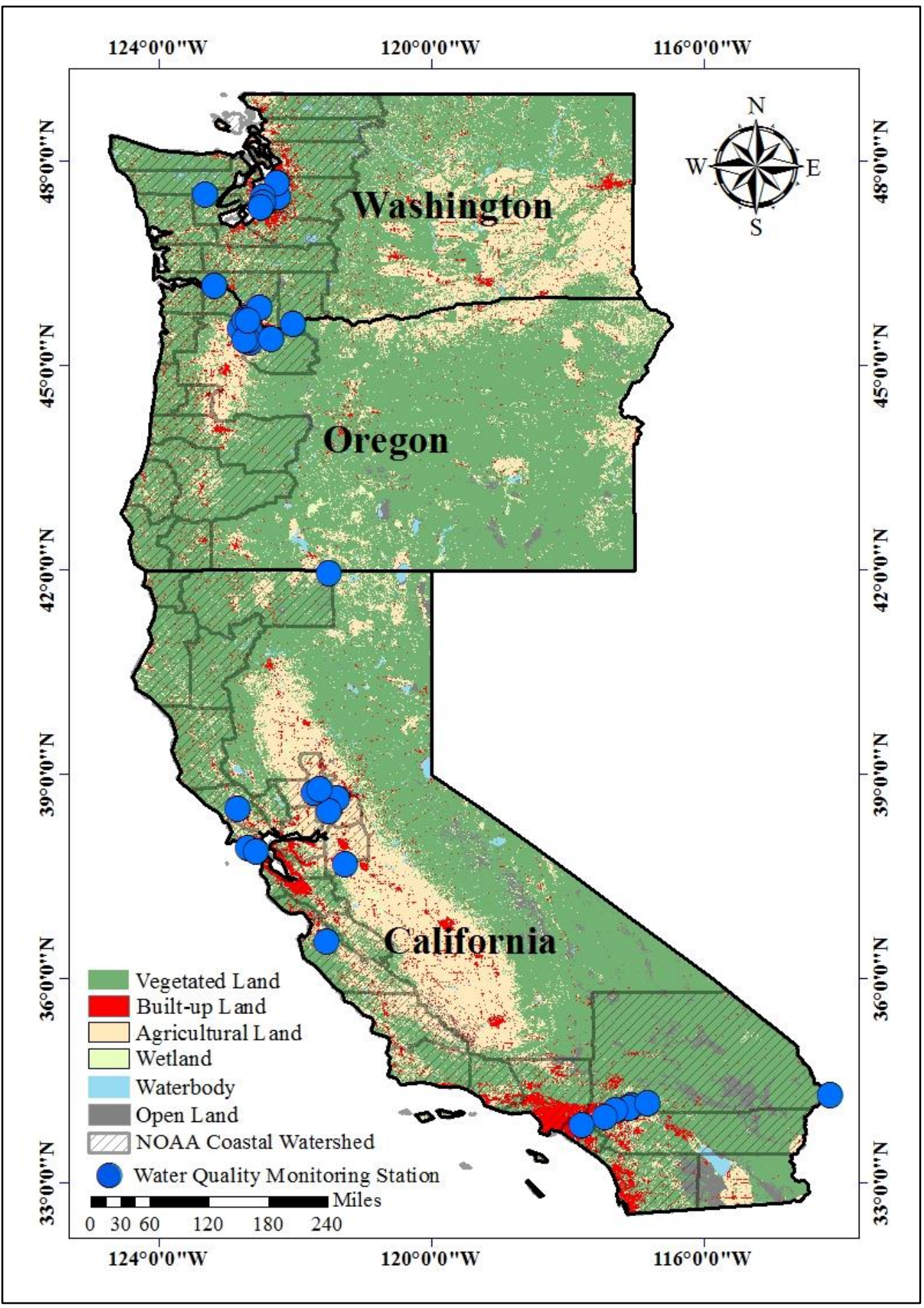

Figure 2.1: Study area and the incorporated water quality monitoring stations across the Pacific Coast of U.S.A. 


\subsubsection{Data Sets}

Temporal data (1998-2015) of DO and the associated environmental variables were gathered for 35 stream water quality monitoring stations of U.S. Geological Survey (USGS) and U.S. Environmental Protection Agency (US EPA) from the National Water Quality Monitoring Council (NWQMC) databases [NWQMC, 2017] (Table 2.1). The water quality data represented grab samples mostly at quarterly interval across the year. The gathered variables are: total nitrogen (TN), total phosphorous (TP), water temperature (TW), specific conductance (SC), potential of hydrogen $(\mathrm{pH})$, dissolved oxygen (DO), and stream flow (Q). Data of solar radiation (SR) and atmospheric pressure (AP) were collected from $4 \times 4 \mathrm{~km}$ grid cells of the National Solar Radiation Database [NSRDB, 2017]. The set of participatory variables were selected based on their importance to indicate and driver stream water quality [Chang, 2008; Chapra, 2008] and a preliminary data analysis. The extreme values (i.e., outliers) in the data were detected and removed using an interquartile range (IQR) criteria [Ben-Gal, 2010; Tukey, 1977]. Any observation outside the range between $\mathrm{Q} 1-2 * \mathrm{IQR}$ and $\mathrm{Q} 3+2 * \mathrm{IQR}(\mathrm{Q} 1=25$ th quartile, $\mathrm{Q} 3=75$ th quartile, and IQR $=$ Q3-Q1) were removed from the dataset. 
Table 2.1: Ensemble mean and standard deviations (in parenthesis) of the observed stream DO and the dynamic environmental drivers across the Pacific Coast of U.S.A.

\begin{tabular}{|c|c|c|c|c|c|c|c|c|c|c|c|c|}
\hline Station ID & I & Year & $\mathrm{n}$ & $\mathrm{TN}(\mathrm{mg} / \mathrm{L})$ & $\mathrm{TP}(\mathrm{mg} / \mathrm{L})$ & $\mathrm{SC}(\mu \mathrm{S} / \mathrm{cm})$ & $\mathrm{pH}$ & $\mathrm{Q}\left(\mathrm{m}^{3} / \mathrm{s}\right)$ & AP (mbar) & $\mathrm{TW}\left({ }^{0} \mathrm{C}\right)$ & $\mathrm{SR}\left(\mathrm{w} / \mathrm{m}^{2}\right)$ & $\overline{\mathrm{DO}}(\mathrm{mg} / \mathrm{L})$ \\
\hline USGS-12128000 & WA_1 & 1998-03 & 37 & $1.46(0.18)$ & $0.07(0.02)$ & $222.46(37.93)$ & $7.92(0.19)$ & $0.20(0.11)$ & $978.38(7.07)$ & 11.51(3.61) & $374.41(263.01)$ & $10.65(1.04)$ \\
\hline USGS-12056500 & WA_2 & 1998-15 & 46 & - & $0.01(0.00)$ & $49.67(13.50)$ & $7.60(0.27)$ & $12.66(9.00)$ & 968.12(5.07) & $6.83(2.81)$ & $433.89(270.57)$ & $12.18(0.91)$ \\
\hline USGS-12113390 & WA_3 & 1998-02 & 54 & $0.56(0.17)$ & $0.05(0.02)$ & $108.09(36.38)$ & 7.47(0.09) & $37.01(22.56)$ & $976.24(6.21)$ & $10.97(4.52)$ & $368.14(273.04)$ & $10.02(1.40)$ \\
\hline a-VA12A & WA_4 & 2006-11 & 64 & $1.01(0.16)$ & $0.05(0.01)$ & $157.39(33.47)$ & $7.66(0.16)$ & - & $1010.80(6.47)$ & $8.75(2.75)$ & $328.79(247.36)$ & $11.26(0.91)$ \\
\hline a-VA37A & WA_5 & 2006-07 & 11 & $1.69(0.21)$ & $0.04(0.01)$ & $117.97(33.24)$ & $7.50(0.20)$ & - & $1008.12(5.76)$ & $9.56(2.63)$ & $323.73(275.67)$ & $10.70(0.73)$ \\
\hline${ }^{\mathrm{a}}-\mathrm{VA} 41 \mathrm{~A}$ & WA_6 & 2006-12 & 60 & $1.27(0.29)$ & $0.06(0.02)$ & $135.27(19.05)$ & $7.46(0.19)$ & - & $1010.38(6.50)$ & $9.23(2.99)$ & $225.90(208.60)$ & $10.97(0.90)$ \\
\hline a-VA42A & WA_7 & 2006-13 & 73 & $1.14(0.15)$ & $0.04(0.01)$ & $136.96(26.76)$ & 7.64(0.19) & - & $1010.21(6.03)$ & $9.33(3.36)$ & $283.03(224.17)$ & $11.09(1.09)$ \\
\hline USGS-4551221* & WA_8 & 2003-15 & 16 & $0.88(0.33)$ & $0.04(0.01)$ & $55.81(12.29)$ & $6.98(0.26)$ & - & 979.31(3.90) & $12.15(3.71)$ & $457.19(247.09)$ & $10.45(0.91)$ \\
\hline USGS-14211955 & WA_9 & 2011-12 & 25 & $0.93(0.18)$ & $0.10(0.04)$ & $136.68(32.24)$ & $7.98(0.33)$ & $44.98(19.84)$ & 991.32(6.09) & $14.04(5.66)$ & $444.54(276.71)$ & $10.48(1.97)$ \\
\hline USGS-14211920 & WA_10 & 2010-12 & 33 & $1.61(0.39)$ & $0.11(0.02)$ & $151.18(38.57)$ & $7.62(0.31)$ & $2.01(0.89)$ & 990.08(7.76) & $10.42(3.59)$ & $234.89(242.00)$ & $10.34(1.12)$ \\
\hline USGS-14144805 & WA_11 & $2010-12$ & 16 & $0.57(0.17)$ & $0.04(0.01)$ & $148.56(19.57)$ & $8.05(0.20)$ & $2.34(1.00)$ & 988.66(5.73) & $12.46(6.57)$ & $353.19(293.06)$ & $11.88(1.61)$ \\
\hline USGS-14246900 & OR_1 & 1998-14 & 114 & $0.44(0.17)$ & $0.04(0.01)$ & $134.54(15.45)$ & $7.82(0.24)$ & $8577.24(3810.48)$ & 993.22(5.67) & $11.33(5.79)$ & $428.10(276.46)$ & $11.55(1.47)$ \\
\hline USGS-14128910 & OR_2 & 1998-00 & 15 & $0.35(0.13)$ & $0.03(0.01)$ & $134.53(20.02)$ & 7.93(0.13) & 9365.31(1692.98) & $938.50(3.19)$ & $13.74(5.20)$ & $355.13(267.30)$ & $11.21(1.48)$ \\
\hline USGS-4533391* & OR_3 & 1998-08 & 111 & $1.03(0.55)$ & $0.11(0.03)$ & 116.44(31.29) & $7.50(0.18)$ & $0.02(0.02)$ & 993.11(5.94) & $9.05(3.35)$ & $329.75(232.62)$ & $11.26(1.26)$ \\
\hline USGS-14206419 & OR_4 & 1998-09 & 196 & $1.36(0.31)$ & $0.12(0.04)$ & $142.52(21.71)$ & $7.58(0.19)$ & $0.03(0.01)$ & 991.98(6.07) & $9.53(3.45)$ & $327.80(241.32)$ & $11.26(1.11)$ \\
\hline USGS-14211720 & OR_5 & 2003-09 & 60 & $0.71(0.28)$ & $0.06(0.01)$ & $72.73(9.57)$ & $7.27(0.17)$ & $1008.77(705.21)$ & $990.96(6.47)$ & $12.09(5.55)$ & $441.33(246.86)$ & $11.40(1.87)$ \\
\hline USGS-45241412 & OR_6 & $2003-15$ & 14 & $1.18(0.39)$ & $0.05(0.01)$ & $68.79(11.68)$ & $7.26(0.38)$ & $33.47(47.99)$ & $991.28(4.06)$ & $12.24(3.05)$ & $390.89(267.32)$ & $10.69(0.71)$ \\
\hline USGS-4523011* & OR_7 & $2000-10$ & 221 & $1.16(0.30)$ & $0.18(0.06)$ & $206.87(43.81)$ & $7.06(0.23)$ & - & 992.04(5.94) & $12.55(5.03)$ & $345.59(229.26)$ & $6.01(2.13)$ \\
\hline USGS-14207050 & OR_8 & 1998-11 & 61 & $2.55(0.82)$ & $0.16(0.06)$ & $123.98(42.10)$ & $7.29(0.21)$ & $81.08(67.12)$ & $992.47(7.33)$ & $8.48(2.16)$ & $238.86(182.54)$ & $10.25(1.03)$ \\
\hline
\end{tabular}

Note: (1) "Year" and “n” refer to data collection year and the sample size, respectively. (2) '-' indicates the "missing data". (3) "a" refers to KINGCOUNTY from STORET water quality station. (4) “*” refer to USGS-455122122310600, USGS-453339122481301, USGS-452912122291200, USGS-452301122442301, USGS-375159122343801, and USGS-341014116494801 respectively. (5) TN, TP, SC, pH, Q, AP, TW, SR, and DO refer to total nitrogen, total phosphorus, specific conductance, potential of hydrogen, stream flow, atmospheric pressure, water temperature, solar radiation, and dissolved oxygen, respectively. 
Table 2.1: (continued).

\begin{tabular}{|c|c|c|c|c|c|c|c|c|c|c|c|c|}
\hline Station ID & I & Year & $\mathrm{n}$ & $\mathrm{TN}(\mathrm{mg} / \mathrm{L})$ & $\mathrm{TP}(\mathrm{mg} / \mathrm{L})$ & $\mathrm{SC}(\mu \mathrm{S} / \mathrm{cm})$ & $\mathrm{pH}$ & $\mathrm{Q}\left(\mathrm{m}^{3} / \mathrm{s}\right)$ & $\mathrm{AP}$ (mbar) & $\mathrm{TW}\left({ }^{\circ} \mathrm{C}\right)$ & $\mathrm{Ra}\left(\mathrm{w} / \mathrm{m}^{2}\right)$ & $\mathrm{DO}(\mathrm{mg} / \mathrm{L})$ \\
\hline USGS-14207600 & OR_9 & 1998-09 & 379 & $3.02(0.90)$ & $0.10(0.04)$ & $224.99(59.53)$ & $7.53(0.20)$ & $15.22(14.46)$ & $991.59(5.05)$ & $16.65(4.81)$ & $502.36(258.10)$ & $9.86(0.89)$ \\
\hline USGS-11488495 & CA_1 & 2013-15 & 50 & $1.82(0.73)$ & $0.41(0.13)$ & $434.76(226.12)$ & $8.38(0.50)$ & $0.80(0.59)$ & $856.07(4.00)$ & $11.80(7.68)$ & $502.91(246.06)$ & $8.67(3.87)$ \\
\hline USGS-11391100 & CA_2 & 1998-03 & 23 & $0.67(0.22)$ & $0.17(0.05)$ & $361.83(200.62)$ & 7.74(0.24) & - & $985.38(5.93)$ & $16.16(5.87)$ & $570.48(278.53)$ & $8.19(1.32)$ \\
\hline USGS-11452600 & CA_3 & 2010-11 & 16 & $1.40(0.75)$ & $0.21(0.28)$ & $580.31(239.65)$ & $8.39(0.18)$ & 46.81(96.39) & $1003.56(6.91)$ & $10.92(4.36)$ & $333.72(283.91)$ & $11.23(1.81)$ \\
\hline USGS-11447360 & CA_4 & 1998-02 & 17 & $1.29(0.29)$ & $0.20(0.06)$ & $260.82(68.88)$ & $7.42(0.26)$ & $0.04(0.01)$ & $1003.97(3.91)$ & $16.14(4.96)$ & $572.94(307.28)$ & $8.06(1.64)$ \\
\hline USGS-11466800 & CA_5 & 2003-10 & 11 & $0.54(0.11)$ & $0.32(0.08)$ & $533.64(44.88)$ & $7.85(0.09)$ & $0.33(0.28)$ & $988.24(3.35)$ & $19.72(2.30)$ & $641.86(248.35)$ & $7.41(0.82)$ \\
\hline USGS-11447650 & CA_6 & 1998-15 & 103 & $0.34(0.13)$ & $0.06(0.02)$ & $153.66(31.12)$ & 7.73(0.18) & $519.08(260.25)$ & $1004.84(4.80)$ & $15.35(4.79)$ & $641.36(275.96)$ & $9.74(1.22)$ \\
\hline USGS-11460170 & CA_7 & 1998-01 & 15 & $0.67(0.45)$ & $0.09(0.03)$ & $247.67(38.53)$ & $7.69(0.18)$ & $0.23(0.36)$ & 1014.31(4.94) & $12.75(2.37)$ & $614.43(290.54)$ & $9.41(1.24)$ \\
\hline USGS-3751591* & CA_8 & 1999-01 & 14 & - & $0.02(0.01)$ & $232.36(27.41)$ & $7.60(0.15)$ & $0.11(0.17)$ & $1014.80(5.42)$ & $12.22(2.23)$ & $586.61(257.21)$ & $8.48(1.93)$ \\
\hline USGS-11152300 & CA_9 & $2002-13$ & 45 & $1.30(0.90)$ & $0.17(0.08)$ & $451.76(124.38)$ & $8.42(0.19)$ & $3.04(3.06)$ & $970.26(3.67)$ & $17.64(3.45)$ & $808.73(214.24)$ & $10.18(0.91)$ \\
\hline USGS-09427520 & CA_10 & 1999-15 & 54 & $0.54(0.08)$ & - & $983.19(65.17)$ & $8.15(0.14)$ & $317.72(154.29)$ & 938.92(3.31) & $20.18(5.50)$ & $730.94(220.25)$ & $8.85(1.51)$ \\
\hline USGS-3410141* & CA_11 & 1998-01 & 16 & - & $0.01(0.01)$ & $66.38(6.94)$ & 7.76(0.17) & $0.15(0.07)$ & $892.43(1.95)$ & $8.38(4.36)$ & $384.84(269.07)$ & $9.50(1.34)$ \\
\hline USGS-11049400 & CA_12 & 2003-06 & 17 & $0.51(0.92)$ & $0.05(0.12)$ & $255.06(56.21)$ & $8.09(0.09)$ & $0.64(1.12)$ & $927.76(3.72)$ & $14.03(3.34)$ & $605.59(323.00)$ & $9.31(0.94)$ \\
\hline USGS-11051500 & CA_13 & 1999-01 & 22 & $0.30(0.13)$ & $0.03(0.04)$ & $399.09(108.95)$ & $8.46(0.28)$ & $0.22(0.31)$ & $928.93(2.41)$ & $18.18(6.32)$ & $643.00(254.62)$ & $9.22(1.07)$ \\
\hline USGS-11060400 & CA_14 & 1998-02 & 50 & $0.76(0.32)$ & $0.03(0.01)$ & $760.28(162.64)$ & $8.23(0.48)$ & $0.06(0.04)$ & $929.03(3.40)$ & $22.33(6.00)$ & $546.28(256.08)$ & $9.60(1.91)$ \\
\hline USGS-11066460 & CA_15 & 1998-00 & 22 & $7.66(1.51)$ & $0.80(0.07)$ & $902.64(28.12)$ & $8.30(0.06)$ & $2.58(0.48)$ & $928.36(2.92)$ & $22.14(5.21)$ & $703.11(276.42)$ & $8.38(1.17)$ \\
\hline USGS-11075610 & CA_16 & 1998-00 & 34 & $5.84(1.02)$ & $0.98(0.16)$ & $940.38(114.88)$ & $8.30(0.11)$ & $8.32(2.92)$ & $975.39(4.41)$ & $18.41(4.42)$ & $579.13(268.60)$ & $9.63(1.16)$ \\
\hline
\end{tabular}

Note: (1) "Year" and “n” refer to data collection year and the sample size, respectively. (2) “-” indicates the "missing data”. (3) “*” refer to USGS375159122343801 and USGS-341014116494801 respectively. (4) TN, TP, SC, pH, Q, AP, TW, Ra, and DO refer to total nitrogen, total phosphorus, specific conductance, potential of hydrogen, stream flow, atmospheric pressure, water temperature, solar radiation, and dissolved oxygen, respectively. 
The data sets represented different environmental process components to control stream water quality. The control of 'climate' component was represented by TW and SR, the 'nutrient' component was represented by $\mathrm{TN}$ and $\mathrm{TP}$, the 'hydro-atmosphere' component was represented by Q and AP, and the control from 'redox' component was represented by SC (a surrogate of salinity) and $\mathrm{pH}$. The data set (Table 2.1) represented wide ranges and considerable gradients of environmental conditions, as well as their controls on stream water quality. Further details on the water quality data are given in the Appendix.

Drainage areas (watersheds) of the stream water quality sites were developed using $30 \mathrm{~m}$ digital elevation model [USGS, 2017a] in ESRI ArcGIS 10.4 platform. For each of the watershed, the percentages of various land uses and imperviousness were estimated from the $30 \mathrm{~m}$ data of National Land Cover Database (NLCD) for 2011 [NLCD, 2017]. Different land uses were classified into six broad categories based on the guidelines of NLCD [2017] as follows: (1) builtup land (BUL), indicating developed areas; (2) agricultural land (AGR), indicating agricultural and grazing areas; (3) waterbody (WAT), indicating open water; (4) vegetated land (VEG), indicating forest and other non-agricultural vegetated lands; (5) open land (OPN), indicating barren lands; (6) wetland (WET), indicating wetlands (Figure A1). The percentages of land uses (Table 9A) can be useful to explain the dynamic controls of stream DO in different environments. 


\subsubsection{Data Analytics Methodology}

The research employed a systematic data-analytics methodology [Abdul-Aziz and Ahmed, 2017], involving Pearson correlation matrix, principal component analysis (PCA), factor analysis (FA), and partial least squares regression (PLSR) (Figure 2.2). Data for all response and predictor variables were first logarithmically $(\log 10)$ transformed to incorporate the non-linear interactions, and then Z-normalized to bring different scales and units to a comparable reference scale (i.e., $Z=\frac{x-\mu}{\sigma}$, where $\mathrm{x}=\log _{10}$-transformed variable, $\mu=$ mean of $\mathrm{x}$, and $\sigma=$ standard deviation of $\mathrm{x}$ ).

The data analytics were performed by coding in MATLAB R2017a.

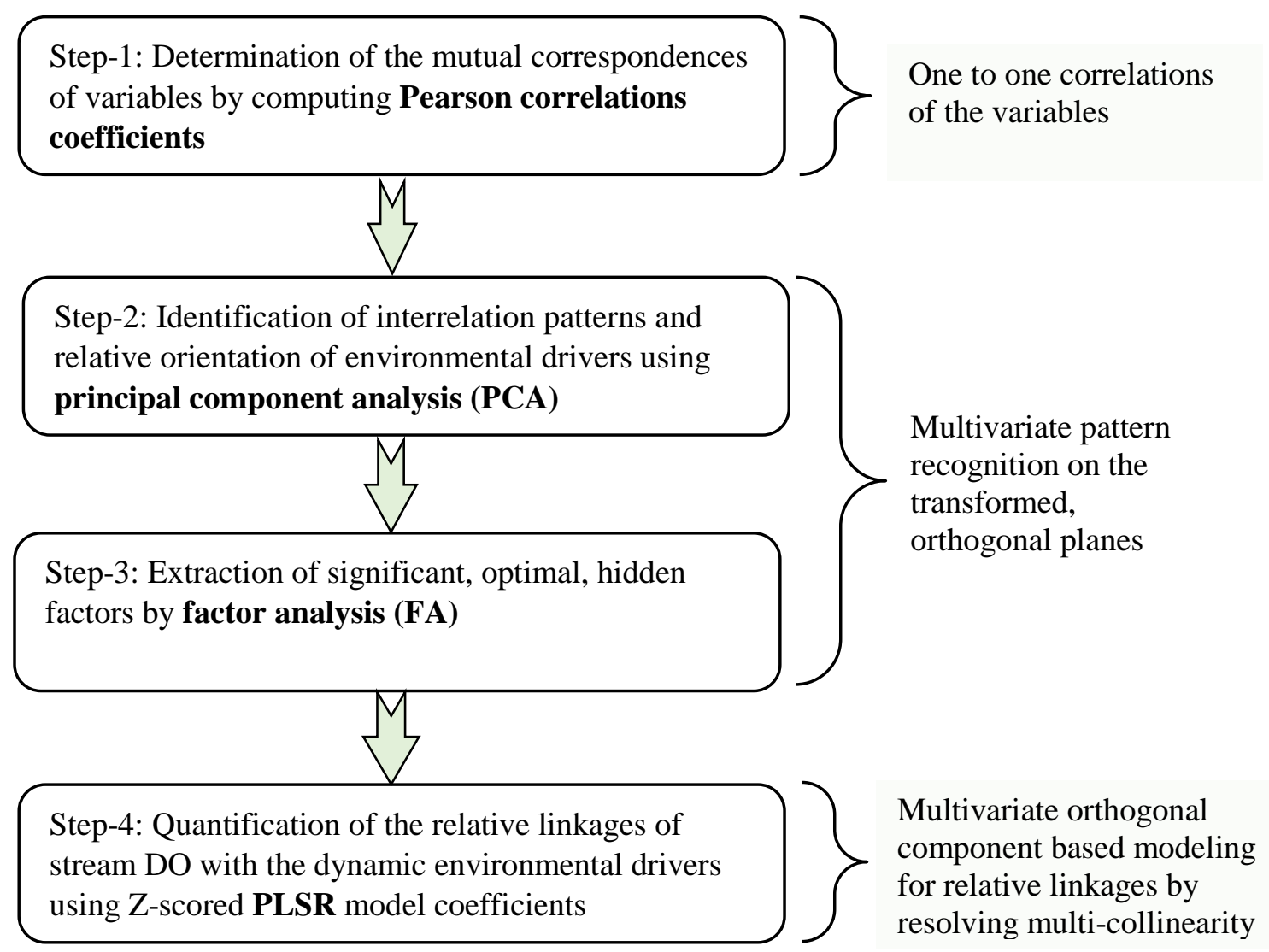

Figure 2.2: The data analytics framework to determine the relative linkages of stream DO with the dynamic environmental drivers. 
Pearson correlation coefficients (r) were first computed to obtain preliminary information on the dependency between stream DO and the dynamic environmental drivers for the different sites. Then triangular correlation matrix for each monitoring station represented the multi-collinear structure of the data. The inter-relationships of stream DO and the dynamic environmental drivers were further examined using PCA and FA by resolving multi-collinearity in the orthogonal (i.e., independent) plane. The mathematical approaches of PCA and FA are different [Jolliffe, 2002], but a relatively unbiased and confirmatory representation of the interrelationships and groupings among variables can be obtained by using them in concert. Each principal component (PC) is a weighted combination of all original variables [Jolliffe, 2002; Peres-Neto, 2003]. The number of PCs is thus inherently equal to the number of original variables. In contrast, the original variables are decomposed into a smaller set of common factors in FA. Therefore, the number of factors is inherently smaller than the number of original variables [Johnson, 1992; Jolliffe, 2002]. A "varimax" orthogonal rotation is typically performed in FA to redistributes the variance of each variable to maximize the explanation of total variance in data, and thereby the loadings of individual variables on each factor is optimized. A minimum number of meaningful factors are then extracted using an eigenvalue criterion such as eigenvalue $\geq 1.0$ [Kaiser, 1960].

The relative linkages between stream DO and the environmental drivers were then quantified by estimating PLSR models that resolved multi-collinearity [Wold, 2001]. PLSR is superior to a conventional principal component regression (PCR). In PCR, the PCs of only predictors (dynamic environmental drivers) are first derived, and then fitted with the response (DO). However, the orthogonal partial least squares (PLS) components of predictors are computed and fitted with the response in PLSR through a simultaneous decomposition of all variables [Schumann et al., 2013]. The Z-score based PLSR model was estimated with the observed data for 
each site separately using SIMPLS algorithm [de Jong, 1993; Hubert and Branden, 2003] and a 10-fold cross validation [Kuhn and Johnson, 2013]. The model estimations involved a bootstrap Monte Carlo procedure (1000 iterations) to ensure reliability and stability of the estimated parameters associated with the PLS components. The optimality of the models was achieved by including a minimum number of PLS components based on a synthesis of minimum Akaike Information Criterion (AIC) [Akaike, 1974], maximum Nash-Sutcliffe efficiency (NSE) criterion [Abdul-Aziz and Ahmed, 2017], and eigenvalue $\geq 1$ criterion [Carrascal et al., 2009].

The estimated parameters of the optimal PLS components were transformed back to the Zscore domain of the original variables to obtain the relative linkages of stream DO with each environmental variables. The 1000 model estimations were averaged to determine the Z-score model coefficients $(\beta)$ - representing the relative linkages of the environmental drivers with DO at each site. Model parameter uncertainties were measured as the standard deviations of the corresponding 1000 estimations. Predictors with higher absolute values of $\beta$ indicated stronger relative linkages of the drivers with DO. The positive or negative sign of $\beta$ indicated the directions of relationship (i.e., increasing or decreasing) between DO and the environmental predictors. Performance of the final models was measured by NSE and the ratio of root-mean-square error to the standard deviation of observations (RSR). Based on mechanistic understanding, the associated $\beta$ of the drivers were aggregated to estimate the relative linkages of DO with different environmental process components. The standard deviations of the aggregated relative linkages were measured from the 1000 estimations to represent the associated uncertainties. The aggregated linkages for the 'climate' $\left(\beta_{C}\right)$, 'nutrients' $\left(\beta_{N}\right)$, 'hydro-atmosphere' $\left(\beta_{H}\right)$, and 'redox' $\left(\beta_{R}\right)$, components were calculated using the method of vector summation as follows: 


$$
\begin{aligned}
& \beta_{C}=\sqrt{\beta_{T W}+\beta_{S R}} \\
& \beta_{N}=\sqrt{\beta_{T N}+\beta_{T P}} \\
& \beta_{H}=\sqrt{\beta_{Q}+\beta_{A P}} \\
& \beta_{R}=\sqrt{\beta_{p H}+\beta_{S C}}
\end{aligned}
$$

\subsection{Results}

\subsubsection{Mutual Correspondences of the Dynamic Environmental Drivers}

The Pearson correlation coefficients between DO and the corresponding dynamic environmental drivers were significant at the $95 \%$ level of confidence $(\mathrm{P}<0.05)$. The non-linear correspondences of stream DO ( $\log _{10}$-transformed and standardized) with the dynamic environmental drivers were first computed with the correlation coefficients. Analysis of the correlation matrices categorized the sites in to four environmental regimes (Type I to Type IV) based on the dominant drivers of stream DO. The correlation coefficients ( $r$ ) of all the sites across the environmental regimes were presented through boxplots (see Figure A2). The ensemble mean correlation coefficients (r) between DO and the environmental drivers were summarized for each regime to describe the outcomes of the correlation analysis (Table 2.2).

In Type I regime, mainly in Pacific Northwest and southern California, stream DO had a strong negative correspondence with TW $(r=-0.79)$. However, DO showed a weak correlation with other parameters. In contrast, streams in the transition region (central and northern California) showed mixed types of environmental regimes. In Type II regime, stream DO have showed a strong negative correlation with TP $(r=-0.66)$. A notable correspondence, respectively, with TN 
and Q ( $\mathrm{r}=-0.23$ and -0.33$)$ were also noted. However, stream DO had a weak correlation with other parameters. Further, in Type III regime, stream DO had a very strong positive relationship with Q $(r=0.67)$. DO also showed moderate to strong negative correlation with TW and SC $(r=$ - 0.56 to - 0.66), respectively. Whereas, in Type IV regime, stream DO had a moderate positive correlation with $\mathrm{pH}(\mathrm{r}=0.56)$ and a moderate negative correlation with $\mathrm{TW}(\mathrm{r}=-0.45)$. A weak correspondence was also noted with other parameters.

Table 2.2: Ensemble mean Pearson correlation coefficients (r) between stream DO and the dynamic environmental drivers.

\begin{tabular}{lcccccccc}
\hline Environmental Regimes & $\mathrm{TN}$ & $\mathrm{TP}$ & $\mathrm{SC}$ & $\mathrm{pH}$ & $\mathrm{Q}$ & $\mathrm{AP}$ & $\mathrm{TW}$ & $\mathrm{SR}$ \\
\hline Type I & 0.24 & -0.19 & -0.24 & -0.07 & 0.20 & 0.20 & $\mathbf{- 0 . 7 9}$ & -0.34 \\
Type II & -0.23 & $\mathbf{- 0 . 6 6}$ & 0.15 & 0.10 & -0.33 & 0.16 & -0.24 & -0.22 \\
Type III & 0.13 & -0.15 & $\mathbf{- 0 . 6 6}$ & 0.14 & $\mathbf{0 . 6 7}$ & 0.34 & $\mathbf{- 0 . 5 6}$ & -0.23 \\
Type IV & 0.20 & 0.07 & 0.14 & $\mathbf{0 . 5 6}$ & -0.20 & 0.03 & $\mathbf{- 0 . 4 5}$ & -0.12 \\
\hline \hline
\end{tabular}

Notes: (1) Data for all variables were $\log _{10}$-transformed to incorporate any non-linear correspondences. (2) Bold indicates significant correlations at the 95\% confidence level (p-values <0.05). (3) TN, TP, SC, pH, Q, AP, TW, and SR refers to total nitrogen, total phosphorus, specific conductance, potential of hydrogen, stream flow, atmospheric pressure, water temperature, and solar radiation. (4) Regime specific mean correlations were obtained by averaging the site-specific correlations for each environmental regime.

The correlation matrices (Table A2-A5), calculated as regime specific mean, showed strong mutual correspondences, indicating the presence of high multi-collinearity among the dynamic environmental drivers. For example, moderate to strong positive correlations $(r=0.26$ to 0.59) between SR and TW across the regime - indicated warming effect of solar radiation on stream water temperature. Moderate to strong negative correlations $(r=-0.34$ to -0.62$)$ were found between Q and SC — indicating higher streamflow reduces salinity of the stream (dilution effect). Further weak to moderate positive correlations were apparent between TN and TP — attributed to stream pollution from both point and non-point sources. The findings were also corroborated by 
scatter-plotting of the variables (not shown). Further, the substantially stronger correlation of stream DO with TP than that of TN dictates that TP is the limiting nutrient in the major streams.

\subsubsection{Relative Orientations and Interrelations of Stream DO with Environmental Drivers}

The non-linear loadings of stream DO and various environmental drivers on the first two PCs explained approximately $51 \%$ to $72 \%$ of the data variances. The presence of the four environmental regimes found in correlation analysis were fairly supported by the PCA. Four example study sites, representing four types of environmental regimes, were chosen to describe the outcomes through biplots (Figure 2.3). The orientations and lengths of the predictor variables suggests interrelationship with the response variable (DO).

Based on the relative orientations and length of the vectors, TW showed strong negative linkage with DO in 'Type I' regime - explaining the first two PCs $66 \%$ of the total variances (Fig. 2.3a). Based on the closeness to the response vector (DO, the red line), it appeared to have a strong negative linkage with TW and SR — suggesting domination of climatic control on stream DO, and a moderate to strong positive linkage with AP. Nutrients (TN and TP), pH, SC, and Q were relatively orthogonal to (i.e., weakly correlated with) DO. Due to its strong non-orthogonal orientation with DO, TW is likely the most dominant driver of stream DO. Whereas, in 'Type II' regime where the first two PCs explained $60 \%$ of the total variances (Fig. 2.3b), stream DO appeared to have moderate to strong negative linkage with TN, TP, and Q- dictating eutrophication effect. It had also a moderate negative linkage of TW and SC with DO. Stream DO had a weak linkage with the remaining variables. Due to its strong non-orthogonal orientation with stream DO, TP is likely the most dominant driver. 
(a)

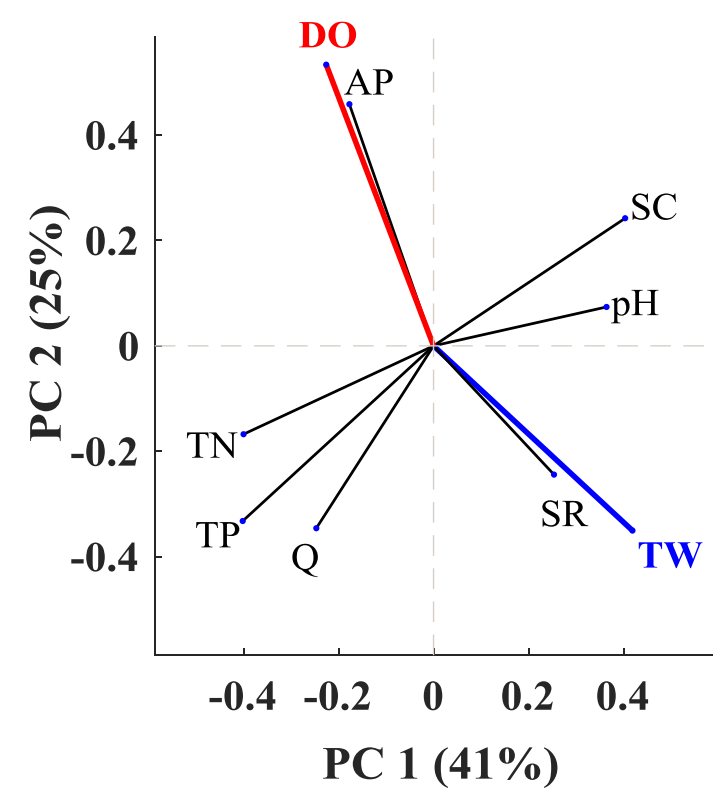

(c)

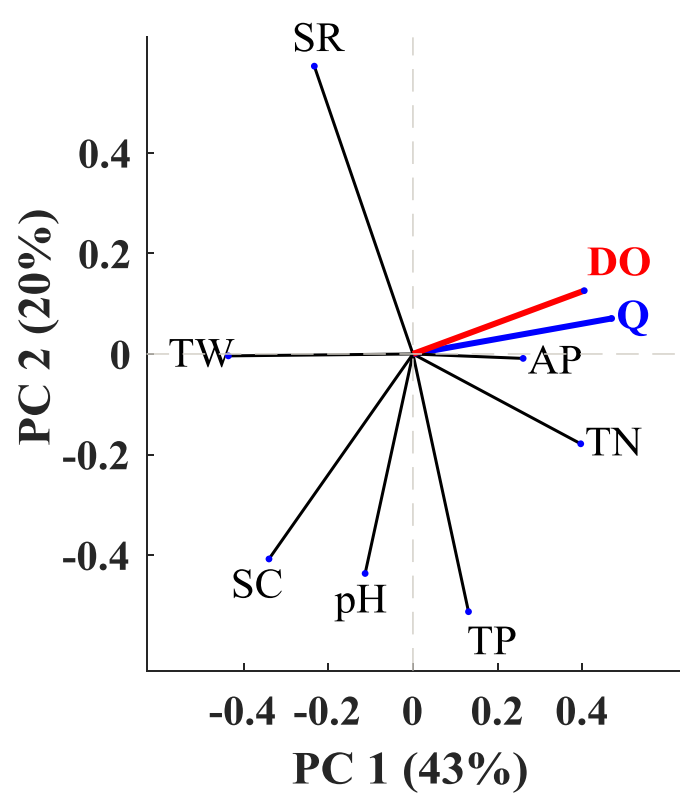

(b)

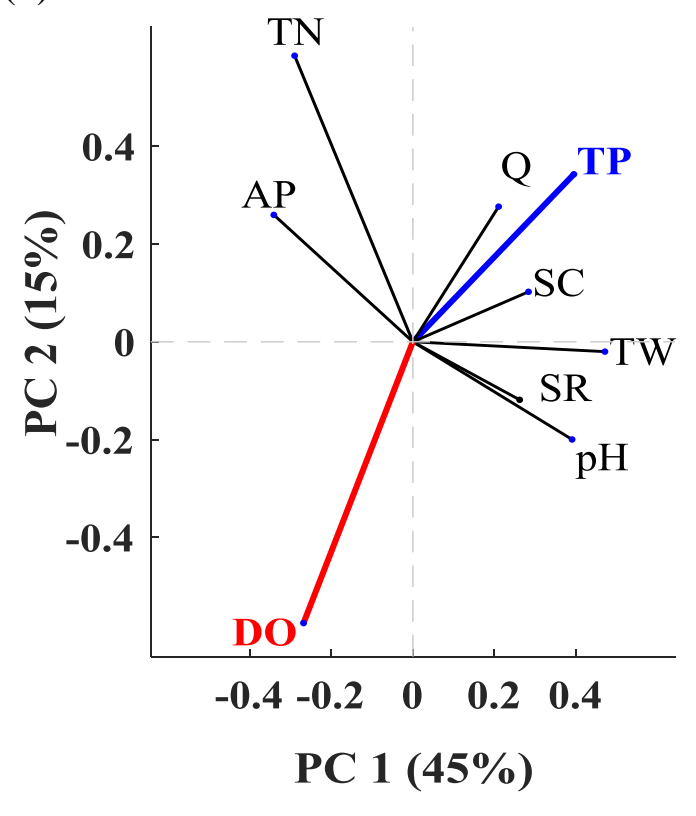

(d)

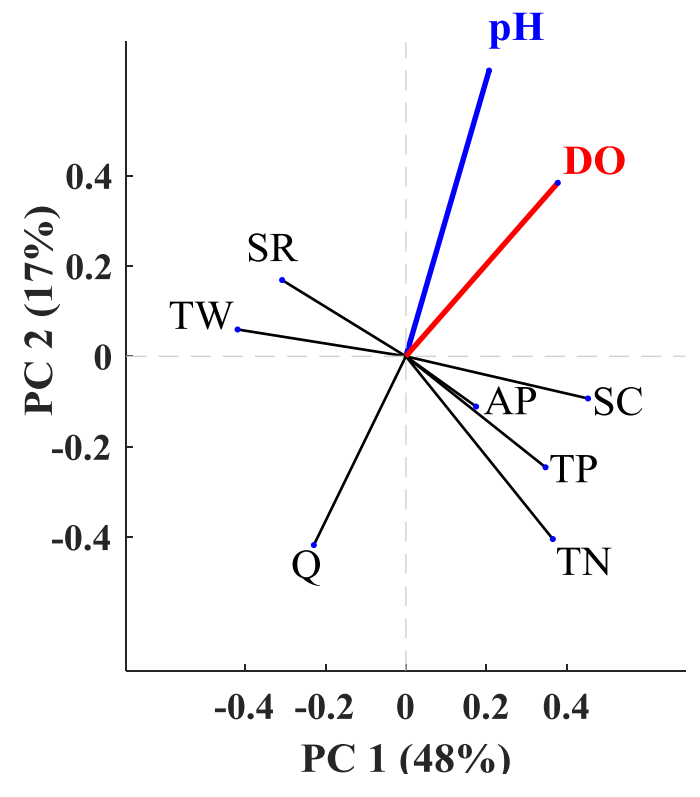

Figure 2.3: Biplots from principal component (PC) analysis, showing the relative orientations and interrelations of stream DO with the environmental drivers for the selected sites from four types of environmental regimes: (a) Type I, (b) Type II, (c) Type III, and (d) Type IV. Percent variance explained by each PC is shown in parenthesis. 
Further, in the 'Type III' regime where the first two PCs explained $63 \%$ of the total variances (Fig. 2.3c), stream DO showed moderate to strong positive linkage with AP and Q suggesting reaeration and atmospheric gas exchange effect. Whereas, a moderate to strong negative linkage of $\mathrm{DO}$ with $\mathrm{pH}, \mathrm{TW}$, and $\mathrm{SC}$ were also apparent. However, with nearly orthogonal orientation, weak linkages of DO were found with the remaining drivers. Due to its strong nonorthogonal orientation with stream DO, Q is likely the most dominant driver in this particular environmental regime. In addition, 'Type IV' regime with the first two PCs explaining 65\% of the total variances (Fig. 2.3d), demonstrated a slightly different pattern than others. Stream DO had, respectively, a moderate to strong positive linkage with $\mathrm{SC}$ and $\mathrm{pH}$ - suggesting domination of redox chemistry. Whereas, Q had a strong negative linkage with DO — indicating nutrient detachment. It had also a moderate negative linkage with TW and TN. Further, TP and SR had relatively weak linkage with DO.

The mutual correspondences among the drivers of DO were also apparent from the biplots (See Figure 2.3). Moderate positive linkage of SR and TW across the regimes indicated the positive effect of solar radiation to increase stream temperature, and strong negative linkage of TW with AP indicated higher temperature reduces density of the air molecules (diffusion effect). Strong negative linkage of $\mathrm{Q}$ with $\mathrm{pH}$ (Fig. 2.3d) - suggested low flow rate creating less turbidity resulting more photosynthesis that can increase $\mathrm{pH}$. In addition, moderate negative linkage of $\mathrm{Q}$ with TW dictated the rapid heat up of streams from low flow rate. Further, moderate positive linkages of Q with nutrients (TN and TP) might indicate the enrichment of in-stream nutrient through detachment that can create higher turbidity lowering photosynthesis. Overall, these biplots provide valuable insights into the variation of water quality of the sites. 


\subsubsection{Major Water Quality Drivers based on Independent Latent Factors}

The eigenvalue $\geq 1$ criterion led to 3 independent latent factors which adequately summarized the system variance at each site. Variance explained by the first three factors are, respectively, $28 \%$ to $51 \%, 15 \%$ to $30 \%$, and $9 \%$ to $20 \%$. Higher loadings of stream DO with the dynamic environmental drivers on the same factor indicates their strong linkages. According to [Liu et al., 2003], the factor loadings are classified as 'strong', 'moderate' and 'weak, corresponding to absolute loading values of $>0.75,0.75-0.50$ and $0.50-0.30$, respectively. FA also supported the findings of the four types of environmental regimes from correlation analysis and PCA. In FA each variable of different stream can be loaded in different factors, so taking mean or median will not represent the actual result of the data. So, the four similar example study sites used to describe PCA were chosen representing the four different environmental regimes to describe the outcomes of FA (Table 2.3).

In 'Type I' regime, stream DO loaded most strongly on factor-1 (-0.98), which had a very high loadings of TW (0.87), moderate loadings of AP (-0.62), and SR (0.44). Similarly, in 'Type II' regime, stream DO was loaded strongly on factor-1 (-0.69), which had very high loadings of TP (0.89) and TW (0.70). It had also a relatively moderate loading with SR (0.48), Q (0.37), SC (0.39), and $\mathrm{pH}(0.36)$. Whereas, in 'Type III' regime, stream DO was loaded strongly on factor-1 (0.85), which had very high loadings of Q (0.92) and SC (-0.90). The strong positive loadings on $\mathrm{Q}$ and strong negative loadings on SC—suggesting dilution effect. Further, in 'Type IV' regime, stream DO was loaded moderately strong on the factor-3 (0.66), which had very high loadings of $\mathrm{pH}(0.91)$ and moderate loadings of Q (-0.44). A moderate loading of DO was also apparent on factor-1 (0.59), which had a very strong loading of TW (-0.96) and SC (0.77), along with a moderate loading of SR (-0.69). 
Table 2.3: Major latent factors with their optimized loadings on the participatory variables for selected sites from four types of environmental regimes.

\begin{tabular}{lllllllllll}
\hline Regimes & $\mathrm{F}$ & $\mathrm{TN}$ & $\mathrm{TP}$ & $\mathrm{SC}$ & $\mathrm{pH}$ & $\mathrm{Q}$ & $\mathrm{AP}$ & $\mathrm{TW}$ & $\mathrm{SR}$ & $\mathrm{DO}$ \\
\hline Type I & 1 & -0.11 & 0.01 & 0.16 & 0.20 & 0.20 & -0.62 & $\mathbf{0 . 8 7}$ & 0.44 & $\mathbf{- 0 . 9 8}$ \\
& 2 & 0.57 & 0.64 & $\mathbf{- 0 . 9 7}$ & -0.27 & 0.61 & -0.20 & -0.24 & -0.12 & 0.02 \\
& 3 & -0.46 & -0.56 & 0.14 & $\mathbf{0 . 7 9}$ & -0.21 & -0.21 & 0.43 & 0.14 & 0.10 \\
Type II & 1 & -0.08 & $\mathbf{0 . 8 9}$ & 0.39 & 0.36 & 0.37 & -0.14 & $\mathbf{0 . 7 0}$ & 0.48 & $\mathbf{- 0 . 6 9}$ \\
& 2 & -0.21 & 0.16 & 0.49 & 0.44 & 0.03 & $\mathbf{- 0 . 9 5}$ & 0.49 & -0.06 & -0.15 \\
& 3 & $\mathbf{- 0 . 9 7}$ & 0.16 & -0.08 & 0.51 & 0.06 & -0.23 & 0.40 & 0.42 & 0.13 \\
Type III & 1 & 0.34 & 0.09 & $\mathbf{- 0 . 9 0}$ & -0.23 & $\mathbf{0 . 9 2}$ & 0.01 & -0.37 & -0.13 & $\mathbf{0 . 8 5}$ \\
& 2 & 0.64 & -0.09 & -0.06 & -0.22 & 0.30 & $\mathbf{0 . 8 4}$ & $\mathbf{- 0 . 9 2}$ & -0.27 & 0.20 \\
& 3 & 0.27 & 0.67 & 0.21 & 0.48 & 0.24 & -0.03 & -0.10 & $\mathbf{- 0 . 8 3}$ & 0.15 \\
Type IV & 1 & 0.49 & 0.21 & $\mathbf{0 . 7 7}$ & 0.09 & -0.16 & 0.02 & $\mathbf{- 0 . 9 6}$ & -0.69 & $\mathbf{0 . 5 9}$ \\
& 2 & $\mathbf{0 . 7 2}$ & $\mathbf{0 . 9 5}$ & 0.50 & 0.05 & -0.19 & 0.40 & -0.21 & -0.12 & 0.14 \\
& 3 & -0.08 & 0.13 & 0.24 & $\mathbf{0 . 9 1}$ & -0.44 & 0.16 & -0.16 & 0.06 & $\mathbf{0 . 6 6}$ \\
\hline
\end{tabular}

Notes: (1) Bold values indicate variables having moderate to high loadings on factors (F); F1-3 refer to three independent factors. (2) TN, TP, SC, pH, Q, AP, TW, SR, and DO refers to total nitrogen, total phosphorus, specific conductance, potential of hydrogen, stream flow, atmospheric pressure, water temperature, solar radiation, and dissolved oxygen respectively.

\subsubsection{Estimations of the Relative Linkages of Stream DO with the Drivers}

PLSR models of DO were optimized based on the synthesis of the minimum AIC, maximum NSE, and eigenvalue $\geq 1$ criterion - which led to the inclusion of first 3 to 4 PLS components (see Figure 2.4). To maintain robust model - Monte-Carlo (1000 bootstrap) estimations was adopted and the optimized models — showed good fitting efficiencies. Based on [Moriasi, 2007], the fitting efficiency (NSE $=0.50-0.95)$ and accuracy $(\mathrm{RSR}=0.20-0.70)$ of the optimal models suggested good predictions of DO for all study sites (Table 2.4). PLSR model coefficients ( $\beta$ ) reiterated the presence of the four types of environmental regimes - based on the dominant stream water quality drivers to control DO. The model coefficients ( $\beta$ ) of all the sites across the environmental regimes 
were presented through boxplots (see Figure A8). The regime-specific ensemble means and corresponding standard deviations across the different environmental regimes (Table 2.4) suggested clear stability of the estimated relative linkages of DO with the dominant environmental drivers.

Table 2.4: Mean coefficients ( $\beta$ ) (and standard deviations in parenthesis) of the Z-score PLSR models after 1000 Monte-Carlo simulations for the four environmental regimes.

\begin{tabular}{ccccc}
\hline & \multicolumn{5}{l}{ Environmental Regimes } \\
\cline { 2 - 5 } Predictors & Type I & Type II & Type III & Type IV \\
\hline TN & $0.06(0.12)$ & $-0.29(0.22)$ & $-0.09(0.17)$ & $-0.06(0.12)$ \\
TP & $-0.09(0.12)$ & $\mathbf{- 0 . 5 8}(0.21)$ & $-0.16(0.17)$ & $-0.13(0.12)$ \\
SC & $-0.06(0.12)$ & $0.15(0.23)$ & $-0.35(0.11)$ & $0.01(0.08)$ \\
pH & $0.07(0.13)$ & $0.10(0.22)$ & $0.21(0.17)$ & $\mathbf{0 . 5 2}(0.11)$ \\
Q & $0.05(0.11)$ & $-0.03(0.17)$ & $\mathbf{0 . 5 3}(0.12)$ & $0.01(0.13)$ \\
AP & $0.04(0.12)$ & $0.11(0.23)$ & $0.03(0.14)$ & $-0.08(0.11)$ \\
TW & $\mathbf{- 0 . 6 3 ( 0 . 1 3 )}$ & $-0.11(0.25)$ & $-0.10(0.14)$ & $-0.40(0.12)$ \\
SR & $0.01(0.12)$ & $0.01(0.19)$ & $-0.01(0.13)$ & $-0.03(0.12)$ \\
& & Model Statistics & & \\
OPC & $3-4$ & 3 & 3 & 0.66 \\
NSE & 0.79 & 0.85 & 0.90 & 0.56 \\
RSR & 0.42 & 0.33 & 0.28 & \\
\hline \hline
\end{tabular}

Notes: (1) OPC refers to the optimum partial least square component. (2) TN, TP, SC, pH, Q, AP, TW, SR, and DO refers to total nitrogen, total phosphorus, specific conductance, potential of hydrogen, stream flow, atmospheric pressure, water temperature, solar radiation, and dissolved oxygen respectively. (3) Regime specific statistics were computed from the corresponding site-specific, obtained from 1000 Monte Carlo estimations. 
(a)

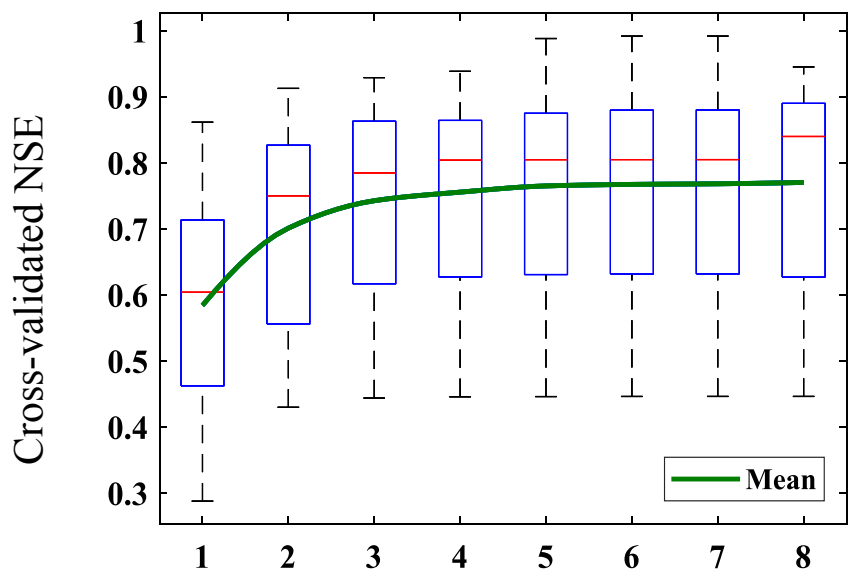

(b)

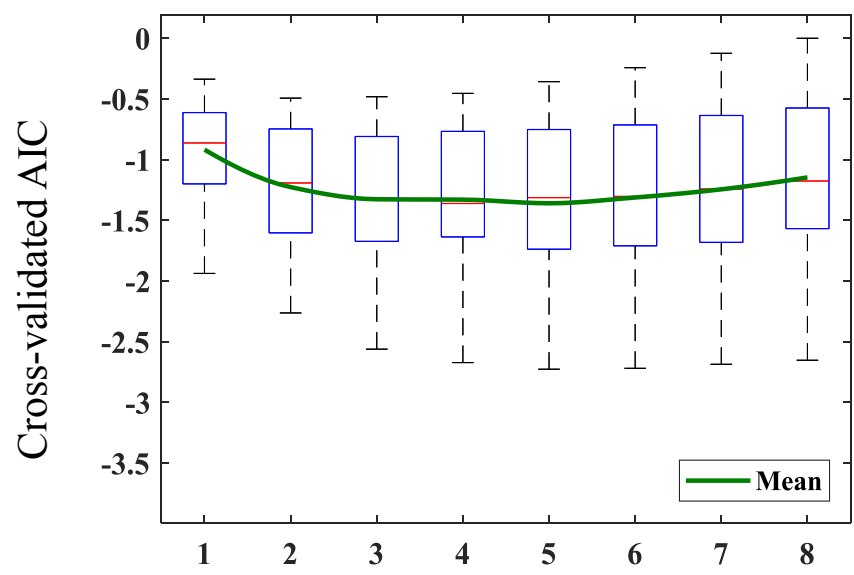

(c)

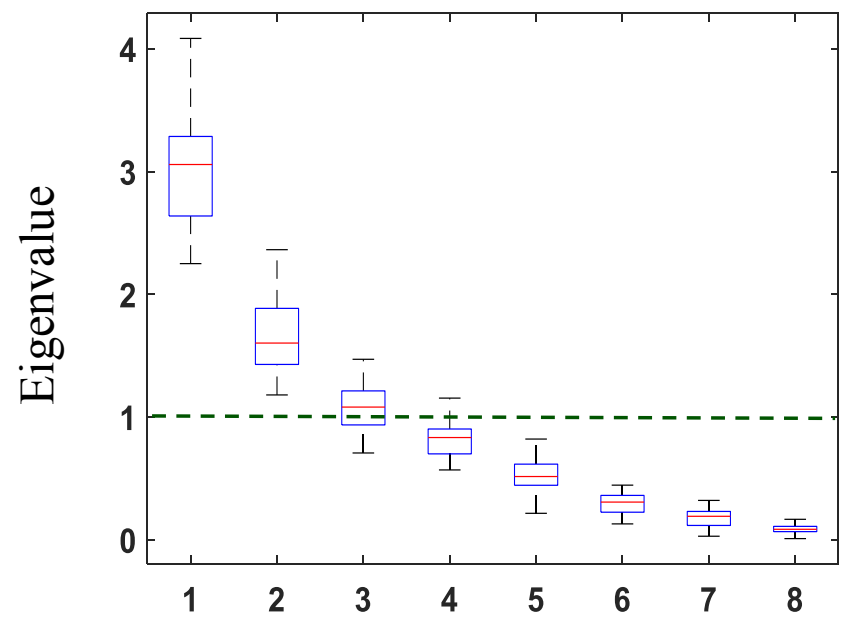

Figure 2.4: Plot of cross-validated (a) Nash-Sutcliffe efficiency (NSE), (b) normalized AIC, and (c) Eigenvalue with the number of partial least squares components for all sites. 
Considering regression coefficients, in 'Type I' regime, stream DO showed strongest linkage with TW ( $\beta=-0.63$; Table 2.4) and relatively weak linkages with the remaining variables. Whereas, in 'Type II' regime, stream DO had a strong negative linkage with TP $(\beta=-0.58$; Table 2.4). It also showed moderate negative linkages with $\mathrm{TN}(\beta=-0.29$; Table 2.4) and notable linkage with $\mathrm{pH}, \mathrm{SC}$, and AP. In 'Type III' regime, stream DO was mainly controlled by $\mathrm{Q}(\beta=0.53$; Table 2.4) and similar control was also observed in FA. TP $(\beta=-0.16)$ and SC $(\beta=-0.35)$ showed comparatively weak to moderate negative linkages with stream DO. A notable positive linkage of pH with DO ( $\beta=0.21$; Table 2.4) was also apparent. Further, in 'Type IV' regime stream DO was linked moderately positive with $\mathrm{pH}(\beta=0.52$; Table 2.4$)$; moderate negative linkages with TW ( $\beta$ $=-0.40$; Table 2.4) and notable linkage with TP. While $\mathrm{Q}, \mathrm{AP}$, and TN showed negligible linkages with stream DO.

Ensemble means of the aggregated beta $(\beta)$ relative linkages of stream DO with different environmental process components were computed directly from the corresponding site-specific (1000 Monte-Carlo) estimations across the environmental regimes (Table 2.5). In 'Regime I', 'climate' component $\left(\beta_{\mathrm{C}}\right)$ had approximately $3.07,2.67$, and 1.55 times stronger linkages with stream DO than that of, respectively, 'nutrient' $\left(\beta_{\mathrm{N}}\right)$, 'hydro-atmosphere' $\left(\beta_{\mathrm{H}}\right)$, and 'redox' $\left(\beta_{\mathrm{R}}\right)$, components. Whereas, 'Regime II' suggested that 'nutrient' component $\left(\beta_{\mathrm{N}}\right)$ was the most dominant driver - exhibiting 2.28, 2.63, and 1.55 times stronger linkages with DO than that of 'climate' $\left(\beta_{\mathrm{C}}\right)$, hydro-atmosphere' $\left(\beta_{\mathrm{H}}\right)$, and 'redox' $\left(\beta_{\mathrm{R}}\right)$, components, respectively. In addition, 'Regime III' showed that 'hydro-atmosphere' component $\left(\beta_{\mathrm{H}}\right)$ was the strongest driver of stream DO; exhibiting approximately $3.06,2.24$, and 1.23 times stronger linkages with DO than that of the 'climate' $\left(\beta_{C}\right)$, 'nutrients' $\left(\beta_{N}\right)$, and 'redox' $\left(\beta_{R}\right)$, components, respectively. Further, 'RegimeIV' showed 'redox' component $\left(\beta_{\mathrm{R}}\right)$ was the strongest predictor of stream DO; approximately 1.28 , 
2.73, and 2.51 times stronger linkages with DO than that of 'climate' $\left(\beta_{\mathrm{C}}\right)$, 'nutrient' $\left(\beta_{\mathrm{N}}\right)$, and 'hydro-atmosphere' $\left(\beta_{\mathrm{H}}\right)$ components, respectively.

Table 2.5: Ensemble mean of the aggregated model coefficients $(\beta)$ along with standard deviations (in parenthesis) with four environmental process components in different environmental regimes.

\begin{tabular}{lllcl}
\hline Aggregated Components & Regime I & Regime II & Regime III & Regime IV \\
\hline Climate & $\mathbf{0 . 6 6}(0.12)$ & $0.30(0.15)$ & $0.18(0.12)$ & $0.44(0.12)$ \\
Nutrient & $0.22(0.10)$ & $\mathbf{0 . 6 9}(0.20)$ & $0.25(0.15)$ & $0.21(0.09)$ \\
Hydro-atmosphere & $0.25(0.09)$ & $0.26(0.17)$ & $\mathbf{0 . 5 5}(0.12)$ & $0.22(0.09)$ \\
Redox & $0.29(0.10)$ & $0.45(0.22)$ & $0.45(0.11)$ & $\mathbf{0 . 5 6}(0.10)$ \\
& \multicolumn{4}{c}{ Ratio to the strongest $\beta$} \\
& $\beta_{\mathrm{C}} / \beta_{\mathrm{N}}=3.07$ & $\beta_{\mathrm{N}} / \beta_{\mathrm{C}}=2.28$ & $\beta_{\mathrm{H}} / \beta_{\mathrm{C}}=3.06$ & $\beta_{\mathrm{R}} / \beta_{\mathrm{C}}=1.28$ \\
& $\beta_{\mathrm{C}} / \beta_{\mathrm{H}}=2.67$ & $\beta_{\mathrm{N}} / \beta_{\mathrm{H}}=2.63$ & $\beta_{\mathrm{H}} / \beta_{\mathrm{N}}=2.24$ & $\beta_{\mathrm{R}} / \beta_{\mathrm{N}}=2.73$ \\
& $\beta_{\mathrm{C}} / \beta_{\mathrm{R}}=1.55$ & $\beta_{\mathrm{N}} / \beta_{\mathrm{R}}=1.55$ & $\beta_{\mathrm{H}} / \beta_{\mathrm{R}}=1.23$ & $\beta_{\mathrm{R}} / \beta_{\mathrm{H}}=2.51$ \\
\hline \hline
\end{tabular}

Note: (1) The regime specific statistics were computed from corresponding site-specific (1000 Monte-Carlo) simulation. (2) The aggregated relative linkages of the 'climate' $\left(\beta_{\mathrm{C}}\right)$, 'nutrient' $\left(\beta_{\mathrm{N}}\right)$, 'hydro-atmosphere' $\left(\beta_{\mathrm{H}}\right)$, and 'redox reaction' $\left(\beta_{\mathrm{R}}\right)$ components were calculated, respectively, by using Eq. (i-iv).

\subsection{Discussion}

\subsubsection{Relative Controls of Environmental Drivers on Stream DO}

This study provides the relative linkages of stream DO with the dynamic environmental drivers across the pacific coast of U.S.A, which has not been thoroughly studied previously. The study area consisted three climatic regions [Gleason et al., 2011]: (i) Pacific Northwest region (PNWR), (ii) central and northern California region (CNCR), and (iii) southern California region (SCR). Based on the dominant stream quality process, data analytics categorized the stream water quality sites into four distinct environmental regimes: (1) 'climate dominated' regime, mainly located in PNWR and SCR, (2) “nutrient dominated' regime, (3) 'hydro-atmosphere dominated' regime, and (4) 'redox dominated' regime, located in central through northern California (i.e., transitional region). 
In PNWR and SCR, the negative linkage of TW with steam DO suggested an environmental regime dominated by climatic control. The inverse relationship between TW and stream DO [Conley et al., 2011; Meire et al., 2013; Shrestha and Kazama, 2007] was further supported by site-specific average (Table 2.1). This strong negative linkage of DO with TW (see Table 2.4) suggested strong thermodynamic effect. Previous research [Shrestha and Kazama, 2007] also reported similar findings at the Fuji river basin, Japan. However, environmental condition of the contribution area have also a huge impact on the biogeochemical and hydroclimatic drivers [de Oliveira et al., 2016]. The highly vegetated land ( 66\%; Table A9) in majority of the climate dominated sites — suggested filtering effect. Vegetation plays an important role as a filter and keep pollutants from entering the stream through leaching or biological fixation [Sliva and Williams 2001; Maillard and Santos 2008] and sequestering excess nutrients from stream flow [Yeakley et al., 2003]. This filtering effect led climate to dominate over metabolism. Climate has a direct effect on stream temperature — reducing solubility of gases, particularly DO [Bograd et al., 2008; Deutsch et al., 2011; Scavia et al., 2002]. It can also affect decomposition rate by increasing microbial activity [Wetzel, 2001]. Further, in this regime, notable built-up land ( 22\%; Table A9) owing to urban expansion which can poses threats to the integrity of streams [Paul and Meyer, 2001] — suggested urban heat island effect. Warmer water increases the microbial decomposition of organic matter in water which affects photosynthesis and respiration [Conley et al., 2011; Meire et al., 2013]. This supports the findings from the previous studies reporting strong negative effect of stream temperature on DO dynamics. For example, [Shrestha and Kazama, 2007] found a clear inverse relationship between DO and temperature in Fuji river basin, Japan owing to the fact that warmer water becomes more easily saturated with oxygen, and the oxygen holding capacity reduces. 
However, in the mild to cold climate of central and northern California region (CNCR), stream DO was controlled by multiple drivers (i.e., TW, TP, Q, and $\mathrm{pH}$ ) — exhibiting a mixed environmental regime. In this transitional region, the mixed pattern of climate and land use (e.g., urban, agriculture), might led to the mixed controls on stream DO. In the 'nutrient dominated' regime, TP was the dominant driver of stream DO. The strong negative linkages of stream DO with TP underline the eutrophication effect [Scholz, 2006]. The higher built-up land ( 65\%) and higher nutrient concentration $(\mathrm{TP}=0.26 \mathrm{mg} / \mathrm{L}$; see Table $\mathrm{A} 10)$ — reiterating nutrient control via urban sewage effect. Urban streams can carry sewage and other pollutants, which, in turn, can lead to eutrophication and stream DO depletion [Paul and Meyer, 2001]. Excessive phosphorus in water is recognized as a main factor leading to eutrophication and deterioration of water bodies resulting in the bloom of aquatic plants, growth of algae, turbidity, and depletion of stream DO [Kudela et al., 2010; Ryan et al., 2010; Saha et al., 2009; Vega et al., 1998]. To some extent, TN demonstrated also an overall moderate negative linkage. In our study, the relative linkage of stream DO with the individual drivers and aggregated process components mostly reflected the corresponding linkage of TP than that of TN, emphasizing the limiting nutrient in majority of the streams. Previous research had also similar findings TP as a limiting nutrient [Abdul-Aziz and Ahmed, 2017; Briceño et al., 2013; Lapointe and Bedford, 2010].

In the 'hydro-atmosphere dominated' regime, stream flow (Q) was found to be the dominant driver of stream DO. In these regime, higher vegetation cover $(\sim 87 \%)$ and slope $(\sim 34 \%$; see Table A11) comparing other sites — suggested reaeration and dilution effect resulting from vegetated mountainous. Atmospheric aeration is a major source of DO in streams that occurs at the air-water interface [Gualtieri et al., 2002; Haider et al., 2013]. Lanoux et al. [2013] also reported similar findings regarding the positive effect of extreme river discharge on stream DO. In 
addition, SC (surrogate of salinity) had also a moderate negative control on stream DO. The reason for the negative linkages of SC with DO could be because higher saline water creates stress (i.e., inhibits the electron transport rate) on the photosynthetic organisms that reduces the photosynthesis rate of phytoplankton [Cloern, 1996].

The positive linkage of $\mathrm{pH}$ with steam DO and the aggregated process components (Table 2.5) suggested 'redox dominated' regime. Similar research also reported [Kaya et al., 2005] at the Dianchi Lake. Algal photosynthesis, aquatic respiration, water temperature and oxidative decomposition of organic matter have an impact on $\mathrm{pH}$ and DO concentration in streams [Scholz, 2006]. In this regime, higher built-up land ( 70\%) and notable vegetated land ( 28\%; Table A12) reiterates the redox control via biodegradation as well as photosynthesis effect. Algal photosynthesis contributes to stream DO and increases $\mathrm{pH}$ by consuming carbon dioxide [King, 1970]. Further, increased microbial decomposition in higher temperature consumes DO and produces carbon dioxide lowering $\mathrm{pH}$ [Cai et al., 2011] — led to the positive linkage between $\mathrm{pH}$ and stream DO.

Investigating the relative dominance of one driver over the other is essential in order to understand clearly the cause and effect relationships [Boyer et al., 2009]. Our study advanced the knowledge of stream water quality across the Pacific Coast by estimating the influence of biogeochemical and hydro-climatic drivers by appropriately resolving multi-collinearity. Overall, water temperature is found to be the most dominant driver of stream DO in majority of the vegetated streams - emphasized how vegetation plays a significant role in improving the water quality by controlling metabolism. The study also highlights the impact of global warming, eutrophication, riparian shading, and urbanization on coastal stream DO dynamics at present and how they can affect them in the future. Controlling agricultural runoff should also receive highest 
priority in land management to reduce in-stream nutrients (TN and TP) which results DO depletion in coastal streams. The reduction of nutrients would also reduce algal biomass and increase DO which are typically low in the coastal streams. So major ecological control (e.g., treatment plant, detention ponds) should be achieved through implementing different engineering mechanisms.

\subsubsection{Management Strategies and Implications}

The study promotes the knowledge of coastal urban/natural stream water quality through quantifying the relative linkages of stream DO with the hydro-climatic and biogeochemical drivers by resolving multi-collinearity. The quantified relative linkages that identified aggregated process component showed the dominance of one driver over the other to control stream DO. Therefore, different environmental regimes suggested urgency in developing effective policy interventions for efficient management of stream water quality under dynamic climate and land use changes in different environmental regimes across the Pacific Coast of U.S.A. and similar regions around the world.

Streams on PNWR owing to high vegetated land, climate had the strongest impact on DO in majority of the streams - suggesting stream shading and nutrient filtering effect. Therefore, removal of vegetation could bring more nutrients in to the stream which could impacts on aquatic ecosystems by degrading the water quality, particularly to salmonids and their habitats. For many millennia in the Pacific Northwest, salmonids have served as a keystone ecological taxa as well as an iconic cornerstones of human culture [Yeakley, 2014]. Most salmonids are commonly observed

at summer habitat temperatures ranging from $10-17{ }^{\circ} \mathrm{C}$ and sensitive to elevated water temperature. Therefore, as water temperature is a key determinant for salmonid, especially streams across the Pacific Northwest should set highest management priority to stream temperature. 
However, in CNCR, highest management priory should be given to control the mixed environmental processes (e.g., biodegradation and eutrophication) to have an efficient control on coastal stream DO. A diverse set of anthropogenic sources have the potential to increase heat inputs to streams and rivers in coastal urban /natural land [Paul and Meyer, 2001]. Due to higher potential of microbial decomposition, point sources from industrial and municipal facilities, a biological treatment of wastewater through constructed wetland would be more efficient in SCR and CNCR than that of PNWR. Further, proper land use management should also be taken to reduce the urban heat island effect. The study suggested control of nutrient enrichment in coastal stream from watershed land uses (e.g., agricultural land, urban land) should also get management priority to minimize eutrophication induced hypoxia [Cai et al., 2011; Diaz and Rosenberg, 2008].

In general, stream temperature showed moderate to strong control on stream DO across the entire region. The Intergovernmental Panel on Climate Change (IPCC) has concluded, based on the synthesis of observations, that earth's surface temperature has increased by approximately $0.57^{\circ} \mathrm{C}-0.92^{\circ} \mathrm{C}$ over the past century, which is primary attributed to anthropogenic greenhouse gas emissions [IPCC, 2007]. Therefore, the positive correlation between stream temperature and atmospheric temperature [Kaushal et al., 2010] underline the prior attention should be given to the worldwide global warming having a direct effect on coastal stream temperature. Additionally, strong management priority should be given as well to reduce stream temperature by controlling thermal pollution from industrial discharge alongside introducing riparian vegetation across the Pacific Coast of U.S.A. 


\subsection{Conclusions}

The relative linkages of stream DO with the dynamic environmental drivers were reliably estimated for the coastal watersheds across the Pacific coast of U.S.A. by resolving multicollinearity through a systematic data analytics framework. Based on the dominant drivers of stream DO, four environmental process components were identified which were complemented in all data-analytics.

In Pacific Northwest region (PNCR) and southern California region (SCR) - owing to filtering effect from highly vegetated land — climate had dominant control on stream DO in majority of the coastal streams. Based on the aggregated process component, 'climate' component $\left(\beta_{\mathrm{C}}\right)$ exhibited approximately $3.07,2.67$, and 1.55 times of control on stream DO than that of 'nutrient', 'hydro-atmosphere', and the 'redox' component. Mainly this is due to the thermodynamic effect in which warmer temperatures decrease oxygen solubility in water while at the same time increasing metabolic rates that affect photosynthesis and respiration.

However, in central and northern California region (CNCR), stream DO was controlled by multiple drivers (i.e., TW, $\mathrm{pH}, \mathrm{Q}$, and TP) — suggesting a mixed environmental regime. In this transitional region, the mixed climate patterns and complex land use led to the mixed control of stream DO. In the 'nutrient dominated' regime, the 'nutrient' component — exhibiting 2.28, 2.63, and 1.55 times stronger linkages with DO than that of 'climate' $\left(\beta_{\mathrm{C}}\right)$, hydro-atmosphere' $\left(\beta_{\mathrm{H}}\right)$, and 'redox' $\left(\beta_{\mathrm{R}}\right)$, components, respectively — had a strong control on stream DO. High built-up land along with higher nutrient concentration reiterates also the urban sewage effect which can reduce stream DO with high turbidity and eutrophication. The relative linkages of stream DO with the 
individual drivers mostly reflected the corresponding linkage of TP than that of $\mathrm{TN}$, emphasizing $\mathrm{TP}$ as the limiting nutrient in the major streams.

In the 'hydro-atmosphere dominated' regime, 'hydro-atmosphere' component $\left(\beta_{\mathrm{H}}\right)$ was the strongest driver of stream DO; showing approximately 3.06, 2.24, and 1.23 times stronger linkages with DO than that of the 'climate' $\left(\beta_{C}\right)$, 'nutrients' $\left(\beta_{N}\right)$, and 'redox' $\left(\beta_{R}\right)$ components, respectively. Higher vegetated land and relatively high slope also suggested a vegetated mountainous land which could lead to higher reaeration and atmospheric gas exchange - reiterating the hydroatmosphere control. This is due to physical absorption of oxygen from the atmosphere by which streams replenishes DO concentration. Further, in the 'redox dominated' regime, based on the aggregated beta $(\beta)$, the 'redox' component $\left(\beta_{R}\right)$ was the strongest predictor of stream DO; exhibiting approximately $1.28,2.73$, and 2.51 times stronger linkages with stream DO than that of the 'climate' $\left(\beta_{\mathrm{C}}\right)$, 'nutrients' $\left(\beta_{\mathrm{N}}\right)$, and 'hydro-atmosphere' $\left(\beta_{\mathrm{H}}\right)$ components, respectively. The higher built-up land and notable vegetated land also reiterates the effect of redox chemistry via biodegradation and photosynthesis on stream DO. The estimated relative linkages and insights would be useful to identify the key management targets and priorities to achieve healthy coastal stream ecosystems across the Pacific Coast of U.S.A and similar regions around the world. 


\title{
Chapter 3: Similitude and Scaling of Stream Dissolved Oxygen across the Pacific Coast of U.S.A.
}

\begin{abstract}
Dissolved oxygen (DO) dynamics is controlled by a multitude of interacting environmental drivers, which highlight to develop a general understanding in various environmental conditions. This study investigates emergent similitude and scaling of stream DO across the Pacific Coast of U.S.A. Similitude and dimensional analysis were employed to investigate the collective control of myriad environmental drivers. The predictor dimensionless number represented the diverse environmental controls from interactions of various hydro-climatic and biogeochemical drivers of stream DO dynamics. Response dimensionless number, DO* represented the concentration of dissolved oxygen (DO), as normalized by the oxygen dissolution capacity of stream water. A graphical exploration of the response and the predictor dimensionless number showed a collapse of observations from diverse streams into a single dimensionless curve, indicating emergent pattern across the Pacific Coast. A threshold value of the predictor dimensionless number showed the existence of two environmental regimes governed by climate versus metabolic controls. The emergent pattern led to the development of scaling relationship which was then leveraged as a non-linear empirical model to robustly predict stream DO in different environmental regimes across the U.S. Pacific Coast (Nash-Sutcliffe Efficiency, NSE=0.72). The research provided a crucial knowledge into the biogeochemical similitude and scaling to guide effective management of coastal streams under diverse environmental conditions across the Pacific Coast of U.S.A.
\end{abstract}




\subsection{Introduction}

Dissolved oxygen (DO) is the crucial indicator of stream biological health exhibiting a wide range variations [Rajwa-Kuligiewicz et al., 2015]. A deficiency of stream DO may cause long-term adverse effects in the aquatic environment [Gonçalves and Costa, 2013], and is a sign of unhealthy stream — creating unbalanced ecosystem, fish mortality, and odors [Mondal et al., 2016; Thomann and Mueller, 1987]. These environmental drivers of stream DO are interconnected to each other and their collective interaction of anthropogenic and natural processes shapes the stream water quality. The multitude of complex interactions and temporal variability of the drivers create a major challenge to develop a general understanding in various environmental conditions to robustly predict stream DO dynamics. Application of similitude and dimensional analysis in stream water quality dynamics can help generalizing the complex interactions of physical, biological, and chemical processes, leading to emerging patterns of stream water quality dynamics [Warnaars et al., 2007]. Although some research investigated similitude in stream water quality analysis, it is yet to be studied whether the myriad interacting environmental drivers possess temporal similitude and scaling relationship across a large spatial scale. The study findings and tool would be useful for engineering applications, particularly in the context of rapidly expanding coastal-urban/natural environments across the Pacific Coast of U.S.A.

The principal sources of in-stream DO are photosynthesis as well as atmospheric gas exchange and aeration [O'Driscoll et al., 2016]. However, stream DO with increased consumption due to microbial organism (i.e., microbial decomposition) can lead to depletion [Lin et al., 2008; Quinn et al., 2005] . Increased inputs of chemicals that react readily with oxygen in the stream eutrophication effect can also cause oxygen depletion[Tran et al., 2010]. In addition, Temperature affects metabolic activities that can lead to DO depletion [Yvon-Durocher et al., 2010]. However, 
a single driver control on stream DO could be inappropriate since it is affected by other factors. For example, similar nutrient concentration may not have similar control on stream DO subjected to different hydro-climatic and biogeochemical conditions in the environment. Therefore, the combined interactions of important physicochemical and biological processes - rather than a single process component - should properly be incorporated to understand the stream DO dynamics for robust modeling and predictions.

Many studies reported major controls from land use, hydro-climatic, and in-stream variables on coastal stream water quality. For example, Tran et al. [2010] reported the effect of riparian buffer zone in reducing contamination from non-point source loading. Carey et al. [2013] found a strong impact from urban and non-urban land on stream dissolved oxygen by bringing high concentration of in-stream nutrients (e.g., nitrogen, phosphorus). Liu et al. [2009] discussed the seawater intrusion effect on the stream water quality by reducing oxygen solubility as well as controlling many biogeochemical reaction. Cai [2011] reported the positive linkage between $\mathrm{pH}$ and stream DO —inferring to photosynthesis and microbial decomposition effect—in the northern Gulf of Mexico. The hydrologic factors have also been reported to control stream DO. Hondzo [2013] found a linkage between stream DO and stream geometry (width, depth) in Minnehaha Creek, Minnesota. However, previous studies didn't investigate the collective interactions of the drivers across a large spatial scale of coastal urban/natural streams. So, it is yet to be investigated how the land use, hydrologic, and in-stream drivers mutually interact to collectively control coastal urban/natural stream water quality by leveraging similitude and dimensional analysis that develop a robust model [Hondzo et al., 2005]. The investigation of combined effect from the mutual interactions of different hydro-climatic and biogeochemical drivers across a large spatial scale 
could suggest an emergent pattern which leads a robust modeling and prediction of coastal stream DO.

Dimensional analysis is a well-known methodology in physics, chemistry, and other traditional engineering areas. It has widely been used in many engineering disciplines to get profound knowledge on process understanding and enhance model formulations [Miragliotta, 2011]. Exclusively, it is used to investigate meaningful set of equations having dimensional homogeneity. Dimensional theory has been investigated and reached its highest achievement with profound contribution of Buckingham theorem (or pi-theorem). Buckingham [1914] states that any equation modelling a physical problem can be arranged in terms of non-dimensional ratios, thus limiting the variables to be handled, and especially enriching the inner physical knowledge of the studied phenomenon. Each dimensionless number represents the collective influence of different environmental processes, and thus, enriches the knowledge of the studied phenomenon [Zeleňáková M, 2013; Miragliotta, 2011]. Dimensional analysis using Buckingham pi-theorem can be used to achieve similitude.

Newtonian fluids, for example, have a well-known rheology governed by two material parameters, viscosity and density, which leads to a handful of well-known dimensionless parameters (e.g., Reynolds number and Froude number) that can be used for controlled scaling analyses [Slonaker et al., 2017]. Moody chart, in hydraulic engineering applications can be another classic example of similitude for pipe flow design [Finnemore and Franzini, 2002]. It reduced 7 parameters of pipe flow (i.e., flow velocity, viscosity, pressure, density, pipe diameter, length, and roughness) to 3 dimensionless parameters (i.e., pipe friction factor, Reynolds Number, and relative roughness) which is called similitude, and the functional relationships among them are "scaling relationships". Hondzo et al. [2013] applied dimensional analysis to investigate how 
photosynthesis, respiration, advection, dispersion, and aeration dominate dissolved oxygen mass balance in the Minnehaha Creek, Minnesota. Guentzel et al. [2014] employed dimensional analysis to study nitrate uptake by sediment denitrification in five streams under diverse land uses in southcentral Minnesota. Warnaars et al. [2007] applied similitude and dimensional analysis to investigate how biotic and abiotic variables are interconnected in different streams and rivers across North America. Zeleňáková M [2013] applied dimensional analysis in water quality modeling to determine nitrogen and phosphorus concentrations using their environmental drivers in the River Laborec located in eastern Slovakia.

The concept of scaling has been known as a key to develop robust modeling and prediction tools in science and engineering disciplines. Hondzo et al. [2005] derived a scaling based power law model to analyze dissolved oxygen distribution at the sediment-water interface of a small lake. Abdul-Aziz et al. [2007a; b] scaled stream dissolved oxygen measured at different clock times of the day by a reference time to get dimensionless dissolved oxygen — employed to formulate an extended stochastic harmonic analysis (ESHA). Abdul-Aziz and Ishtiaq [2014] developed a spatiotemporally robust empirical model for simulating the diurnal cycle of stream DO leveraging the dimensionless dissolved oxygen from a single reference observation. However, all previous studies were in a small spatial scale. Therefore, this knowledge gap motivates to investigate similitude and scaling relationship of stream DO across the Pacific Coast of U.S.A.

The goal of the study is to investigate the combined effect from mutual interactions of hydro-climatic and biogeochemical controls on urban/natural stream DO dynamics by formulating similitude and dimensionless numbers. The study investigates if the coastal stream DO follows distinct similitude and emergent patterns across a large spatial scale of U.S. Pacific Coast. We employed dimensional analysis to formulate important and meaningful dimensionless numbers to 
represent collective as well as contrasting effect of different environmental process components. The dimensionless numbers were leveraged to develop scaling relationship which could lead to develop a robust model for coastal stream DO. The characteristic process diagram alongside their generalized characteristic process diagrams are expected to guide efficient management to achieve healthy coastal urban/natural stream ecosystems across the Pacific Coast of U.S.A and beyond.

\subsection{Materials and Methods}

\subsubsection{Study Area}

The study area incorporated 12 stream water quality monitoring sites-assembling stream geometric variables - of NOAA's coastal watersheds across the Pacific Coast of USA (sec Figure 3.1). The study area, located between $33^{\circ} 0^{\prime} 0^{\prime \prime}$ and $49^{\circ} 0^{\prime} 0^{\prime \prime} \mathrm{N}$ and between $114^{\circ} 02^{\prime} 0^{\prime \prime}$ and $124^{\circ} 08^{\prime} 0^{\prime \prime}$, encompassing three US states: (i) Washington; (ii) Oregon, and (iii) California with a reasonable spatial distribution along the Pacific Coast. However, the entire Pacific Coast of U.S.A is located in the temperate zone. It has an oceanic climate in its Northern edge towards the Canada-US border, warm to cold climate in its central and northern California, and Mediterranean climate in the southern California towards the Mexico-US border [Peel et al., 2007]. 


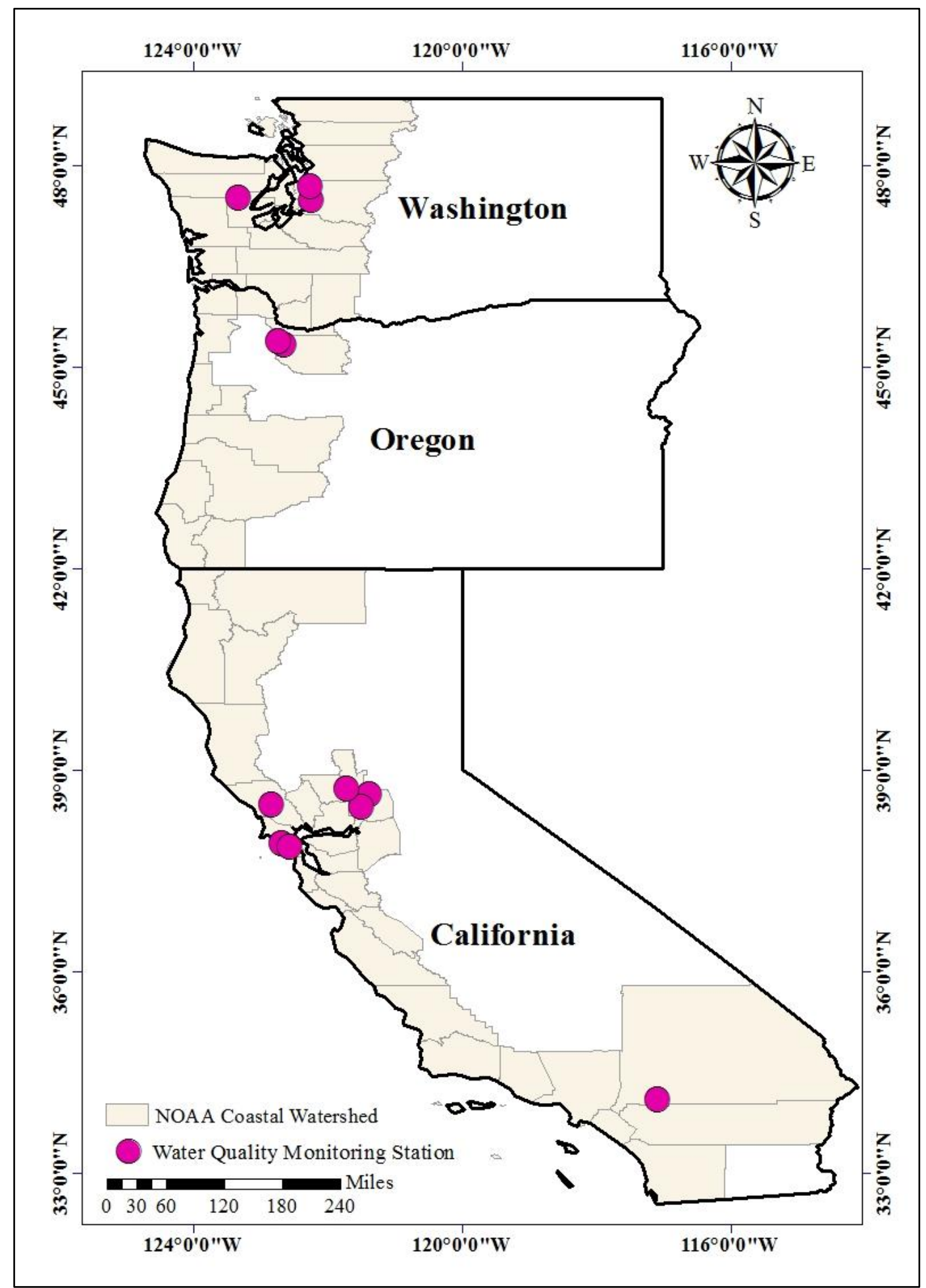

Figure 3.1: Study area and the incorporated water quality monitoring stations with hydro-geometric data across the Pacific Coast of U.S.A. 


\subsubsection{Data Sets}

Temporal data (1998-2015) of grab sample stream water quality (Table 3.1) sampled mostly at quarterly interval across the year by USGS NWIS and EPA STORET were gathered from National Water Quality Monitoring Council (NWQMC) databases [NWQMC, 2017]. The stream water quality variables were selected accounting for their importance in representing the health of aquatic ecosystem [Chang, 2008; Chapra, 2008; Daniel et al., 2010; R Wan et al., 2014] and based on the preliminary analysis. These allowed us to hypothesize that coastal stream DO is dependent on a small set of environmental drivers such as: total phosphorous (TP), water temperature (TW), specific conductance (SC), potential of hydrogen $(\mathrm{pH})$, and dissolved oxygen (DO), along with concurrent stream flow (Q). The atmospheric pressure (AP) data was collected from 4 x $4 \mathrm{~km}$ grid cells of National Solar Radiation Database [NSRDB, 2017]. Saturated concentration of dissolved oxygen, $\mathrm{DO}_{\text {sat }}($ i.e., the oxygen dissolution capacity of water), was estimated leveraging water temperature, salinity, and atmospheric pressure following Chapra [2008]. The hydrologic and nonnutrient factors - reaeration variables: stream depth (D) and width (W), have also been reported to control stream DO [Hondzo et al., 2013]. Further, in order to have unit conformity with water temperature (TW), specific heat of water $\left(c_{\mathrm{p}}\right)$, i.e., $4,184 \mathrm{Jkg}^{-10} \mathrm{C}^{-1}$, has been incorporated in the analysis. Salinity was calculated using specific conductance [Schemel, 2001]. The hydrogen ion concentration $(\mathrm{H})$ which is estimated from $\mathrm{pH}$, has also included for dimensional analysis. Finally, 10 variables (see Table 3.1) that include the response variables (DO and $\mathrm{DO}_{\text {sat }}$ ) were considered in the dimensional analysis. 
Table 3.1: Summary of water quality and hydro-geometric variables.

\begin{tabular}{lccccccc}
\hline & & & $25^{\text {th }}$ & $50^{\text {th }}$ & $75^{\text {th }}$ & \\
Variables & Mean & SD & Minimum & Percentile & Percentile & Percentile & Maximum \\
\hline $\mathrm{DO}(\mathrm{mg} / \mathrm{L})$ & 8.69 & 2.57 & 1.30 & 6.93 & 9.20 & 10.60 & 13.80 \\
$\mathrm{DO}$ sat $(\mathrm{mg} / \mathrm{L})$ & 10.55 & 1.18 & 7.27 & 9.56 & 10.59 & 11.48 & 13.62 \\
$\mathrm{TP}(\mathrm{mg} / \mathrm{L})$ & 0.12 & 0.09 & 0.01 & 0.05 & 0.10 & 0.17 & 1.10 \\
$\mathrm{TW}\left({ }^{\circ} \mathrm{C}\right)$ & 12.44 & 5.04 & 2 & 8.40 & 12 & 16.50 & 27 \\
$\mathrm{AP}(\mathrm{mbar})$ & 989.90 & 16.86 & 926.23 & 981.65 & 992.44 & 1000.71 & 1023.72 \\
$\mathrm{~S}(\mathrm{ppt})$ & 0.08 & 0.05 & 0.01 & 0.05 & 0.07 & 0.10 & 0.47 \\
$\mathrm{pH}$ & 7.47 & 0.41 & 6.50 & 7.13 & 7.50 & 7.70 & 8.80 \\
$\mathrm{Q}\left(\mathrm{ft}^{3} \mathrm{~s}^{-1}\right)$ & 3827.15 & 7676.98 & 0.01 & 193 & 478 & 2230 & 48600 \\
$\mathrm{D}\left(\mathrm{ft}^{-}\right)$ & 23.99 & 55.85 & 0.05 & 3.40 & 5.49 & 17.28 & 324.56 \\
$\mathrm{~W}(\mathrm{ft})$. & 171.35 & 224.88 & 4.82 & 18.83 & 46.65 & 183.21 & 695.33 \\
\hline \hline
\end{tabular}

Note: DO, DO sat, TP, TW, AP, SC, pH, Q, D, and W, respectively, refer to dissolved oxygen, saturated dissolved oxygen, total phosphorous, water temperature, atmospheric pressure, specific conductance, potential of hydrogen, flow rate, stream depth, and stream width.

Temporal data of cross sectional area (A) and stream width (W) were collected from USGS [USGS, 2017b]. The streams depth (D) was calculated leveraging the dynamic data of ' $W$ ' and 'A' assuming trapezoidal cross section. Concurrent stream geometric data with the corresponding water quality data were not available. Therefore, we employed regression of the stream geometric variables (i.e., A, D, and $\mathrm{W}$ ) with stream flow $(\mathrm{Q})$ to estimate their data corresponding to stream water quality [Castro and Jackson, 2001; Raymond et al., 2012]. The extreme values (outliers) in the data were detected and removed using the interquartile range (IQR) criteria - the distance between the 25th and 75th sample percentile [Tukey, 1977]. Any observation outside a range obtained from $\mathrm{Q} 1-2 * \mathrm{IQR}$ and $\mathrm{Q} 3+2 * \mathrm{IQR}$ (here, Q1= 25th quartile, Q3=75th quartile, and $\mathrm{IQR}=\mathrm{Q} 3-\mathrm{Q} 1)$ were removed from the dataset. With the limited availability of hydro-geometric data across the study area, the analysis was performed on the 12 water quality monitoring stations having a reasonable spatial distribution across the U.S Pacific Coast (see Figure 3.1). 
The dataset incorporated major environmental process component to control coastal stream water quality. For example, stream temperature (TW) was represented by "climatic controls". Whereas, TP, H, and S were represented by "biogeochemical/metabolic controls". Further, AP, W, and D were also represented by "aeration and atmospheric gas exchange controls". The final data set (see Table 3.1) represented wide ranges of the diverse environmental conditions of the stream water quality processes.

\subsubsection{Methodology}

Three-step analysis procedures were used to achieve the study goals: (i) formulation and identification of different dimensionless numbers through dimensional analysis, (ii) examining similitude and scaling relationship leveraging the dimensionless numbers across different environmental regimes, and (iii) scaling relationship and model development.

\subsubsection{Dimensional Analysis}

Dimensional analysis is a conceptual tool developed in the field of fluid mechanics to understand functional dependencies among different variables that influence a particular process [Warnaars et al., 2007]. It is extensively used in fluid mechanics and hydraulic engineering [Kundu and Cohen, 2004] to formulate dimensionless functional groups or numbers, and derive scaling relationships between the response and the predictor variables. The aim of similitude and dimensional analysis is to formulate useful dimensionless groups to create a basis of similarity among the processes of stream water quality at diverse environments [Potter et al., 2002]. 
Table 3.2: Variables used in dimensionless analysis and their corresponding units and dimensions.

\begin{tabular}{llll}
\hline Variables & Symbol & Units & Dimensions \\
\hline Dissolved oxygen & $\mathrm{DO}$ & $\mathrm{kgm}^{-3}$ & {$\left[\mathrm{ML}^{-3}\right]$} \\
Saturated dissolved oxygen & $\mathrm{DO}$ sat & $\mathrm{kgm}^{-3}$ & {$\left[\mathrm{ML}^{-3}\right]$} \\
Total phosphorus & $\mathrm{TP}$ & $\mathrm{kgm}^{-3}$ & {$\left[\mathrm{ML}^{-3}\right]$} \\
Water temperature & $\mathrm{TW}$ & ${ }^{\circ} \mathrm{C}$ & {$[\mathrm{K}]$} \\
Atmospheric pressure & $\mathrm{AP}$ & $\mathrm{Kgm}^{-1} \mathrm{~s}^{-2}$ & {$\left[\mathrm{ML}^{-1} \mathrm{~T}^{-2}\right]$} \\
Salinity & $\mathrm{S}$ & $\mathrm{kgm}^{-3}$ & {$\left[\mathrm{ML}^{-3}\right]$} \\
Concentration of hydrogen ion & $\mathrm{H}$ & $\mathrm{kgm}^{-3}$ & {$\left[\mathrm{ML}^{-3}\right]$} \\
Stream width & $\mathrm{W}$ & $\mathrm{m}$ & {$\left[\mathrm{L}^{-3}\right.$} \\
Stream depth & $\mathrm{D}$ & $\mathrm{m}$ & {$\left[\mathrm{L}^{-3}\right.$} \\
Specific heat of water & $\mathrm{c}_{\mathrm{p}}$ & $\mathrm{J}_{\mathrm{kg}}{ }^{-1} \cdot{ }^{\circ} \mathrm{C}^{-1}$ & {$\left[\mathrm{~L}^{2} \mathrm{~T}^{-2} \mathrm{~K}^{-1}\right]$} \\
\hline \hline
\end{tabular}

Note: Dimensions K, L, M, and T, respectively, refer to temperature, length, mass, and time.

We employed dimensional analysis using Buckingham's pi theorem [Cohen et al., 2004; Finnemore and Franzini, 2002], which states 'n' variables can always be combined to form exactly (n-r) dimensionless (pi or $\Pi$ ) numbers, where ' $r$ ' is the number of relevant fundamental dimensions.

According to the Buckingham pi theorem, different combinations of repetitive primary variables can be chosen to form various pi groups. Different iterations were performed while formulating the pi groups by changing the primary variables. As example, the detailed derivations of the possible alternatives were given below, which provided most significant dimensionless groups:

$f\left(D O, D O_{s a t}, T W, c_{p}, A P, H, S, T P, W, D\right)=0$

Where total number of variables, $\mathrm{n}=10$; number of relevant fundamental dimensions, $\mathrm{r}=$ $4(\mathrm{M}, \mathrm{L}, \mathrm{T}, \mathrm{K})$ (see Table 3.2 for dimensions of the variables); number of dimensionless groups= $\mathrm{n}-\mathrm{r}=6$. Therefore, Eq. (1) can be written as a functional relationship 
$\phi\left(\Pi_{1}, \Pi_{2}, \Pi_{3}, \Pi_{4}, \Pi_{5}, \Pi_{6}\right)=0$

Now we need to select four (i.e., $r=4$ ) "repeating variables", which must have different dimensions, and among them must contain all the fundamental dimensions (in this study M, L, T, $\mathrm{K})$. Each pi number is formed by combining this four repeating variable with one of the remaining variables. To formulate the response pi number, let's consider TW, $\mathrm{c}_{\mathrm{p}}, \mathrm{AP}$, and $\mathrm{D}$ as a repeating variables:

$\Pi_{1}=T W^{a} \cdot c_{p}^{b} \cdot A P^{c} \cdot D^{d} \cdot T P$

For $\Pi$ to be dimensionless it is required that

$M^{0} L^{0} T^{0} K^{0}=(K)^{a}\left(\frac{L^{2}}{T^{2} K}\right)^{b}\left(\frac{M}{L T^{2}}\right)^{c}(L)^{d}\left(\frac{M}{L^{3}}\right)$

Equating the indices, we get;

$K: a-b=0 ; a=1$

$M: c=-1$

$L: 2 b-c+d-3=0 ; d=0$

$T:-2 b-2 c=0 ; b=1$

Therefore,

$\Pi_{1}=T W^{1} \cdot c_{p}{ }^{1} \cdot A P^{-1} \cdot D^{0} \cdot T P$

Thus, $\Pi_{1}=\frac{c_{p} \cdot T W \cdot T P}{A P}$

$\Pi$ numbers can be written also as inverse function;

$$
\Pi_{1}^{-1}=\frac{A P}{c_{p} \cdot T W \cdot T P}
$$


Similarly, other pi numbers can be formed as;

$$
\Pi_{2}=\frac{A P}{c_{p} \cdot T W \cdot H} ; \Pi_{3}=\frac{A P}{c_{p} \cdot T W \cdot S} ; \Pi_{4}=\frac{A P}{c_{p} \cdot T W \cdot D O} ; \Pi_{5}=\frac{A P}{c_{p} \cdot T W \cdot D O_{s a t}} ; \Pi_{6}=\frac{W}{D} ;
$$

Therefore, the functional relationship becomes

$$
\phi\left[\left(\frac{A P}{c_{p} \cdot T W \cdot D O}\right)\left(\frac{A P}{c_{p} \cdot T W \cdot D O_{s a t}}\right)\left(\frac{A P}{c_{p} \cdot T W \cdot H}\right)\left(\frac{A P}{c_{p} \cdot T W \cdot T P}\right)\left(\frac{A P}{c_{p} \cdot T W \cdot S}\right)\left(\frac{W}{D}\right)\right]=0
$$

Thus, dimensional analysis has reduced the 10 parameters to a collective meaningful dimensionless number. Recalling the definition of similitude from the physical domain [Cohen et al., 2004], such parametric reductions of stream water quality process are termed as 'stream biogeochemical'. Different combinations of repeating variables can result in different sets of pi numbers. Different set of pi numbers are formed by dividing among themselves to form new set of pi-numbers [Finnemore and Franzini, 2002]. Following the method above, various other sets of pi numbers were derived through changing the primary variables. Finally, we selected the appropriate and meaningful sets of four pi numbers based on the process based knowledge of stream water quality dynamics to represent different dynamic environmental processes. The selected pi numbers emerged into the following functional relationships:

$$
\frac{D O}{D O_{s a t}}=\phi\left[\left(\frac{A P}{c_{p} \cdot T W \cdot H}\right)\left(\frac{A P}{c_{p} \cdot T W \cdot T P}\right)\left(\frac{A P}{c_{p} \cdot T W \cdot S}\right)\left(\frac{W}{D}\right)\right]
$$

Further multiplication of the dimensionless groups among them, we get;

$$
\frac{D O}{D O_{\text {sat }}}=\phi\left[\left(\frac{A P^{3} \cdot W}{c_{p}^{3} \cdot T W^{3} \cdot T P \cdot S \cdot H \cdot D}\right)\right]
$$


For simplicity in presenting the dimensionless groups, I denoted the derived dimensionless groups as follows:

$$
\begin{aligned}
& D O^{*}=\frac{D O}{D O_{\text {sat }}}(\text { Dimensionless response group }) \\
& \Pi_{r}=\frac{A P^{3} \cdot W}{c_{p}{ }^{3} \cdot T W^{3} \cdot T P \cdot S \cdot H \cdot D}(\text { Dimensionless predictor group })
\end{aligned}
$$

In the above Eq. (3), collecting all the individual variables together formed a meaningful dimensionless predictor number which assemble the collective environmental effect on stream DO. The response dimensionless number (DO*) represented the concentration of DO, as scaled by the oxygen dissolution capacity of stream water (i.e., DO at saturation point, $\mathrm{DO}$ sat). In the predictor dimensionless number, the numerator has sources (e.g., AP, W) of stream DO indicating the aeration and atmospheric gas exchange effect. Whereas, the denominator shows the sinks (TW, S, TP, and D) of stream DO — indicating controls from stream metabolism, salinity, and temperature.

\subsubsection{Investigating Similitude and Environmental Regimes}

At first, the most important and meaningful predictor dimensionless numbers were identified by plotting them on semi-logarithmic and normal papers against the response dimensionless number (DO*) to explore characteristic process diagrams and environmental regimes. A potential collapse of different pi numbers, representing different environmental process groups, in a comparable zone showed the existence of similitude. To have a clear pattern, we investigated the graphical exploration with a bin-based average data. For any clear regimes found with the specific pi 
numbers, it was investigated if the regime can be defined based on the critical threshold values which can possibly identify environmental regimes.

\subsubsection{Determination of the Regimes-specific Environmental Linkages}

We further investigated the characteristics of the environmental regime by quantifying the relative linkages of stream DO with the environmental drivers using Z-scored PLSR model coefficients to identify the individual dominant drivers by resolving multi-collinearity [Abdul-Aziz and Ahmed, 2017; Ishtiaq and Abdul-Aziz, 2015]. The analytics method was well-suited for our datasets given their reputation of providing reliable results across small to large samples [Winter et al., 2009; Wold, 2001]. Data for all response and predictor variables were first logarithmically (log10) transformed to incorporate the non-linear interactions. The log-transformed variables were then standardized to bring different scales and units to a comparable reference scale (dimensionless Z-

scores) as follows: $Z=\frac{x-\mu}{\sigma}$, where $\mathrm{x}=\log _{10}$-transformed variable, $\mu=$ mean of $\mathrm{x}$, and $\sigma=$ standard deviation of $\mathrm{x}$. Each layer of the data analytics was performed with the Z-score using MATLAB R2017a.

PLSR is superior to a conventional principal component regression (PCR). In PCR, the PCs of only predictors are first derived, and then fitted with the response. However, the orthogonal partial least squares (PLS) components of predictors are computed and fitted with the response in PLSR through a simultaneous decomposition of all variables [Schumann et al., 2013]. The Z-score based PLSR model was estimated with the observed data for each site separately using SIMPLS algorithm [de Jong, 1993; Hubert and Branden, 2003] and a 10-fold cross validation [Kuhn and Johnson, 2013]. The optimality of the models was achieved by including a minimum number of PLS components based on a synthesis of the minimum Akaike Information Criterion (AIC) 
[Akaike, 1974] and maximum Nash-Sutcliffe efficiency (NSE) criterion [Abdul-Aziz and Ahmed, 2017].

Predictors with higher absolute values of $\beta$ indicated stronger relative linkages of the drivers with DO. The positive or negative sign of $\beta$ indicated the direction of relationship (i.e., increasing or decreasing) between the variables. However, the directions of relationships are mechanistically more meaningful for important predictors than that of the weak predictors. The model fitting efficiency was measured by NSE, and the accuracy of predictions was evaluated by the ratio of root-mean-square error to the standard deviation of observations (RSR). Since the fitting of the optimal PLSR models was performed using the minimum number of independent PLS components, the model bias and instability arising from multi-collinearity among the predictors had been optimally resolved [Kuhn and Johnson, 2013].

\subsubsection{Development of Scaling Relationships and Predictive Models}

A potential collapse of the different groups in a comparable zone would indicate the existence of biogeochemical-ecological similitude and scaling relationship in a coastal stream DO. Then, the nonlinear scaling relationship Eq. (1) among the predictor $\left(\Pi_{\mathrm{r}}\right)$ and response (DO*) dimensionless groups were investigated by applying a numerical solution based Levenberg-Marquardt non-linear least squares algorithm [Seber and Wild, 2005] in the MATLAB R2017a environment.

$$
D O^{*}=\left(1-a \Pi_{r}{ }^{b}\right)
$$

Where $\mathrm{a}$ and $\mathrm{b}$ are model parameters ( $\mathrm{a}$ is the coefficient, and $\mathrm{b}$ represented the shape factor), $\Pi_{\mathrm{r}}$ is the driver dimensionless number of the response dimensionless number DO*.

The model shape factor shows the scaling relationship between the driver and the response dimensionless number. The power-law scaling function which was then used as non-linear 
empirical model was used to predict coastal stream DO across the different environmental regimes. The dimensionless numbers with the relationship Eq. (5) can be also written in another form Eq. (4) to express DO in the original domain as follows:

$D O=D O_{s a t}\left(1-a \Pi_{r}{ }^{b}\right)$

The predictive model was developed by using the Monte Carlo cross-validation approach with 1000 iterations [Kuhn and Johnson, 2013]. For each iteration, 80\% of the data was randomly chosen for model training (i.e. fitting), and the rest of the $20 \%$ was used for testing (i.e., validating). Mean values of the parameters obtained from the iterations were used as the final parameter set to predict stream DO from the predictor variables for the water stream quality. The comparable parameter values would indicate the potential similitude and scaling relation among the response and predictor groups in a range of environmental gradient that could lead to the temporal robust predictive model development of coastal stream DO in the dimensionless domain.

\subsection{Results}

\subsubsection{Similitude and Environmental Regimes}

The dimensionless driver group, $\Pi_{\mathrm{r}}$ was plotted (Figure 3.2a) against the dimensionless response group, DO* on semi-logarithmic and normal paper for different study sites across the Pacific Coast of U.S.A. Graphical exploration of the predictor and response dimensionless number unraveled emergent patterns by collapsing observations from diverse environmental conditions into a single curve. To get clearer picture of the pattern, further exploration was also performed with a bin based average data (Figure 3.2b). The study revealed that with increasing trend the curve reaches to a critical point (i.e., saturation point, DO* 1) and then it gets flattened. This identify two distinct 
environmental regimes - low consumption (saturated) and high consumption (unsaturated) regime.

(a)

(b)
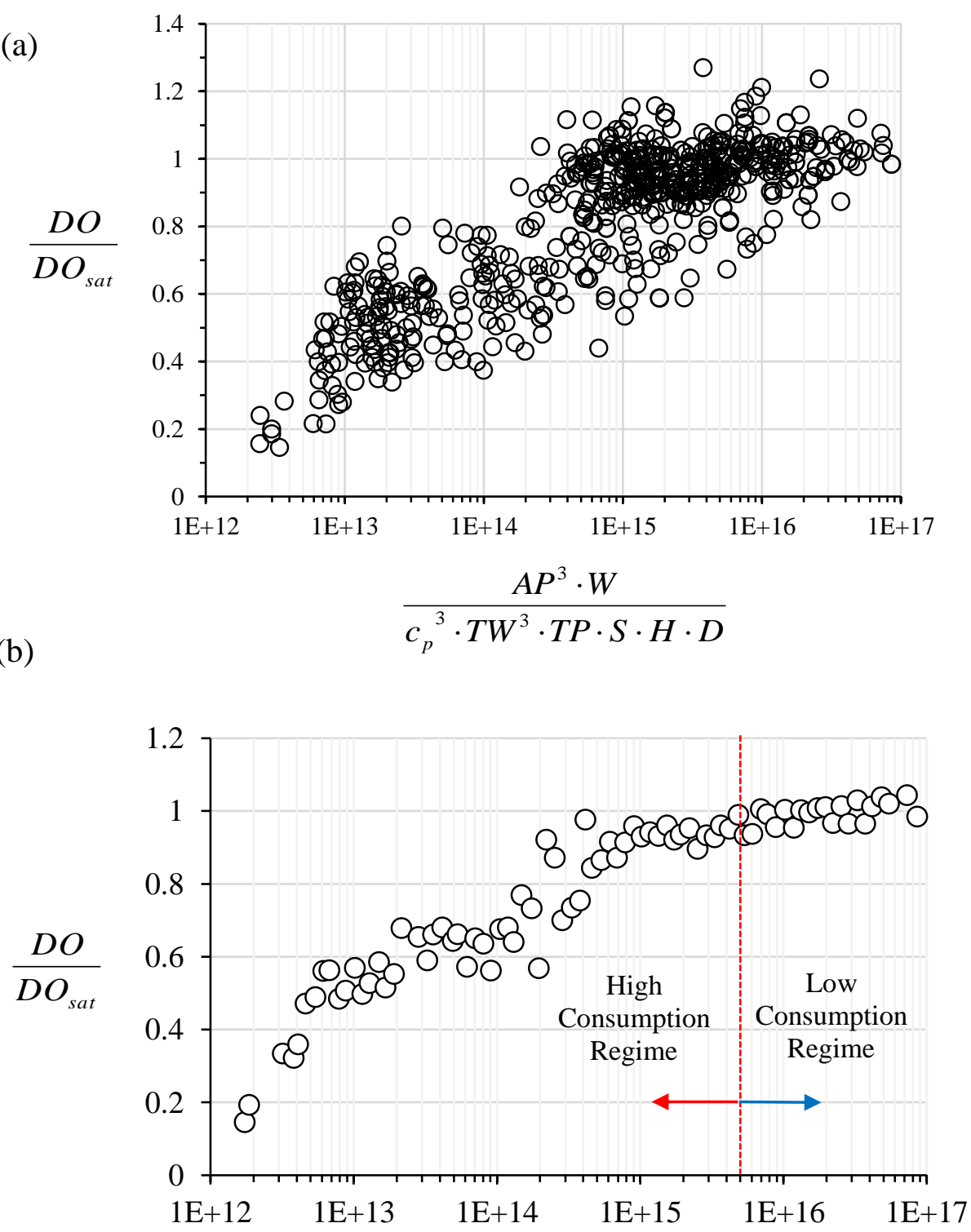

$$
\frac{A P^{3} \cdot W}{c_{p}^{3} \cdot T W^{3} \cdot T P \cdot S \cdot H \cdot D}
$$

Figure 3.2: Plot of the predictor dimensionless group $\left(\Pi_{\mathrm{r}}\right)$ with the response dimensionless group (DO*): collapse of (a) all original data and (b) bin-based averaged data from different streams across different environmental regimes. 
These two environmental regimes were separated by a threshold value of the driver dimensionless number and that value indicates the saturation point of stream DO. Based on the threshold value: a) $\log _{10}\left(\Pi_{\mathrm{r}}\right)>15.5$ and b) $\log _{10}\left(\Pi_{\mathrm{r}}\right) \leq 15.5$ - two environmental regimes were revealed governed by climate and metabolic process variables respectively (Figure 3.2). The normalized concentration of DO was relatively lower in high consumption regime $\left(\log _{10}\left(\Pi_{\mathrm{r}}\right) \leq\right.$ 15.5) - showing the adverse effect of stream metabolism, salinity, and temperature on stream water quality. However, the low consumption regime $\left(\log _{10}\left(\Pi_{r}\right)>15.5\right)$ had DO concentration close to its saturation point — owing to less/weak control from stream metabolism—suggesting a climatic control dominated regime.

\subsubsection{Regime-Specific Relative Linkages of the Environmental Drivers}

The relative linkages of DO with the dominant environmental drivers were quantified for the two environmental regimes. Optimization of the power-law based PLSR models (using minimum AIC along with acceptable NSE; see Figure 3.3) led to inclusion of 3 PLS components. Based on [Moriasi, 2007], the fitting efficiency ( $\mathrm{NSE}=0.62$ to 0.64 ) and accuracy (RSR $=0.54$ to 0.59 ) of the optimal models suggested good predictions of stream DO for the two distinct environmental regimes (Table 3.3). PLSR model coefficients $(\beta)$ also confirms our result from the previous graphical exploration analysis to investigate the two environmental regimes. 
(a)

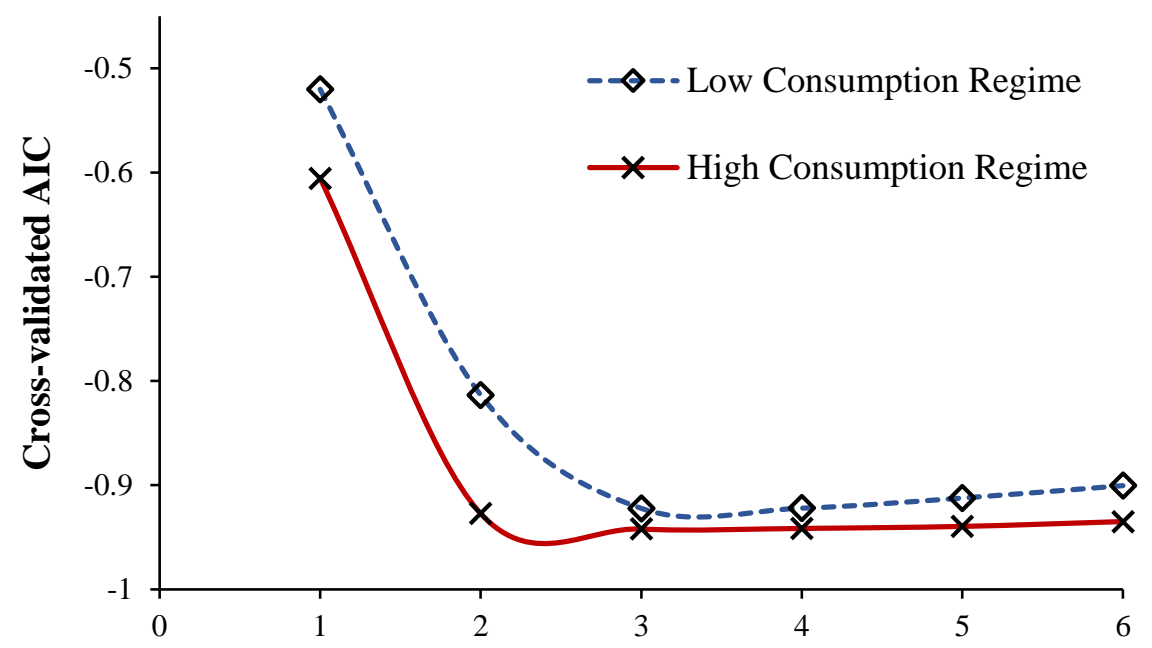

(b)

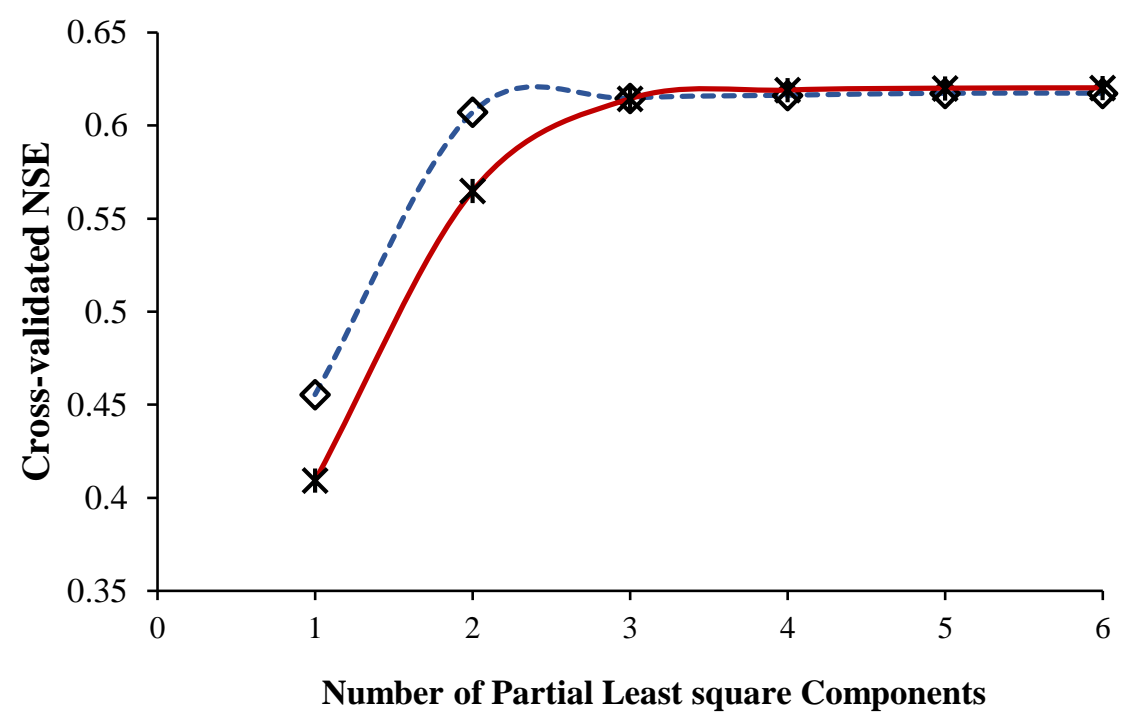

Figure 3.3: Plot of cross-validated (a) normalized AIC and (b) Nash-Sutcliffe efficiency (NSE) with the number of partial least square components for all sites. 
Table 3.3: Estimated coefficients $(\beta)$ of the Z-score PLSR models for the two environmental regimes.

\begin{tabular}{lcc}
\hline Predictor variables & $\begin{array}{c}\text { Low consumption } \\
\text { regime }\end{array}$ & $\begin{array}{c}\text { High consumption } \\
\text { regime }\end{array}$ \\
\hline TW & $\mathbf{- 0 . 8 8}$ & $\mathbf{- 0 . 5 9}$ \\
pH & 0.15 & $\mathbf{0 . 6 3}$ \\
S & 0.08 & -0.21 \\
TP & -0.19 & $\mathbf{- 0 . 2 5}$ \\
Q & 0.06 & -0.04 \\
AP & 0.02 & 0.08 \\
& Model statistics & \\
PLS component & 3 & 3 \\
NSE & 0.64 & 0.62 \\
RSR & 0.59 & 0.54 \\
\hline \hline
\end{tabular}

Notes: TW, pH, TP, S, Q, and AP, respectively, refer to water temperature, potential of hydrogen, total phosphorus, salinity, flow rate, and atmospheric pressure.

In high consumption regime $\left(\log _{10}\left(\Pi_{\mathrm{r}}\right) \leq 15.5\right)$, $\mathrm{pH}$ showed a strong positive linkage $(\beta=$ $0.63)$ with stream DO. In addition, TW $(\beta=-0.59), \mathrm{S}(\beta=-0.21)$, and TP $(\beta=-0.25)$ had also moderate to strong negative linkage with stream DO. This implies high consumption rate of stream DO - suggested microbial decomposition. In contrast, the low consumption regime $\left(\log _{10}\left(\Pi_{\mathrm{r}}\right)>\right.$ 15.5), TW showed a strong negative linkage $(\beta=-0.88)$ with stream DO — suggested climatic control. However, $\mathrm{pH}, \mathrm{TP}$, and $\mathrm{S}$ showed comparatively weak linkages with stream DO which clearly indicated the weak control from metabolism.

\subsubsection{Scaling Relationships and Robust Models}

The emergent patterns led to the estimation of scaling relationship and predict the response dimensionless group, DO* from the important and meaningful predictor group $\left(\Pi_{\mathrm{r}}\right)$ across different environmental regimes (Figure 3.2). The shape factor value (b) was estimated from a bin averaged data using a non-linear numerical solution (Equation 6) based on Levenberg-Marquardt non-linear least squares algorithm. To maintain robust model, Monte-Carlo (1000 bootstrap) estimations was 
adopted with a good efficiency of the optimized models. The estimated mean values of the parameters obtained from the iterations were used as the final parameter set, the shape factor $(b=$ -0.30) indicated the scaling relationship between the pi numbers (see Table 3.4). Performance of the developed models (calibration $\mathrm{NSE}=0.89$, validation $\mathrm{NSE}=0.87$ ) indicated effectiveness of the model to predict stream DO from diverse ecosystems.

$$
D O^{*}=1-4312\left(\frac{A P^{3} \cdot W}{c_{p}^{3} \cdot T W^{3} \cdot T P \cdot S \cdot D \cdot H}\right)^{-0.30}
$$

Table 3.4: The estimated model parameters and model fitting efficiency (with validation in parenthesis) for predicting stream DO.

\begin{tabular}{|c|c|}
\hline Parameters & Estimate \\
\hline $\mathrm{a}$ & 4312 \\
\hline b & -0.30 \\
\hline \multicolumn{2}{|c|}{ Model Statistics } \\
\hline NSE & $0.89(0.87)$ \\
\hline RSR & $0.32(0.34)$ \\
\hline
\end{tabular}

Note: $\mathrm{a}$ and $\mathrm{b}$ are the estimated model parameters

The scaling relationship was leveraged to develop nonlinear empirical model to successfully predict stream DO across the different environmental regimes. The scaling relationship of the DO can be expressed from Eq. (6), as a sole function of DO:

$$
D O=D O_{\text {sat }}\left[1-4312\left(\frac{A P^{3} \cdot W}{c_{p}^{3} \cdot T W^{3} \cdot T P \cdot S \cdot D \cdot H}\right)^{-0.30}\right]
$$


The model shows a good efficiency (NSE=0.72) with a good homoscedasticity in predicting stream DO (Figure 3.4) in various streams across the Pacific Coast of U.S.A.

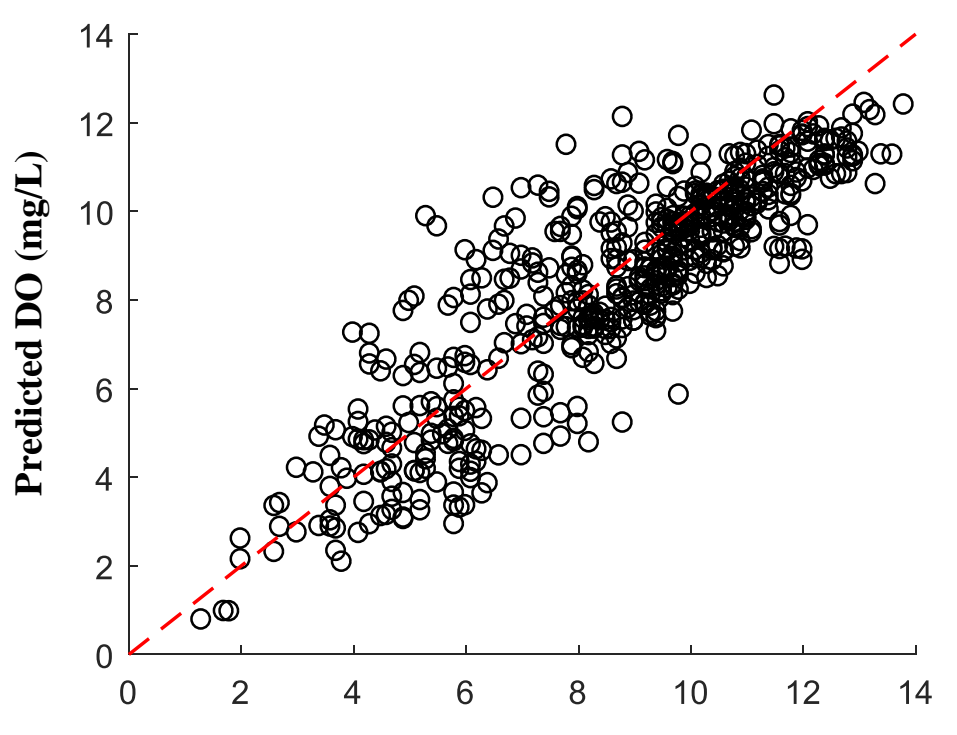

Observed DO (mg/L)

Figure 3.4: Plot of observed vs. predicted stream dissolved oxygen across the Pacific Coast of U.S.A. 


\subsection{Discussion}

Different environmental variables in the predictor dimensionless number show various environmental process components - (climate, biochemistry, aeration and atmospheric gas exchange) to control DO. Combining all the variables using Buckingham pi theorem shows the collective control of the hydro-climatic and biogeochemical on stream water quality. Based on the threshold of the predictor dimensionless number, two distinct environmental regimes (climate vs metabolic control) were identified. The dimensionless numbers and emergent patterns led to the estimation of scaling relationship, which was robust across the different environmental regimes. The scaling relationship was then leveraged to develop a nonlinear empirical model to successfully predict stream DO in various streams across the Pacific Coast of U.S.A.

A graphical exploration of the predictor and response dimensionless numbers unraveled emergent patterns by collapsing observations from diverse environmental conditions into a single curve (Figure 3.2). The driver dimensionless number has a source (width, W; and atmospheric pressure, AP) of stream DO in the numerator - attributed to the aeration and atmospheric gas exchange effect. In contrast, it has a sink (water temperature, TW; Salinity, S; Total phosphorous, TP; and concentration of hydrogen ion, $\mathrm{H}$ ) of DO in the denominator exhibiting the controls from stream metabolism, salinity, and temperature. This combined effect let to the increasing positive trend of the curve. To get a clear picture, further investigation was performed with a bin based average data - showing with an increase positive trend the curve reaches the highest point (i.e., where stream DO gets saturated, DO* 1) and then gets flattened.

Plot of the response dimensionless group, DO* and the driver dimensionless group, $\Pi_{\mathrm{r}}$ unraveled an existence of an environmental regimes that were previously hidden in the data. Based 
on the threshold of the predictor dimensionless number, which indicates DO saturation point, the study revealed the existence of two distinct environmental regimes governed by the climate and metabolic process variables. Observations below the threshold value $\left(\log _{10}\left(\Pi_{\mathrm{r}}\right) \leq 15.5\right)$ refers to the environmental condition governed by the $\mathrm{pH}$ and $\mathrm{TW}$ - suggested dominance of metabolic control causing high consumption of stream DO. Whereas, observations that falls in the saturated regime $\left(\log _{10}\left(\Pi_{\mathrm{r}}\right)>15.5\right)$ with low or weak metabolic process (high consumption of DO) suggested climatic control.

The characteristic of each environmental regime was further investigated by utilizing Zscored based PLSR model to quantify the relative linkages of the stream DO with the environmental drivers. The analysis also confirmed our graphical exploration curve. In the high consumption regime $\left(\log _{10}\left(\Pi_{\mathrm{r}}\right) \leq 15.5\right)$, $\mathrm{pH}$ showed strong positive linkages $(\beta=0.63)$ with stream DO. In addition, TW, S, and TP had also moderate negative linkages $(\beta=-0.21$ to -0.59$)$ with DO. This implies that stream metabolism had driven to the high consumption rate (high stress) of stream DO - suggesting microbial decomposition. The excessive microbial decomposition in high consumption regime induces carbon dioxide which reduce $\mathrm{pH}$ [Cai et al., 2011] — led to the positive linkage between DO and pH. Cai et al. [2011] found significant positive linkage between DO and $\mathrm{pH}$ in the northern Gulf of Mexico, and attributed it to their simultaneous increase and decrease, respectively, with primary production (e.g., photosynthesis) and respiration (microbial decomposition). While salinity $(\beta=-0.21)$, directly affect DO by reducing oxygen solubility, it can also indirectly affect DO by controlling many biogeochemical reactions that creates stress (i.e., inhibits the electron transport rate) on the photosynthetic organisms [Cloern, 1996]. TP had also moderate negative linkage $(\beta=-0.25)$ with DO — suggesting the turbidity effect from higher algal blooms which can decrease DO in the coastal streams [Kudela et al., 2010; Ryan et al., 2010; Vega 
et al., 1998]. Therefore, streams in this regime having relatively low DO, needs more attention in water quality management. However, in the low consumption regime $\left(\log _{10}\left(\Pi_{\mathrm{r}}\right)>15.5\right)$, TW showed a strong negative linkage $(\beta=-0.88)$ with stream DO. However, in this regime the metabolic process variables (i.e., TP, S, and H) showed a weak linkages with stream DO suggesting an environmental condition dominated by climatic control only, and not favorable for microbial decomposition.

The collapse of observations from diverse environmental conditions resulted in a single curve. The emergent pattern of the driver's dimensionless number and the response dimensionless number (i.e., normalized DO) were used to establish a scaling relationship as a non-linear power law model (Equation 4) which were robust across the different environmental regimes. Iterative solution using Levenberg-Marquardt non-linear least squares algorism have applied and the model parameters have robustly estimated by repeating the model 1000 iterations using Monte Carlo bootstrap procedure. The coefficient and shape factor $(b=-0.30)$ were reliably estimated. The model shape factor shows the scaling relationship among the driver dimensionless numbers and the response dimensionless number. Even though they have different characteristics, single scaling relationship could represent them — implying that coastal stream DO follows distinct similitude and scaling relationship. The scaling relationship was successfully leveraged to develop stream water quality model to predict DO in original domain. The good performance of the model to predict DO across the different environmental regimes in different hydro-climatic and biogeochemical conditions shows that the developed scaling relationship can be used to predict stream DO robustly across the different water quality sites across the Pacific Coast of U.S.A. This implies that the similitude and scaling relationship can lead to the development of a robust 
predictive model of stream DO in different environmental conditions across the Pacific Coast of U.S.A.

\subsection{Conclusions}

The study provides a primary understanding of the similitude, different environmental regimes, scaling relationship, and model development of coastal urban/natural stream DO. A single predictor is intricate, so the dimensionless numbers represent collective control from the interaction of multitude of the dynamic environmental drivers investigated for the analysis. The hydro-climatic and biogeochemical controls of coastal urban/natural stream DO were evaluated by conducting similitude and dimensional analysis. Those mechanistically meaningful dimensionless numbers were identified from a diligent application of the Buckingham-Pi theorem. The driver dimensionless number consists of various hydro-climatic and biogeochemical drivers of the stream DO. Whereas, response dimensionless numbers, DO* represented the concentration of DO as normalized by the oxygen dissolution capacity of stream water. A graphical exploration of the predictor and response dimensionless number unraveled emergent patterns by collapsing observations from diverse environmental conditions into a single curve.

The study revealed the existence of two distinct environmental regimes across the Pacific Coast of U.S.A. Based on the threshold value, two separate regimes (climate vs. metabolic controls) were identified. These two environmental regimes were separated by a threshold value of the driver dimensionless number and that value corresponds to the saturation point of stream DO. The thresholds of the predictor dimensionless number: a) $\log _{10}\left(\Pi_{r}\right)>15.5$ and b) $\log _{10}\left(\Pi_{r}\right)$ $\leq 15.5$ - revealed two environmental regimes governed, respectively, by climate and metabolic process variables. In higher consumption regime $\left(\log _{10}\left(\Pi_{\mathrm{r}}\right) \leq 15.5\right)$, the unsaturated stream DO 
was due to the adverse effect of microbial decomposition. This suggest that substantial reduction of in-stream DO attributes to the extreme metabolic activities in the stream. This regime had relatively lower dissolved oxygen, and therefore, needs higher attention in water quality management. However, in low consumption regime $\left(\log _{10}\left(\Pi_{r}\right)>15.5\right)$, the nearly saturated DO suggested dominant control from climate and weak/no control from stream metabolism.

The dimensionless numbers and emergent patterns led to the estimation of scaling relationships, which were robust across the different environmental regimes. This implied that coastal stream DO follows distinct similitude and scaling relationship. The scaling relationship was then leveraged as a non-linear empirical model to successfully predict stream DO in various streams across the Pacific Coast of U.S.A. The good performance of the model to predict DO across the environmental regime in different hydro-climatic and biogeochemical conditions shows that the developed scaling relationship can be used to predict DO robustly across the different water quality sites of the study area. This research contributed to new knowledge on the dominant stream water quality drivers, stream biogeochemical-ecological similitude, and scaling relationship, which are expected to guide efficient water resource management to achieve healthy coastal urban/natural stream ecosystems across the Pacific Coast and similar regions around the world. 


\section{Chapter 4: Summary and Conclusions}

The thesis investigated the dominant environmental drivers, emergent similitude (parametric reductions), scaling relationships, and robust predictions of DO dynamics in diverse stream ecosystems across the Pacific Coast of U.S.A. The research was conducted by assembling a dataset for 1998-2015 at 35 water quality monitoring stations of U.S. Geological Survey and Environmental Protection Agency. The research objectives were pursued by conducting data analytics, dimensional analysis (from fluid mechanics), and predictive empirical modeling.

In chapter 3, a systematic multivariate data analytics methodology was employed to determine the relative linkages and controls of different environmental drivers of stream DO dynamics. The data analytics revealed four distinct environmental regimes across the study area. In the Pacific Northwest (Washington and Oregon) and southern California, water temperature was the most dominant driver of DO in majority of the streams, indicating a climate-controlled environmental regime. However, in central and northern California, stream DO was controlled by multiple drivers (water temperature, $\mathrm{pH}$, stream flow, and phosphorus), exhibiting a mixed environmental regime. Further, phosphorus appeared to be the limiting nutrient for most streams.

Chapter 4 investigated the biogeochemical-ecological similitudes, environmental regimes, and scaling relationships of stream DO across the Pacific Coast of U.S.A. The study identified a driver dimensionless group — representing the collective effect of different environmental drivers on stream DO. A graphical exploration of the response dimensionless group (DO*) and the predictor dimensionless group showed a collapse of observations from diverse streams into a single

dimensionless curve — indicating a remarkable emergent pattern across the U.S. Pacific Coast. A threshold value of the predictor dimensionless number reiterated the existence of two environmental regimes (i.e., low vs. high consumption), showing controls of climatic vs. metabolic 
processes on stream DO. In the low consumption regime, stream temperature had a strong and dictating control on DO. However, in the high consumption regime, strong controls on DO were exerted by both stream $\mathrm{pH}$ and temperature - representing a combination of climatic and metabolic controls. The dimensionless numbers were leveraged to develop a generalized scaling relationship, which was then used as a non-linear empirical model to robustly predict stream DO in diverse environmental regimes across the Pacific Coast of U.S.A.

In summary, this research presented a systematic approach for data-based mechanistic knowledge-building on coastal stream water quality processes under diverse climate and environments. The knowledge of the dominant drivers was successfully leveraged to investigate similitude and scaling-based emergent patterns, which were then utilized to develop a robust predictive model of DO for diverse streams along the Pacific Coast of U.S.A. The research findings are expected to assist ecologists, engineers, and stakeholders derive appropriate management strategies to achieve and maintain a healthy stream water quality and associated services under a changing environment.

\section{Acknowledgements}

The research was funded by a National Science Foundation (NSF) CAREER Award to Dr. Omar I. Abdul-Aziz (NSF CBET Environmental Sustainability Award Number 1561942/1454435). Funding support from Dr. Abdul-Aziz's WVU start-up grant is also thankfully acknowledged. 


\section{References}

Abdul-Aziz, O. I., and K. S. Ishtiaq (2014), Robust empirical modeling of dissolved oxygen in small rivers and streams: Scaling by a single reference observation, Journal of Hydrology, 511, 648-657, doi: http://dx.doi.org/10.1016/j.jhydrol.2014.02.022.

Abdul-Aziz, O. I., and S. Ahmed (2017), Relative linkages of stream water quality and environmental health with the land use and hydrologic drivers in the coastal-urban watersheds of southeast Florida, GeoHealth, 1(4), 180-195, doi: 10.1002/2017gh000058.

Abdul-Aziz, O. I., B. N. Wilson, and J. S. Gulliver (2007a), Calibration and validation of an empirical dissolved oxygen model, Journal Environmental Engineering, 133(7), 698-710, doi: doi:10.1061/(ASCE)0733-9372(2007)133:7(698).

Abdul-Aziz, O. I., B. N. Wilson, and J. S. Gulliver (2007b), An extended stochastic harmonic analysis algorithm: Application for dissolved oxygen, Water Resource Research, 43(8), n/a-n/a, doi: 10.1029/2006WR005530.

Akaike, H. (1974), A new look at the statistical model identification, IEEE Transactions on Automatic Control, 19(6), 716-723, doi: 10.1109/TAC.1974.1100705.

Aulinger, A., J. W. Einax, and A. Prange (2004), Setup and optimization of a PLS regression model for predicting element contents in river sediments, Chemometrics Intelligent Laboratory Systems, 72(1), 35-41, doi: http://dx.doi.org/10.1016/j.chemolab.2004.03.001.

Ben-Gal, I. (2010), Outlier Detection, in Data Mining and Knowledge Discovery Handbook, edited by O. Maimon and L. Rokach, pp. 117-130, Springer US, Boston, MA.

Bograd, S. J., C. G. Castro, E. Di Lorenzo, D. M. Palacios, H. Bailey, W. Gilly, and F. P. Chavez (2008), Oxygen declines and the shoaling of the hypoxic boundary in the California Current, Geophysical Research Letters, 35(12), n/a-n/a, doi: 10.1029/2008g1034185.

Boyer, J. N., C. R. Kelble, P. B. Ortner, and D. T. Rudnick (2009), Phytoplankton bloom status: Chlorophyll a biomass as an indicator of water quality condition in the southern estuaries of Florida, USA, Ecological Indicators, 9(6), S56-S67, doi: http://dx.doi.org/10.1016/j.ecolind.2008.11.013.

Briceño, H. O., J. N. Boyer, J. Castro, and P. Harlem (2013), Biogeochemical classification of South Florida's estuarine and coastal waters, Marine Pollution Bulletin, 75(1), 187-204, doi: http://dx.doi.org/10.1016/j.marpolbul.2013.07.034.

Brown, C. A., and J. H. Power (2011), Historic and recent patterns of dissolved oxygen in the Yaquina Estuary (Oregon, USA): Importance of anthropogenic activities and oceanic conditions, Estuarine Coastal and Shelf Science, 92(3), 446-455, doi: http://dx.doi.org/10.1016/j.ecss.2011.01.018. 
Buckingham, E. (1914), On physically similar systems; Illustrations of the use of dimensional equations, Physical Review, 4(4), 345-376.

Cai, W.J., X. Hu, W.J. Huang, M.C. Murrell, J.C. Lehrter, S.E. Lohrenz, W.C. Chou, W. Zhai, J.T. Hollibaugh, Y. Wang, P. Zhao, X. Guo, K. Gundersen, M. Dai, G.C. Gong (2011), Acidification of subsurface coastal waters enhanced by eutrophication, Nature Geoscience, 4, 766-770, doi: 10.1038/ngeo1297 https://www.nature.com/articles/ngeo1297\#supplementary-information.

Carey, R. O., G. J. Hochmuth, C. J. Martinez, T. H. Boyer, M. D. Dukes, G. S. Toor, and J. L. Cisar (2013), Evaluating nutrient impacts in urban watersheds: Challenges and research opportunities, Environmental Pollution, 173, 138-149, doi: 10.1016/j.envpol.2012.10.004.

Carrascal, L. M., I. Galván, and O. Gordo (2009), Partial least squares regression as an alternative to current regression methods used in ecology, Oikos, 118(5), 681-690, doi: 10.1111/j.1600-0706.2008.16881.x.

Castro, J. M., and P. L. Jackson (2001), Bankfull discharge recurrence intervals and regional hydraulic geometry relationships: Patterns in the Pacific Northwest, USA, Journal of the American Water Resources Association, 37(5), 1249-1262, doi: 10.1111/j.17521688.2001.tb03636.x.

Chang, H. (2008), Spatial analysis of water quality trends in the Han River basin, South Korea, Water Research, 42(13), 3285-3304, doi: 10.1016/j.watres.2008.04.006.

Chapman, D. (1992), Water Quality Assessment; A guide to the use of biota, sediments and water in environmental monitoring: Chapman D. (Ed.), on behalf of UNESCO, WHO and UNEP, Chapman and Hall, London, 585pp.

Chapra, S. C. (2008), Surface Water-Quality Modeling, pp. 3-20, Waveland Press, Long Grove, Illinois.

Cloern, J. E. (1996), Phytoplankton bloom dynamics in coastal ecosystems: A review with some general lessons from sustained investigation of San Francisco Bay, California, Reviews of Geophysics, 34(2), 127-168, doi: 10.1029/96RG00986.

Cohen, I. M., P. K. Kundu, and H. Hu (2004), Fluid Mechanics, 3rd ed., Elsevier Science, NY.

Conley, D.J, J. J. Carstensen, P. Aigars, E. Axe, T. Bonsdorff, B.M. Eremina, C. Haahti, Humborg (2011), Hypoxia is increasing in the coastal zone of the Baltic Sea, Environmental Science Technology, 45(16), 6777-6783, doi: 10.1021/es201212r.

Crossett, K. M, T.J. Culliton, P.C. Wiley, and T. R. Goodspeed (2004), Population trends along the Coastal United States, 1980-2008. Silver Spring, Maryland: National Oceanic and Atmospheric Administration, 47p.

Culliton, T. J. (1998), Population: Distribution, Density, and Growth. NOAA's State of the Coast Report. Silver Spring, Maryland: National Oceanic and Atmospheric Administration, 33p. 
Daniel, F. B., M. B. Griffith, and M. E. Troyer (2010), Influences of spatial scale and soil permeability on relationships between land cover and baseflow stream nutrient concentrations, Environmental Management, 45(2), 336-350, doi: 10.1007/s00267-0099401-x.

de Jong, S. (1993), SIMPLS: An alternative approach to partial least squares regression, Chemometrics Intelligent Laboratory Systems, 18(3), 251-263, doi: doi: 10.1016/01697439(93)85002-x.

de Oliveira, L. M., P. Maillard, and É. J. de Andrade Pinto (2016), Modeling the effect of land use/land cover on nitrogen, phosphorous and dissolved oxygen loads in the Velhas River using the concept of exclusive contribution area, Environmental Monitoring Assessment, 188(6), 333, doi: 10.1007/s10661-016-5323-2.

Deutsch, C., H. Brix, T. Ito, H. Frenzel, and L. Thompson (2011), Climate-forced variability of ocean hypoxia, Science, 333(6040), 336-339, doi: 10.1126/science.1202422.

Diaz, R. J., and R. Rosenberg (2008), Spreading dead zones and consequences for marine ecosystems, Science, 321(5891), 926-929, doi: 10.1126/science.1156401.

Ficklin, D. L., I. T. Stewart, and E. P. Maurer (2013), Effects of climate change on stream temperature, dissolved oxygen, and sediment concentration in the Sierra Nevada in California, Water Resource Research, 49(5), 2765-2782, doi: 10.1002/wrcr.20248.

Filik Iscen, C., O. Emiroglu, S. Ilhan, N. Arslan, V. Yilmaz, and S. Ahiska (2008), Application of multivariate statistical techniques in the assessment of surface water quality in Uluabat Lake, Turkey, Environmental Monitoring Assessment, 144(1-3), 269-276, doi: 10.1007/s10661-007-9989-3.

Finnemore, E. J., and J. B. Franzini (2002), Fluid Mechanics with Engineering Applications, McGraw-Hill.

Gonçalves, A. M., and M. Costa (2013), Predicting seasonal and hydro-meteorological impact in environmental variables modelling via Kalman filtering, Stochastic Environmental Research and Risk Assessment, 27(5), 1021-1038, doi: 10.1007/s00477-012-0640-7.

Gualtieri, C., P. Gualtieri, and G. P. Doria (2002), Dimensional analysis of reaeration rate in streams, Journal of Environmental Engineering, 128(1), 12-18, doi: doi:10.1061/(ASCE)0733-9372(2002)128:1(12).

Guentzel, K. S., M. Hondzo, B. D. Badgley, J. C. Finlay, M. J. Sadowsky, and J. L. Kozarek (2014), Measurement and modeling of denitrification in sand-bed streams under various land sses, Journal of Environmental Quality, 43(3), 1013-1023, doi: 10.2134/jeq2013.06.0249.

Haider, H., W. Ali, and S. Haydar (2013), Evaluation of various relationships of reaeration rate coefficient for modeling dissolved oxygen in a river with extreme flow variations in Pakistan, Hydrological Processes, 27(26), 3949-3963, doi: 10.1002/hyp.9528. 
Hondzo, M., and H. Wang (2002), Effects of turbulence on growth and metabolism of periphyton in a laboratory flume, Water Resources Research, 38(12), 13-1-13-9, doi: 10.1029/2002WR001409.

Hondzo, M., T. Feyaerts, R. Donovan, and B. L. O'Connor (2005), Universal scaling of dissolved oxygen distribution at the sediment-water interface: A power law, Limnology Oceanography, 50(5), 1667-1676, doi: 10.4319/lo.2005.50.5.1667.

Hondzo, M., V. R. Voller, M. Morris, E. Foufoula-Georgiou, J. Finlay, V. Ganti, and M. E. Power (2013), Estimating and scaling stream ecosystem metabolism along channels with heterogeneous substrate, Ecohydrology, 6(4), 679-688, doi: 10.1002/eco.1391.

Huang, J., M. Ho, and P. Du (2011), Assessment of temporal and spatial variation of coastal water quality and source identification along Macau peninsula, Stochastic Environmental Research and Risk Assessment, 25(3), 353-361, doi: 10.1007/s00477-010-0373-4.

Hubert, M., and K. V. Branden (2003), Robust methods for partial least squares regression, Journal of Chemometrics, 17(10), 537-549, doi: 10.1002/cem.822.

IPCC (2007), Synthesis Report, A contribution of Working Group I, II and III to the Fourth Assessment Report of the Intergovernmental Panel on Climate Change. Cambridge University Press, Cambridge, UK

Iriarte, A., F. Villate, I. Uriarte, L. Alberdi, and L. Intxausti (2014), Dissolved oxygen in a temperate estuary: The influence of hydro-climatic factors and eutrophication at seasonal and inter-annual time scales, Estuaries and Coasts, 38(3), 1000-1015, doi: 10.1007/s12237-014-9870-x.

Ishtiaq, K. S., and O. I. Abdul-Aziz (2015), Relative linkages of canopy-level CO(2) fluxes with the climatic and environmental variables for US deciduous forests, Environmental Management, 55(4), 943-960, doi: 10.1007/s00267-014-0437-1.

Ji, X., X. Shang, R. A. Dahlgren, and M. Zhang (2017), Prediction of dissolved oxygen concentration in hypoxic river systems using support vector machine: a case study of WenRui Tang River, China, Environmental Science and Pollution Research, 24(19), 1606216076, doi: 10.1007/s11356-017-9243-7.

Johnson, R. A., and D. W. Wichern (1992), Applied Multivariate Statistical Analysis (6th ed.), Prentice-Hall, Englewood Cliffs, NJ.

Jolliffe, I. T. (2002), Principal Component Analysis (2nd ed.), Springer, New York, doi: 10.1007/978-3-642-04898-2.

Kaiser, H. F. (1960), The application of electronic computers to factor analysis. Educational and Psychological Measurement, 20:141-151.

Kaushal, S. S., G. E. Likens, N. A. Jaworski, M. L. Pace, A. M. Sides, D. Seekell, K. T. Belt, D. H. Secor, and R. L. Wingate (2010), Rising stream and river temperatures in the United States, Frontiers in Ecology and the Environment, 8(9), 461-466, doi: 10.1890/090037. 
Kaya, K., Y. D. Liu, Y. W. Shen, B. D. Xiao, and T. Sano (2005), Selective control of toxic Microcystis water blooms using lysine and malonic acid: An enclosure experiment, Environment Toxicology, 20(2), 170-178, doi: 10.1002/tox.20092.

Kemp, W. M., J. M. Testa, D. J. Conley, D. Gilbert, and J. D. Hagy (2009), Temporal responses of coastal hypoxia to nutrient loading and physical controls, Biogeosciences, 6(12), 29853008, doi: 10.5194/bg-6-2985-2009.

King, D. L. (1970), The role of carbon in eutrophication, Water Pollution Control Federation, 42(12), 2035-2051.

Koklu, R., B. Sengorur, and B. Topal (2009), Water quality assessment using multivariate statistical methods-A Case Study: Melen River System (Turkey), Water Resource Management, 24(5), 959-978, doi: 10.1007/s11269-009-9481-7.

Kudela, R. M., S. Seeyave, and W. P. Cochlan (2010), The role of nutrients in regulation and promotion of harmful algal blooms in upwelling systems, Progress in Oceanography, 85(1), 122-135, doi: http://dx.doi.org/10.1016/j.pocean.2010.02.008.

Kuhn, and Johnson (2013), Applied predictive modeling. Springer, New York.

Lanoux, A., H. Etcheber, S. Schmidt, A. Sottolichio, G. Chabaud, M. Richard, and G. Abril (2013), Factors contributing to hypoxia in a highly turbid, macrotidal estuary (the Gironde, France), Environmental Science: Processes and Impacts, 15(3), 585, doi: $10.1039 / \mathrm{c} 2 \mathrm{em} 30874 \mathrm{f}$.

Lapointe, B. E., and B. J. Bedford (2010), Ecology and nutrition of invasive Caulerpa brachypus f. parvifolia blooms on coral reefs off southeast Florida, U.S.A, Harmful Algae, 9(1), 1-12, doi: http://dx.doi.org/10.1016/j.hal.2009.06.001.

Li, Y., L. XU, and S. LI (2009), Water quality analysis of the Songhua River Basin using multivariate techniques, Journal of Water Resource and Protection, Vol.01No.02, 12, doi: 10.4236/jwarp.2009.12015.

Lin, J., H. Xu, C. Cudaback, and D. Wang (2008), Inter-annual variability of hypoxic conditions in a shallow estuary, Journal of Marine Systems, 73(1), 169-184, doi: https://doi.org/10.1016/j.jmarsys.2007.10.011.

Liu, C.W., K.H. Lin, and Y.M. Kuo (2003), Application of factor analysis in the assessment of groundwater quality in a blackfoot disease area in Taiwan, Science of Total Environment, 313(1), 77-89, doi: http://dx.doi.org/10.1016/S0048-9697(02)00683-6.

Liu, D., X. Chen, and Z. Lou (2009), A Model for the optimal allocation of water resources in a saltwater intrusion area: A case study in Pearl River Delta in China, Water Resource Management, 24(1), 63, doi: 10.1007/s11269-009-9437-y.

Lyon, G. S., and E. D. Stein (2008), How effective has the Clean Water Act been at reducing pollutant mass emissions to the Southern California Bight over the past 35 years?, Environmental Monitoring Assessment, 154(1), 413, doi: 10.1007/s10661-008-0408-1. 
Gleason MG, S Newkirk, MS Merrifield, J Howard, R Cox, M Webb, J Koepcke, B Stranko, B Taylor, MW Beck, R Fuller, P Dye, D Vander Schaaf, J. Carter (2011), A Conservation Assessment of West Coast (USA) Estuaries, The Nature Conservancy, Arlington, VA, 65 pp.

Meier, H. E. M., H. C. Andersson, K. Eilola, B. G. Gustafsson, I. Kuznetsov, B. Müller-Karulis, T. Neumann, and O. P. Savchuk (2011), Hypoxia in future climates: A model ensemble study for the Baltic Sea, Geophysical Research Letters, 38(24), n/a-n/a, doi: 10.1029/2011GL049929.

Meire, L., K. E. R. Soetaert, and F. J. R. Meysman (2013), Impact of global change on coastal oxygen dynamics and risk of hypoxia, Biogeosciences, 10(4), 2633-2653, doi: 10.5194/bg10-2633-2013.

Miragliotta, G. (2011), The power of dimensional analysis in production systems design, International Journal of Production Economics, 131(1), 175-182, doi: http://dx.doi.org/10.1016/j.ijpe.2010.08.009.

Mondal, I., J. Bandyopadhyay, and A. K. Paul (2016), Water quality modeling for seasonal fluctuation of Ichamati river, West Bengal, India, Modeling Earth Systems and Environment, 2(3), 113, doi: 10.1007/s40808-016-0153-3.

Moore, T. S., D. B. Nuzzio, D. M. Di Toro, and G. W. Luther (2009), Oxygen dynamics in a well mixed estuary, the lower Delaware Bay, USA, Marine Chemistry, 117(1), 11-20, doi: http://dx.doi.org/10.1016/j.marchem.2009.08.003.

Moriasi, D. N., J. G. Arnold, M. W. Van Liew, R. L. Bingner, R. D. Harmel, and T. L. Veith (2007), Model evaluation guidelines for systematic quantification of accuracy in watershed simulations, Transaction American Society Agricultural Biological Engineers, 50(3), 885900.

National Land Cover Database (2017), Available online at NLCD, 2017 (http://www.mrlc.gov/). (Accessed on November 01, 2017).

National Solar Radiation Data Base (NSRDB) (2017), Available online at http://rredc.nrel.gov/solar/old_data/nsrdb/ (Accessed on January 01, 2017).

United States Geological Survey (USGS) (2017), Available online at https://www.waterqualitydata.us/ (Accessed on January 12, 2017).

O'Driscoll, C., M. O'Connor, Z. U. Asam, E. de Eyto, L. E. Brown, and L. Xiao (2016), Forest clearfelling effects on dissolved oxygen and metabolism in peatland streams, Journal of Environmental Management, 166, 250-259, doi: 10.1016/j.jenvman.2015.10.031.

Odum, H. T. (1956), Primary production in flowing waters, Limnology and Oceanography, 1(2), 102-117, doi: 10.4319/lo.1956.1.2.0102. 
Ouyang, Y., P. Nkedi-Kizza, Q. T. Wu, D. Shinde, and C. H. Huang (2006), Assessment of seasonal variations in surface water quality, Water Research, 40(20), 3800-3810, doi: http://dx.doi.org/10.1016/j.watres.2006.08.030.

Paerl, H. W., N. S. Hall, B. L. Peierls, and K. L. Rossignol (2014), Evolving paradigms and challenges in estuarine and coastal eutrophication dynamics in a culturally and climatically stressed world, Estuaries and Coasts, 37(2), 243-258, doi: 10.1007/s12237-014-9773-x.

Paul, M. J., and J. L. Meyer (2001), Streams in the Urban Landscape, Annual Review of Ecology and Systematics, 32(1), 333-365, doi: 10.1146/annurev.ecolsys.32.081501.114040.

Peel, M. C., B. L. Finlayson, and T. A. McMahon (2007), Updated world map of the KöppenGeiger climate classification, Hydrology and Earth System Science, 11(5), 1633-1644, doi: 10.5194/hess-11-1633-2007.

Peres-Neto, P. R., D. A. Jackson, and K. M. Somers (2003), Giving meaningful interpretation to ordination axes: Assessing loading significance in principal component analysis, Ecology, 84(9), 2347-2363.

Potter, M. C., M. H. D. C. Wiggert, and T. I. P. Shih (2002), Mechanics of Fluids, 3rd ed., Brooks/Cole, Brooks/Cole, Pacific Grove, Calif.

Prasad, M. B. K., W. Long, X. Zhang, R. J. Wood, and R. Murtugudde (2011), Predicting dissolved oxygen in the Chesapeake Bay: Applications and implications, Aquatic Science, 73(3), 437-451, doi: 10.1007/s00027-011-0191-x.

Quinn, N. W. T., K. Jacobs, C. W. Chen, and W. T. Stringfellow (2005), Elements of a decision support system for real-time management of dissolved oxygen in the San Joaquin River deep water ship channel, Environmental Modelling and Software, 20(12), 1495-1504, doi: https://doi.org/10.1016/j.envsoft.2004.08.014.

Rabalais, R. E. Turner, and W. J. W. Jr. (2002), Gulf of Mexico Hypoxia, A.K.A. "The Dead Zone", Annual Review of Ecology and Systematics, 33(1), 235-263, doi: 10.1146/annurev.ecolsys.33.010802.150513.

Rajwa-Kuligiewicz, A., J. Bialik Robert, and M. Rowiński Paweł (2015), Dissolved oxygen and water temperature dynamics in lowland rivers over various timescales, in Journal of Hydrology and Hydromechanics, edited, p. 353.

Raymond, P. A., C. J. Zappa, D. Butman, T. L. Bott, J. Potter, P. Mulholland, A. E. Laursen, W. H. McDowell, and D. Newbold (2012), Scaling the gas transfer velocity and hydraulic geometry in streams and small rivers, Limnology and Oceanography: Fluids and Environments, 2(1), 41-53, doi: doi:10.1215/21573689-1597669.

Ryan, J. P., M. A. McManus, and J. M. Sullivan (2010), Interacting physical, chemical and biological forcing of phytoplankton thin-layer variability in Monterey Bay, California, Continental Shelf Research, 30(1), 7-16, doi: http://dx.doi.org/10.1016/j.csr.2009.10.017. 
Saha, B., S. Chakraborty, and G. Das (2009), A mechanistic insight into enhanced and selective phosphate adsorption on a coated carboxylated surface, Journal of Colloid and Interface Science, 331(1), 21-26, doi: http://dx.doi.org/10.1016/j.jcis.2008.11.007.

Scavia, D., et al. (2002), Climate change impacts on U.S. Coastal and Marine Ecosystems, Estuaries, 25(2), 149-164, doi: 10.1007/bf02691304.

Schemel, L. E. (2001), Simplified conversions between specific conductance and salinity units for use with data from monitoring stations, Interagency Ecological Program Newsletter, 14(1), 17-18.

Scholz, M. (2006), Wetland systems to control urban runoff, Amsterdam: Elsevier.

Schumann, S., L.P. Nolte, and G. Zheng (2013), Comparison of partial least squares regression and principal component regression for pelvic shape prediction, Journal of Biomechanics, 46(1), 197-199, doi: http://dx.doi.org/10.1016/j.jbiomech.2012.11.005.

Seber, G. A. F., and C. J. Wild (2005), Computational Methods for Nonlinear Least Squares, in Nonlinear Regression, 619-660, edited.

Shrestha, S., and F. Kazama (2007), Assessment of surface water quality using multivariate statistical techniques: A case study of the Fuji river basin, Japan, Environmental Modelling and Software, 22(4), 464-475, doi: 10.1016/j.envsoft.2006.02.001.

Simeonov, V., J. A. Stratis, C. Samara, G. Zachariadis, D. Voutsa, A. Anthemidis, M. Sofoniou, and T. Kouimtzis (2003), Assessment of the surface water quality in Northern Greece, Water Research, 37(17), 4119-4124, doi: 10.1016/s0043-1354(03)00398-1.

Singh, K. P., A. Malik, D. Mohan, and S. Sinha (2004), Multivariate statistical techniques for the evaluation of spatial and temporal variations in water quality of Gomti River (India)--a case study, Water Research, 38(18), 3980-3992, doi: 10.1016/j.watres.2004.06.011.

Singh, K. P., A. Malik, N. Basant, and P. Saxena (2007), Multi-way partial least squares modeling of water quality data, Analytica Chimica Acta, 584(2), 385-396, doi: 10.1016/j.aca.2006.11.038.

Slonaker, J., D. C. Motley, Q. Zhang, S. Townsend, C. Senatore, K. Iagnemma, and K. Kamrin (2017), General scaling relations for locomotion in granular media, Physical Review E, 95(5), 052901.

Thomann, R. V., and J. A. Mueller (1987), Principles of Surface Water Quality Modeling and Control, HarperCollins, New York.

Tran, C. P., R. W. Bode, A. J. Smith, and G. S. Kleppel (2010), Land-use proximity as a basis for assessing stream water quality in New York State (USA), Ecological Indicators,10(3), 727-733, doi: https://doi.org/10.1016/j.ecolind.2009.12.002.

Tukey, J. W. (1977), Exploratory data analysis. Menlo Park, CA: AddisonWesley. 
USGS (2017b), Available online at http://maps.waterdata.usgs.gov/mapper/index.html (Accessed on November 21, 2017).

Vaquer-Sunyer, R., and C. M. Duarte (2008), Thresholds of hypoxia for marine biodiversity, Proceedings of the National Academy of Sciences, 105(40), 15452-15457, doi: 10.1073/pnas.0803833105.

Vega, M., R. Pardo, E. Barrado, and L. Debán (1998), Assessment of seasonal and polluting effects on the quality of river water by exploratory data analysis, Water Research, 32(12), 35813592, doi: 10.1016/s0043-1354(98)00138-9.

Wan, R., S. Cai, H. Li, G. Yang, Z. Li, and X. Nie (2014), Inferring land use and land cover impact on stream water quality using a Bayesian hierarchical modeling approach in the Xitiaoxi River Watershed, China, Journal of Environmental Management, 133, 1-11, doi: https://doi.org/10.1016/j.jenvman.2013.11.035.

Wan, Y., Y. Qian, K. W. Migliaccio, Y. Li, and C. Conrad (2014), Linking spatial variations in water quality with water and land management using multivariate techniques, Journal of Environmental Quality, 43(2), 599-610, doi: 10.2134/jeq2013.09.0355.

Warnaars, T. A., M. Hondzo, and M. E. Power (2007), Abiotic controls on periphyton accrual and metabolism in streams: Scaling by dimensionless numbers, Water Resource Research, 43(8), n/a-n/a, doi: 10.1029/2006WR005002.

Wetzel, R. (2001), Limnology: Lake and River Ecosystems. San Diego: Academic Press. 1006p.

Winter, J. C. F., D. Dodou*, and P. A. Wieringa (2009), Exploratory factor analysis with small sample sizes, Multivariate Behavioral Research, 44(2), 147-181, doi: 10.1080/00273170902794206.

Wold, S. (2001), PLS-regression: a basic tool of chemometrics.

$\mathrm{Xu}, \mathrm{Z}$., and Y. Xu (2016), A deterministic model for predicting hourly dissolved oxygen change: Development and application to a shallow eutrophic lake, Water, 8(2), 41.

Yeakley, J. A. (2014), Introduction to Wild Salmonids in the Urbanizing Pacific Northwest, in Wild Salmonids in the Urbanizing Pacific Northwest, edited by J. A. Yeakley, K. G. MaasHebner and R. M. Hughes, pp. 1-10, Springer New York, New York, NY.

Yeakley, J. A., D. C. Coleman, B. L. Haines, B. D. Kloeppel, J. L. Meyer, W. T. Swank, B. W. Argo, J. M. Deal, and S. F. Taylor (2003), Hillslope nutrient dynamics following upland riparian vegetation disturbance, Ecosystems, 6(2), 0154-0167.

Yvon-Durocher, G., J. I. Jones, M. Trimmer, G. Woodward, and J. M. Montoya (2010), Warming alters the metabolic balance of ecosystems, Philosophical Transactions of the Royal Society B: Biological Sciences, 365(1549), 2117-2126, doi: 10.1098/rstb.2010.0038. 
Zeleňáková M, Č. M., Šlezingr M, Słyś D, Purcz P (2012) (2013), A model based on dimensional analysis for prediction of nitrogen and phosphorus concentrations at the river station Ižkovce, Slovakia., Hydrology and Earth System Sciences, doi: 10.5194/hess-17-201-2013.

Zhou, F., Y. Liu, and H. Guo (2007), Application of multivariate statistical methods to water quality assessment of the watercourses in northwestern new territories, Hong Kong, Environmental Monitoring and Assessment, 132(1), 1-13, doi: 10.1007/s10661-006-9497$\mathrm{x}$. 


\section{Appendix A}

Table A1: Correlation coefficients of stream DO with the dynamic environmental predictors for the water quality monitoring stations along the U.S. Pacific Coast.

\begin{tabular}{|c|c|c|c|c|c|c|c|c|c|}
\hline Stations ID & I & $\mathrm{TN}$ & $\mathrm{TP}$ & SC & $\mathrm{pH}$ & $\mathrm{Q}$ & AP & TW & SR \\
\hline \multicolumn{10}{|c|}{ Type I Regime } \\
\hline USGS-12128000 & WA_1 & 0.08 & -0.59 & -0.53 & -0.40 & 0.61 & 0.03 & -0.87 & -0.15 \\
\hline USGS-12056500 & WA_2 & - & 0.31 & -0.31 & -0.48 & 0.40 & 0.03 & -0.91 & -0.40 \\
\hline USGS-12113390 & WA_3 & 0.39 & -0.02 & -0.69 & -0.17 & 0.75 & 0.08 & -0.90 & -0.50 \\
\hline${ }^{\mathrm{a}}-\mathrm{VA} 12 \mathrm{~A}$ & WA_4 & 0.33 & -0.64 & -0.56 & -0.37 & - & 0.18 & -0.83 & -0.45 \\
\hline a-VA37A & WA_5 & 0.33 & -0.70 & -0.49 & -0.46 & - & 0.14 & -0.88 & -0.02 \\
\hline a-VA41A & WA_6 & 0.39 & -0.63 & -0.50 & -0.45 & - & 0.15 & -0.83 & -0.30 \\
\hline a-VA42A & WA_7 & 0.23 & -0.72 & -0.56 & -0.48 & - & 0.13 & -0.91 & -0.41 \\
\hline USGS-4551221* & WA_8 & 0.76 & -0.39 & 0.01 & -0.35 & - & 0.20 & -0.89 & -0.57 \\
\hline USGS-14211955 & WA_9 & -0.23 & -0.74 & -0.56 & 0.55 & 0.42 & -0.13 & -0.79 & -0.34 \\
\hline USGS-14144805 & WA_11 & 0.44 & -0.14 & 0.58 & 0.28 & 0.18 & 0.01 & -0.92 & -0.30 \\
\hline USGS-14246900 & OR_1 & 0.74 & 0.38 & 0.29 & 0.19 & 0.15 & 0.19 & -0.91 & -0.27 \\
\hline USGS-14128910 & OR_2 & 0.66 & 0.38 & 0.24 & 0.38 & 0.15 & -0.01 & -0.79 & -0.34 \\
\hline USGS-4533391* & OR_3 & 0.63 & -0.51 & -0.68 & 0.19 & 0.20 & 0.29 & -0.88 & -0.34 \\
\hline USGS-14211720 & OR_4 & 0.67 & 0.33 & -0.59 & -0.41 & 0.73 & 0.18 & -0.94 & -0.60 \\
\hline USGS-45241412 & OR_5 & 0.22 & 0.06 & -0.18 & -0.11 & - & 0.38 & -0.87 & -0.71 \\
\hline USGS-4523011* & OR_6 & 0.39 & -0.35 & -0.30 & -0.08 & - & 0.05 & -0.73 & -0.34 \\
\hline USGS-14207050 & OR_7 & -0.07 & -0.13 & -0.33 & -0.17 & 0.39 & 0.10 & -0.55 & -0.25 \\
\hline USGS-14207600 & OR_8 & -0.03 & 0.34 & -0.42 & -0.21 & 0.37 & 0.15 & -0.66 & -0.25 \\
\hline USGS-11391100 & CA_2 & -0.15 & -0.24 & -0.18 & -0.30 & - & 0.27 & -0.69 & -0.51 \\
\hline USGS-11452600 & CA_3 & -0.41 & 0.08 & -0.10 & 0.13 & 0.02 & 0.20 & -0.64 & -0.05 \\
\hline USGS-11447650 & CA_6 & 0.35 & 0.19 & 0.09 & -0.16 & 0.23 & 0.50 & -0.67 & -0.43 \\
\hline USGS-11152300 & CA_9 & 0.40 & -0.29 & 0.48 & 0.22 & -0.07 & 0.43 & -0.59 & -0.34 \\
\hline USGS-09427520 & CA_10 & 0.22 & - & 0.07 & 0.26 & -0.10 & 0.07 & -0.67 & -0.29 \\
\hline USGS-3410141* & CA_11 & - & -0.05 & -0.50 & -0.03 & 0.63 & 0.01 & -0.82 & -0.30 \\
\hline USGS-11049400 & CA_12 & -0.58 & -0.52 & -0.63 & 0.26 & 0.39 & 0.20 & -0.67 & -0.14 \\
\hline USGS-11051500 & CA_13 & 0.04 & -0.07 & -0.17 & -0.13 & -0.15 & 0.58 & -0.77 & -0.52 \\
\hline USGS-11066460 & CA_15 & 0.57 & -0.22 & -0.12 & 0.45 & 0.20 & 0.46 & -0.80 & -0.21 \\
\hline USGS-11075610 & CA_16 & 0.50 & -0.56 & -0.09 & -0.02 & 0.16 & 0.68 & -0.76 & -0.31 \\
\hline
\end{tabular}

Note: (1) WA, OR, and CA, respectively, refers to stations in Washington, Oregon, and California. (2) '-' indicates the "missing data". (3) "a" refers to KINGCOUNTY from STORET water quality station. (4) "**" refer to USGS455122122310600, USGS-453339122481301, USGS-452301122442301, and USGS-341014116494801 respectively. (5) Bold value indicates moderate to strong correlation. (6) "I" is station identifier. 
Table A1: (continued).

\begin{tabular}{|c|c|c|c|c|c|c|c|c|c|}
\hline Stations ID & I & TN & $\mathrm{TP}$ & $\mathrm{SC}$ & $\mathrm{pH}$ & $\mathrm{Q}$ & $\mathrm{AP}$ & TW & SR \\
\hline \multicolumn{10}{|c|}{ Type II Regime } \\
\hline USGS-11447360 & CA_4 & -0.04 & -0.63 & -0.16 & -0.36 & -0.30 & 0.26 & -0.52 & -0.18 \\
\hline USGS-11466800 & CA_5 & -0.42 & -0.68 & 0.45 & 0.57 & -0.36 & 0.07 & 0.05 & -0.27 \\
\hline \multicolumn{10}{|c|}{ Type III Regime } \\
\hline USGS-11460170 & CA_7 & 0.26 & 0.12 & -0.73 & -0.02 & 0.75 & 0.21 & -0.51 & -0.33 \\
\hline USGS-3751591* & CA_8 & - & -0.41 & -0.60 & 0.29 & 0.58 & 0.46 & -0.62 & -0.13 \\
\hline \multicolumn{10}{|c|}{ Type IV Regime } \\
\hline USGS-14211920 & WA_10 & 0.18 & -0.27 & 0.20 & 0.45 & -0.18 & -0.17 & -0.41 & -0.04 \\
\hline USGS-11488495 & CA_1 & 0.44 & 0.43 & 0.68 & 0.68 & -0.39 & 0.22 & -0.69 & -0.41 \\
\hline USGS-11060400 & CA_14 & -0.04 & 0.04 & -0.47 & 0.53 & -0.03 & 0.04 & -0.27 & 0.10 \\
\hline
\end{tabular}

Note: (1) WA, OR, and CA, respectively, refers to stations in Washington, Oregon, and California. (2) '-' indicates the "missing data". (3) “*” refer to USGS-375159122343801. (4) Bold value indicates moderate to strong correlation. (5) "I" is station identifier. 
Table A2: Ensemble mean triangular matrices and mutual correlation of the dynamic environmental drivers for Type I regime.

\begin{tabular}{cccccccccc}
\hline Variables & $\mathrm{TN}$ & $\mathrm{TP}$ & $\mathrm{SC}$ & $\mathrm{pH}$ & $\mathrm{Q}$ & $\mathrm{AP}$ & $\mathrm{TW}$ & $\mathrm{SR}$ & $\mathrm{DO}$ \\
\hline $\mathrm{TN}$ & 1.00 & 0.20 & 0.06 & -0.10 & 0.05 & 0.11 & -0.31 & -0.15 & 0.24 \\
$\mathrm{TP}$ & 0.19 & 1.00 & 0.16 & -0.01 & 0.10 & -0.05 & 0.16 & 0.04 & -0.19 \\
$\mathrm{SC}$ & 0.06 & 0.16 & 1.00 & 0.31 & -0.36 & 0.02 & 0.27 & 0.14 & -0.24 \\
$\mathrm{pH}$ & -0.10 & -0.01 & 0.31 & 1.00 & -0.10 & 0.01 & 0.20 & 0.22 & -0.07 \\
$\mathrm{Q}$ & 0.05 & 0.10 & -0.36 & -0.10 & 1.00 & -0.01 & -0.20 & -0.08 & 0.20 \\
AP & 0.11 & -0.05 & 0.02 & 0.01 & -0.01 & 1.00 & -0.25 & -0.07 & 0.20 \\
TW & -0.31 & 0.16 & 0.27 & 0.20 & -0.20 & -0.25 & 1.00 & 0.53 & $\mathbf{- 0 . 7 9}$ \\
SR & -0.15 & 0.04 & 0.14 & 0.22 & -0.08 & -0.07 & 0.53 & 1.00 & -0.34 \\
DO & 0.24 & -0.19 & -0.24 & -0.07 & 0.20 & 0.20 & $\mathbf{- 0 . 7 9}$ & -0.34 & 1.00 \\
\hline \hline
\end{tabular}

Notes: (1) Data for all variables were log10-transformed to incorporate any non-linear correspondences; (2) Bold indicates significant correlations at the 95\% confidence level (p-values < 0.05). (3) Regime specific mean correlations were obtained by averaging the site-specific correlations.

Table A3: Ensemble mean triangular matrices and mutual correlation of the dynamic environmental drivers for Type II regime.

\begin{tabular}{cccccccccc}
\hline Variables & $\mathrm{TN}$ & $\mathrm{TP}$ & $\mathrm{SC}$ & $\mathrm{pH}$ & $\mathrm{Q}$ & $\mathrm{AP}$ & $\mathrm{TW}$ & $\mathrm{SR}$ & $\mathrm{DO}$ \\
\hline $\mathrm{TN}$ & 1.00 & -0.09 & -0.26 & $\mathbf{- 0 . 5 0}$ & 0.20 & 0.44 & -0.42 & -0.19 & -0.23 \\
$\mathrm{TP}$ & -0.09 & 1.00 & 0.05 & 0.13 & 0.27 & -0.13 & 0.51 & 0.46 & $\mathbf{- 0 . 6 6}$ \\
$\mathrm{SC}$ & -0.26 & 0.05 & 1.00 & 0.43 & -0.34 & -0.44 & 0.46 & -0.07 & 0.15 \\
$\mathrm{pH}$ & $\mathbf{- 0 . 5 0}$ & 0.13 & 0.43 & 1.00 & -0.08 & -0.35 & 0.61 & 0.23 & 0.10 \\
$\mathrm{Q}$ & 0.20 & 0.27 & -0.34 & -0.08 & 1.00 & 0.33 & 0.01 & 0.03 & -0.33 \\
AP & 0.44 & -0.13 & -0.44 & -0.35 & 0.33 & 1.00 & $\mathbf{- 0 . 5 0}$ & -0.11 & 0.16 \\
TW & -0.42 & 0.51 & 0.46 & 0.61 & 0.01 & $\mathbf{- 0 . 5 0}$ & 1.00 & 0.26 & -0.24 \\
SR & -0.19 & 0.46 & -0.07 & 0.23 & 0.03 & -0.11 & 0.26 & 1.00 & -0.22 \\
DO & -0.23 & $\mathbf{- 0 . 6 6}$ & 0.15 & 0.10 & -0.33 & 0.16 & -0.24 & -0.22 & 1.00 \\
\hline \hline
\end{tabular}

Notes: (1) Data for all variables were log10-transformed to incorporate any non-linear correspondences;

(2) Bold indicates significant correlations at the 95\% confidence level (p-values < 0.05). (3) Regime specific mean correlations were obtained by averaging the site-specific correlations. 
Table A4: Ensemble mean triangular matrices and mutual correlation of the dynamic environmental drivers for Type III regime.

\begin{tabular}{cccccccccc}
\hline Variables & $\mathrm{TN}$ & $\mathrm{TP}$ & $\mathrm{SC}$ & $\mathrm{pH}$ & $\mathrm{Q}$ & $\mathrm{AP}$ & $\mathrm{TW}$ & $\mathrm{SR}$ & $\mathrm{DO}$ \\
\hline $\mathrm{TN}$ & 1.00 & 0.27 & -0.13 & -0.12 & 0.12 & 0.24 & -0.33 & -0.18 & 0.13 \\
$\mathrm{TP}$ & 0.27 & 1.00 & -0.07 & -0.11 & 0.20 & -0.21 & 0.16 & -0.14 & -0.15 \\
$\mathrm{SC}$ & -0.13 & -0.07 & 1.00 & 0.18 & $\mathbf{- 0 . 6 2}$ & 0.04 & 0.25 & -0.18 & $\mathbf{- 0 . 6 6}$ \\
$\mathrm{pH}$ & -0.12 & -0.11 & 0.18 & 1.00 & -0.19 & 0.06 & -0.01 & -0.19 & 0.14 \\
$\mathrm{Q}$ & 0.12 & 0.20 & $\mathbf{- 0 . 6 2}$ & -0.19 & 1.00 & 0.31 & $\mathbf{- 0 . 5 2}$ & -0.31 & 0.67 \\
$\mathrm{AP}$ & 0.24 & -0.21 & 0.04 & 0.06 & 0.31 & 1.00 & $\mathbf{- 0 . 7 9}$ & $\mathbf{- 0 . 5 1}$ & 0.34 \\
TW & -0.33 & 0.16 & 0.25 & -0.01 & $\mathbf{- 0 . 5 2}$ & $\mathbf{- 0 . 7 9}$ & 1.00 & 0.58 & $\mathbf{- 0 . 5 6}$ \\
SR & -0.18 & -0.14 & -0.18 & -0.19 & -0.31 & $\mathbf{- 0 . 5 1}$ & 0.58 & 1.00 & -0.23 \\
DO & 0.13 & -0.15 & $\mathbf{- 0 . 6 6}$ & 0.14 & 0.67 & 0.34 & $\mathbf{- 0 . 5 6}$ & -0.23 & 1.00 \\
\hline \hline
\end{tabular}

Notes: (1) Data for all variables were log10-transformed to incorporate any non-linear correspondences; (2) Bold indicates significant correlations at the 95\% confidence level (p-values <0.05). (3) Regime specific mean correlations were obtained by averaging the site-specific correlations

Table A5: Ensemble mean triangular matrices and mutual correlation of the dynamic environmental drivers for Type IV regime.

\begin{tabular}{cccccccccc}
\hline Variables & $\mathrm{TN}$ & $\mathrm{TP}$ & $\mathrm{SC}$ & $\mathrm{pH}$ & $\mathrm{Q}$ & $\mathrm{AP}$ & $\mathrm{TW}$ & $\mathrm{SR}$ & $\mathrm{DO}$ \\
\hline $\mathrm{TN}$ & 1.00 & 0.37 & 0.19 & 0.03 & 0.02 & 0.25 & $\mathbf{- 0 . 4 4}$ & -0.20 & 0.20 \\
$\mathrm{TP}$ & 0.37 & 1.00 & 0.00 & 0.19 & 0.06 & 0.20 & -0.04 & -0.15 & 0.07 \\
$\mathrm{SC}$ & 0.19 & 0.00 & 1.00 & 0.08 & -0.35 & 0.19 & -0.10 & -0.14 & 0.14 \\
$\mathrm{pH}$ & 0.03 & 0.19 & 0.08 & 1.00 & -0.15 & 0.07 & 0.07 & 0.24 & $\mathbf{0 . 5 6}$ \\
Q & 0.02 & 0.06 & -0.35 & -0.15 & 1.00 & -0.06 & 0.13 & 0.14 & -0.20 \\
AP & 0.25 & 0.20 & 0.19 & 0.07 & -0.06 & 1.00 & -0.23 & -0.13 & 0.03 \\
TW & $\mathbf{- 0 . 4 4}$ & -0.04 & -0.10 & 0.07 & 0.13 & -0.23 & 1.00 & $\mathbf{0 . 5 9}$ & $\mathbf{- 0 . 4 5}$ \\
SR & -0.20 & -0.15 & -0.14 & 0.24 & 0.14 & -0.13 & $\mathbf{0 . 5 9}$ & 1.00 & -0.12 \\
DO & 0.20 & 0.07 & 0.14 & $\mathbf{0 . 5 6}$ & -0.20 & 0.03 & $\mathbf{- 0 . 4 5}$ & -0.12 & 1.00 \\
\hline \hline
\end{tabular}

Notes: (1) Data for all variables were log10-transformed to incorporate any non-linear correspondences; (2) Bold indicates significant correlations at the 95\% confidence level ( $\mathrm{p}$-values < 0.05 ). (3) Regime specific mean correlations were obtained by averaging the site-specific correlations. 
Table A6: Percent variance explained by each principal components (PC) for each water quality monitoring stations across the Pacific Coast.

\begin{tabular}{|c|c|c|c|c|c|c|c|c|c|}
\hline Sites & I & PC_1 & PC_2 & PC_3 & $\overline{\mathrm{PC} \_4}$ & PC_5 & PC_6 & PC_7 & $\overline{\text { PC_8 }}$ \\
\hline USGS-12128000 & WA_1 & 42.79 & 17.68 & 13.40 & 10.59 & 6.70 & 4.27 & 2.82 & 1.24 \\
\hline USGS-12056500 & WA_2 & 40.64 & 21.74 & 13.54 & 10.09 & 7.27 & 4.41 & 1.47 & 0.83 \\
\hline USGS-12113390 & WA_3 & 41.57 & 20.70 & 12.70 & 10.92 & 6.30 & 3.66 & 2.54 & 0.94 \\
\hline a-VA12A & WA_4 & 47.66 & 20.02 & 9.01 & 7.88 & 6.85 & 4.10 & 2.69 & 1.78 \\
\hline a-VA37A & WA_5 & 45.28 & 21.35 & 17.59 & 7.00 & 4.79 & 2.00 & 1.98 & 0.02 \\
\hline a-VA41A & WA_6 & 49.74 & 18.53 & 11.28 & 7.44 & 5.62 & 3.75 & 2.15 & 1.49 \\
\hline${ }^{a}-\mathrm{VA} 42 \mathrm{~A}$ & WA_7 & 47.16 & 20.31 & 11.44 & 7.71 & 6.26 & 3.39 & 2.76 & 0.99 \\
\hline USGS-4551221* & WA_8 & 46.31 & 19.10 & 13.87 & 9.69 & 5.06 & 3.26 & 1.98 & 0.73 \\
\hline USGS-14211955 & WA_9 & 38.01 & 26.85 & 13.92 & 7.61 & 6.62 & 4.00 & 1.87 & 0.79 \\
\hline USGS-14211920 & WA_10 & 36.51 & 18.12 & 13.68 & 11.55 & 9.18 & 6.80 & 2.24 & 1.25 \\
\hline USGS-14144805 & WA_11 & 32.53 & 22.45 & 16.56 & 13.49 & 7.55 & 3.31 & 2.16 & 1.64 \\
\hline USGS-14246900 & OR_1 & 36.37 & 15.46 & 14.51 & 10.65 & 9.14 & 6.80 & 4.64 & 1.93 \\
\hline USGS-14128910 & OR_2 & 43.64 & 21.57 & 12.91 & 8.78 & 7.33 & 3.62 & 1.23 & 0.73 \\
\hline USGS-4533391* & OR_3 & 42.39 & 13.42 & 11.72 & 10.15 & 8.06 & 7.42 & 3.11 & 2.67 \\
\hline USGS-14211720 & OR_4 & 49.64 & 16.14 & 10.18 & 8.30 & 7.72 & 4.97 & 1.60 & 1.13 \\
\hline USGS-45241412 & OR_5 & 45.21 & 22.31 & 15.11 & 11.03 & 2.95 & 1.95 & 1.12 & 0.33 \\
\hline USGS-4523011* & OR_6 & 37.94 & 18.82 & 14.44 & 11.50 & 7.22 & 4.82 & 3.44 & 1.82 \\
\hline USGS-14207050 & OR_7 & 29.91 & 26.07 & 12.62 & 10.39 & 8.21 & 5.05 & 3.45 & 2.69 \\
\hline
\end{tabular}

Note: (1) WA, OR, and CA, respectively, refers to stations in Washington, Oregon, and California. (2) '-' indicates the "missing data". (3) "a" refers to KINGCOUNTY from STORET water quality station. (4) “*” refer to USGS455122122310600, USGS-453339122481301, USGS-452301122442301, USGS-375159122343801, and USGS341014116494801 respectively. (5) "I" is station identifier. 
Table A6: (continued).

\begin{tabular}{llllllllll}
\hline Stations ID & I & PC_1 & PC_2 & PC_3 & PC_4 & PC_5 & PC_6 & PC_7 & PC_8 \\
\hline USGS-14207600 & OR_8 & 46.04 & 14.45 & 11.73 & 8.82 & 6.68 & 5.34 & 4.42 & 1.59 \\
USGS-11488495 & CA_1 & 47.77 & 16.80 & 14.38 & 8.50 & 6.09 & 2.33 & 1.87 & 1.24 \\
USGS-11391100 & CA_2 & 43.21 & 22.09 & 14.19 & 8.47 & 5.97 & 2.48 & 2.20 & 1.40 \\
USGS-11452600 & CA_3 & 34.74 & 24.91 & 16.64 & 10.39 & 6.07 & 4.24 & 1.71 & 1.09 \\
USGS-11447360 & CA_4 & 44.75 & 16.53 & 11.21 & 9.66 & 8.25 & 4.27 & 3.04 & 1.42 \\
USGS-11466800 & CA_5 & 39.71 & 20.92 & 13.42 & 10.62 & 7.96 & 4.80 & 1.86 & 0.46 \\
USGS-11447650 & CA_6 & 40.71 & 18.42 & 13.62 & 9.95 & 6.54 & 4.87 & 2.67 & 1.91 \\
USGS-11460170 & CA_7 & 40.94 & 20.33 & 15.24 & 12.06 & 6.79 & 2.37 & 1.13 & 0.93 \\
USGS-3751591* & CA_8 & 42.61 & 23.46 & 14.57 & 10.35 & 3.85 & 2.16 & 1.65 & 1.35 \\
USGS-11152300 & CA_9 & 35.45 & 25.52 & 13.07 & 10.15 & 5.76 & 4.04 & 3.47 & 1.72 \\
USGS-09427520 & CA_10 & 33.91 & 18.42 & 17.11 & 9.81 & 8.68 & 5.98 & 4.09 & 1.99 \\
USGS-3410141* & CA_11 & 39.87 & 20.39 & 15.35 & 10.69 & 7.60 & 4.25 & 1.10 & 0.76 \\
USGS-11049400 & CA_12 & 35.90 & 22.35 & 13.79 & 11.92 & 8.92 & 3.86 & 2.76 & 0.42 \\
USGS-11051500 & CA_13 & 41.54 & 28.11 & 7.96 & 6.99 & 6.33 & 3.98 & 3.33 & 1.33 \\
USGS-11060400 & CA_14 & 31.77 & 24.04 & 15.04 & 9.83 & 7.29 & 4.94 & 3.39 & 2.85 \\
USGS-11066460 & CA_15 & 40.55 & 19.68 & 13.55 & 11.90 & 5.27 & 4.26 & 2.48 & 1.82 \\
USGS-11075610 & CA_16 & 48.98 & 23.45 & 9.13 & 6.88 & 5.23 & 2.30 & 2.07 & 1.22 \\
\hline \hline Nof & & & & & & & & & \\
\hline
\end{tabular}

Note: (1) WA, OR, and CA, respectively, refers to stations in Washington, Oregon, and California. (2) '-' indicates the "missing data". (3) "**" refer to USGS-375159122343801 and USGS-341014116494801 respectively. (4) "I" is station identifier. 
Table A7: Ranges of percent variance explained by each principal component (PC) for the four environmental regimes.

\begin{tabular}{ccccc}
\hline $\begin{array}{c}\text { Principal } \\
\text { Component }\end{array}$ & $\begin{array}{c}\text { Type I } \\
\text { Regime }\end{array}$ & $\begin{array}{c}\text { Type II } \\
\text { Regime }\end{array}$ & $\begin{array}{c}\text { Type III } \\
\text { Regime }\end{array}$ & $\begin{array}{c}\text { Type IV } \\
\text { Regime }\end{array}$ \\
\hline 1 & $30-50$ & $40-45$ & $41-43$ & $48-32$ \\
2 & $13-28$ & $17-21$ & $20-23$ & $17-24$ \\
3 & $8-18$ & $11-13$ & $15-15$ & $14-15$ \\
4 & $7-13$ & $10-11$ & $10-12$ & $9-12$ \\
5 & $3-9$ & $8-8$ & $4-7$ & $6-9$ \\
6 & $2-7$ & $4-5$ & $2-2$ & $2-7$ \\
7 & $1-5$ & $2-3$ & $1-2$ & $2-3$ \\
8 & $0-3$ & $0-1$ & $1-1$ & $1-3$ \\
9 & $0-2$ & $0-1$ & 0 & $1-1$ \\
\hline \hline
\end{tabular}


Table A8: Coefficient $(\beta)$ of the normalized (dimensionless) PLSR models of stream dissolved oxygen with the dynamic environmental drives after 1000 Monte Carlo simulation of the Pacific Coast water quality monitoring stations.

\begin{tabular}{|c|c|c|c|c|c|c|c|c|c|c|c|c|}
\hline Stations ID & $\mathrm{I}$ & $\mathrm{TN}$ & $\mathrm{TP}$ & $\mathrm{SC}$ & $\mathrm{pH}$ & $\mathrm{Q}$ & $\mathrm{AP}$ & TW & SR & NSE & RSR & $\overline{\mathrm{OPC}}$ \\
\hline \multicolumn{13}{|c|}{ Type I Regime } \\
\hline USGS-12128000 & WA_1 & 0.04 & -0.22 & -0.03 & -0.06 & 0.13 & -0.02 & -0.68 & 0.26 & 0.84 & 0.39 & 3.00 \\
\hline USGS-12056500 & WA_2 & - & 0.06 & -0.01 & 0.01 & 0.18 & 0.16 & -0.77 & -0.09 & 0.88 & 0.34 & 3.00 \\
\hline USGS-12113390 & WA_3 & 0.13 & -0.02 & -0.20 & -0.03 & 0.25 & 0.11 & -0.56 & 0.05 & 0.89 & 0.33 & 3.00 \\
\hline a-VA12A & WA_4 & -0.01 & -0.21 & -0.01 & -0.07 & - & 0.09 & -0.59 & -0.12 & 0.77 & 0.48 & 3.00 \\
\hline a-VA37A & WA_5 & -0.08 & -0.31 & -0.13 & -0.12 & - & -0.08 & -0.55 & 0.31 & 0.93 & 0.22 & 3.00 \\
\hline a-VA41A & WA_6 & 0.03 & -0.19 & -0.07 & 0.04 & - & 0.01 & -0.65 & 0.04 & 0.72 & 0.52 & 3.00 \\
\hline a-VA42A & WA_7 & 0.06 & -0.34 & -0.06 & -0.01 & - & -0.03 & -0.60 & 0.02 & 0.85 & 0.38 & 3.00 \\
\hline USGS-4551221* & WA_8 & 0.15 & 0.01 & 0.06 & 0.12 & - & 0.04 & -0.66 & -0.20 & 0.89 & 0.30 & 3.00 \\
\hline USGS-14211955 & WA_9 & -0.07 & -0.35 & -0.08 & 0.38 & -0.09 & 0.01 & -0.54 & -0.05 & 0.93 & 0.26 & 3.00 \\
\hline USGS-14144805 & WA_11 & 0.14 & 0.13 & 0.11 & 0.30 & 0.20 & 0.12 & -0.73 & 0.18 & 0.94 & 0.22 & 4.00 \\
\hline USGS-14246900 & OR_1 & 0.25 & 0.02 & -0.20 & 0.26 & 0.04 & -0.02 & -0.78 & 0.08 & 0.89 & 0.33 & 3.00 \\
\hline USGS-14128910 & OR_2 & 0.32 & 0.16 & -0.25 & 0.10 & 0.20 & -0.26 & -0.52 & -0.15 & 0.90 & 0.30 & 3.00 \\
\hline USGS-4533391* & OR_3 & 0.12 & 0.02 & -0.21 & 0.15 & -0.08 & 0.02 & -0.64 & -0.07 & 0.81 & 0.43 & 3.00 \\
\hline USGS-14211720 & OR_4 & 0.27 & -0.08 & -0.23 & 0.11 & 0.09 & 0.02 & -0.65 & 0.00 & 0.94 & 0.25 & 3.00 \\
\hline USGS-45241412 & OR_5 & 0.03 & 0.11 & -0.04 & 0.15 & - & -0.02 & -0.56 & -0.37 & 0.84 & 0.35 & 3.00 \\
\hline USGS-4523011* & OR_6 & 0.12 & -0.26 & -0.10 & 0.24 & - & -0.02 & -0.61 & 0.12 & 0.60 & 0.63 & 3.00 \\
\hline USGS-14207050 & OR_7 & 0.04 & -0.18 & -0.08 & -0.03 & 0.27 & 0.05 & -0.51 & 0.07 & 0.52 & 0.68 & 3.00 \\
\hline USGS-14207600 & OR_8 & 0.14 & -0.12 & -0.24 & 0.31 & -0.02 & 0.05 & -0.80 & 0.08 & 0.50 & 0.70 & 3.00 \\
\hline USGS-11391100 & CA_2 & -0.14 & 0.30 & 0.07 & -0.27 & - & -0.12 & -0.76 & -0.06 & 0.71 & 0.51 & 3.00 \\
\hline USGS-11452600 & CA_3 & -0.01 & -0.13 & 0.04 & 0.01 & -0.10 & 0.04 & -0.75 & 0.23 & 0.72 & 0.48 & 3.00 \\
\hline USGS-11447650 & CA_6 & 0.04 & -0.22 & 0.00 & -0.18 & 0.11 & 0.24 & -0.51 & -0.04 & 0.54 & 0.67 & 3.00 \\
\hline USGS-11152300 & CA_9 & 0.04 & -0.12 & 0.20 & 0.11 & -0.36 & 0.19 & -0.41 & -0.10 & 0.65 & 0.58 & 3.00 \\
\hline USGS-09427520 & CA_10 & 0.11 & - & 0.03 & -0.16 & 0.16 & -0.07 & -0.83 & 0.05 & 0.56 & 0.66 & 3.00 \\
\hline USGS-3410141* & CA_11 & - & 0.10 & 0.02 & -0.01 & 0.17 & -0.13 & -0.76 & 0.08 & 0.84 & 0.37 & 3.00 \\
\hline USGS-11049400 & CA_12 & -0.15 & -0.14 & -0.39 & -0.03 & 0.29 & 0.26 & -0.56 & -0.01 & 0.95 & 0.20 & 4.00 \\
\hline USGS-11051500 & CA_13 & -0.22 & -0.12 & -0.25 & 0.20 & -0.21 & 0.18 & -0.69 & -0.16 & 0.89 & 0.31 & 3.00 \\
\hline USGS-11066460 & CA_15 & 0.18 & -0.17 & 0.17 & 0.15 & -0.18 & 0.12 & -0.65 & 0.09 & 0.86 & 0.36 & 3.00 \\
\hline USGS-11075610 & CA_16 & 0.12 & -0.30 & 0.05 & 0.27 & -0.04 & 0.30 & -0.44 & 0.06 & 0.80 & 0.44 & 3.00 \\
\hline
\end{tabular}

Note: (1) WA, OR, and CA, respectively, refers to stations in Washington, Oregon, and California. (2) '-' indicates the "missing data". (3) "a" refers to KINGCOUNTY from STORET water quality station. (4) "“*” refer to USGS455122122310600, USGS-453339122481301, USGS-452301122442301, USGS-375159122343801, and USGS341014116494801 respectively. (5) "I" is station identifier. 
Table A8: (continued).

\begin{tabular}{|c|c|c|c|c|c|c|c|c|c|c|c|c|}
\hline Stations ID & I & $\mathrm{TN}$ & $\mathrm{TP}$ & $\mathrm{SC}$ & $\mathrm{pH}$ & Q & $\mathrm{AP}$ & TW & SR & NSE & RSR & OPC \\
\hline \multicolumn{13}{|c|}{ Type II Regime } \\
\hline USGS-11447360 & CA_4 & -0.36 & -0.59 & 0.27 & -0.21 & -0.06 & 0.13 & -0.15 & 0.05 & 0.76 & 0.45 & 3.00 \\
\hline USGS-11466800 & CA_5 & -0.22 & -0.57 & 0.03 & 0.41 & - & 0.09 & -0.08 & -0.06 & 0.93 & 0.20 & 3.00 \\
\hline \multicolumn{13}{|c|}{ Type III Regime } \\
\hline USGS-11460170 & CA_7 & -0.09 & -0.08 & -0.39 & 0.27 & 0.55 & 0.06 & -0.11 & -0.03 & 0.89 & 0.30 & 3.00 \\
\hline USGS-3751591* & CA_8 & - & -0.25 & -0.31 & 0.16 & 0.52 & 0.00 & -0.09 & 0.01 & 0.92 & 0.26 & 3.00 \\
\hline \multicolumn{13}{|c|}{ Type IV Regime } \\
\hline USGS-14211920 & WA_10 & 0.01 & -0.11 & 0.08 & 0.70 & 0.13 & -0.21 & -0.48 & -0.19 & 0.71 & 0.52 & 3.00 \\
\hline USGS-11488495 & CA_1 & -0.07 & -0.07 & 0.20 & 0.45 & -0.11 & 0.08 & -0.39 & -0.05 & 0.78 & 0.46 & 3.00 \\
\hline USGS-11060400 & CA_14 & -0.14 & -0.20 & -0.25 & 0.39 & - & -0.12 & -0.33 & 0.14 & 0.50 & 0.70 & 3.00 \\
\hline
\end{tabular}

Note: (1) WA, OR, and CA, respectively, refers to stations in Washington, Oregon, and California. (2) '-' indicates the "missing data". (3) “*” refer to USGS-375159122343801. (4) "I" is station identifier. 
Table A9: Summary of the stream water quality indicators and land use compositional attributes for climate dominated regime.

\begin{tabular}{lccccccc}
\hline Variables & Mean & SD & Minimum & $\begin{array}{c}25^{\text {th }} \\
\text { Percentile }\end{array}$ & $\begin{array}{c}50^{\text {th }} \\
\text { Percentile }\end{array}$ & $\begin{array}{c}75^{\text {th }} \\
\text { Percentile }\end{array}$ & Maximum \\
\hline A $\left(\mathrm{km}^{2}\right)$ & 6759.54 & 11500.51 & 3 & 69.5 & 887.5 & 8775 & 39153 \\
S $(\%)$ & 19.21 & 12.32 & 3.07 & 9.48 & 18.19 & 23.835 & 61.66 \\
I $(\%)$ & 8.52 & 14.27 & 0.06 & 0.64 & 2.815 & 9.155 & 57.48 \\
VEG $(\%)$ & 66.14 & 26.79 & 1.46 & 53.38 & 70.49 & 84.75 & 97.57 \\
BUL $(\%)$ & 21.40 & 26.29 & 0.37 & 5.05 & 13.815 & 23.68 & 96.7 \\
AGR $(\%)$ & 8.88 & 9.96 & 0.01 & 0.1 & 5.885 & 14.16 & 34.42 \\
WTL $(\%)$ & 1.31 & 1.39 & 0.04 & 0.29 & 0.815 & 2.05 & 5.75 \\
WAT $(\%)$ & 1.33 & 1.84 & 0.01 & 0.26 & 0.785 & 1.76 & 8.4 \\
OPN $(\%)$ & 0.92 & 0.87 & 0.01 & 0.225 & 0.785 & 1.14 & 3.26 \\
TN $(\mathrm{mg} / \mathrm{L})$ & 0.95 & 0.70 & 0 & 0.5 & 0.97 & 1.29 & 7.66 \\
TP $(\mathrm{mg} / \mathrm{L})$ & 0.07 & 0.05 & 0 & 0.04 & 0.055 & 0.125 & 0.97 \\
SC $(\mu \mathrm{s} / \mathrm{cm})$ & 267.76 & 268.66 & 53.7 & 114.625 & 149.36 & 308.48 & 984.4 \\
pH & 7.75 & 0.41 & 7.03 & 7.465 & 7.725 & 8.06 & 8.44 \\
AP $(\mathrm{mbar})$ & 977.13 & 30.54 & 892.43 & 969.33 & 989.965 & 992.58 & 1010.8 \\
SR $\left(\mathrm{W} / \mathrm{m}^{2}\right)$ & 452.10 & 155.26 & 225.9 & 342.675 & 407.965 & 575.605 & 808.43 \\
TW $\left({ }^{\circ} \mathrm{C}\right)$ & 12.97 & 3.79 & 6.83 & 9.49 & 12.495 & 15.31 & 22.14 \\
DO $(\mathrm{mg} / \mathrm{L})$ & 10.19 & 1.31 & 6.02 & 9.44 & 10.335 & 11.14 & 12.18 \\
\hline \hline
\end{tabular}

Notes: (1) A, S, I, VEG, BUL, AGR, WTL, WAT, and OPN, respectively, refer to subwatershed area, slope, imperviousness, vegetated land, built-up, agricultural land, wetlands, waterbody, and open land. (2) TN, TP, SC, pH, AP, SR, TW, and DO refers to total nitrogen, total phosphorous, specific conductance, potential of hydrogen, atmospheric pressure, solar radiation, water temperature, and dissolved oxygen respectively. 
Table A10: Summary of the stream water quality indicators and land use compositional attributes for nutrient dominated regime.

\begin{tabular}{|c|c|c|c|c|c|c|c|}
\hline & & & & $25^{\text {th }}$ & $50^{\text {th }}$ & $75^{\text {th }}$ & \\
\hline Variables & Mean & SD & Minimum & Percentile & Percentile & Percentile & Maximum \\
\hline $\mathrm{A}\left(\mathrm{km}^{2}\right)$ & 368.50 & 405.17 & 82.00 & 82.00 & 368.50 & 655.00 & 655.00 \\
\hline $\mathrm{S}(\%)$ & 7.90 & 7.58 & 2.54 & 2.54 & 7.90 & 13.26 & 13.26 \\
\hline I (\%) & 27.56 & 23.57 & 10.89 & 10.89 & 27.56 & 44.23 & 44.23 \\
\hline VEG $(\%)$ & 27.33 & 38.62 & 0.02 & 0.02 & 27.33 & 54.64 & 54.64 \\
\hline BUL (\%) & 65.34 & 48.42 & 31.10 & 31.10 & 65.34 & 99.58 & 99.58 \\
\hline $\operatorname{AGR}(\%)$ & 6.75 & 9.40 & 0.10 & 0.10 & 6.75 & 13.40 & 13.40 \\
\hline WTL (\%) & 0.29 & 0.27 & 0.10 & 0.10 & 0.29 & 0.48 & 0.48 \\
\hline WAT $(\%)$ & 0.22 & 0.17 & 0.10 & 0.10 & 0.22 & 0.34 & 0.34 \\
\hline OPN (\%) & 0.07 & 0.04 & 0.04 & 0.04 & 0.07 & 0.10 & 0.10 \\
\hline $\mathrm{TN}(\mathrm{mg} / \mathrm{L})$ & 0.96 & 0.59 & 0.54 & 0.54 & 0.96 & 1.38 & 1.38 \\
\hline $\mathrm{TP}(\mathrm{mg} / \mathrm{L})$ & 0.26 & 0.09 & 0.20 & 0.20 & 0.26 & 0.32 & 0.32 \\
\hline $\mathrm{TW}\left({ }^{\circ} \mathrm{C}\right)$ & 17.35 & 3.35 & 14.99 & 14.99 & 17.36 & 19.72 & 19.72 \\
\hline $\mathrm{SC}(\mu \mathrm{S} / \mathrm{cm})$ & 382.18 & 214.19 & 230.73 & 230.73 & 382.19 & 533.64 & 533.64 \\
\hline $\mathrm{pH}$ & 7.64 & 0.29 & 7.44 & 7.44 & 7.65 & 7.85 & 7.85 \\
\hline AP (mbar) & 996.46 & 11.63 & 988.24 & 988.24 & 996.46 & 1004.68 & 1004.68 \\
\hline $\mathrm{SR}\left(\mathrm{W} / \mathrm{m}^{2}\right)$ & 596.60 & 64.01 & 551.34 & 551.34 & 596.60 & 641.86 & 641.86 \\
\hline $\mathrm{DO}(\mathrm{mg} / \mathrm{L})$ & 7.88 & 0.67 & 7.41 & 7.41 & 7.88 & 8.35 & 8.35 \\
\hline
\end{tabular}

Notes: (1) A, S, I, VEG, BUL, AGR, WTL, WAT, and OPN, respectively, refer to subwatershed area, slope, imperviousness, vegetated land, built-up, agricultural land, wetlands, waterbody, and open land. (2) TN, TP, SC, pH, AP, SR, TW, and DO refers to total nitrogen, total phosphorous, specific conductance, potential of hydrogen, atmospheric pressure, solar radiation, water temperature, and dissolved oxygen respectively. 
Table A11: Summary of the stream water quality indicators and land use compositional attributes for hydro-atmosphere dominated regime.

\begin{tabular}{lccccccc}
\hline & & & $25^{\text {th }}$ & $50^{\text {th }}$ & $7^{\text {th }}$ & \\
Variables & Mean & SD & Minimum & Percentile & Percentile & Percentile & Maximum \\
\hline A $\left(\mathrm{km}^{2}\right)$ & 24.20 & 8.20 & 18.40 & 18.40 & 24.20 & 30.00 & 30.00 \\
S $(\%)$ & 33.83 & 3.89 & 31.08 & 31.08 & 33.83 & 36.58 & 36.58 \\
I $(\%)$ & 0.89 & 0.11 & 0.81 & 0.81 & 0.89 & 0.97 & 0.97 \\
VEG $(\%)$ & 86.87 & 2.26 & 85.27 & 85.27 & 86.87 & 88.46 & 88.46 \\
BUL $(\%)$ & 8.43 & 2.52 & 6.64 & 6.64 & 8.43 & 10.21 & 10.21 \\
AGR $(\%)$ & 0.08 & 0.04 & 0.10 & 0.10 & 0.10 & 0.10 & 0.10 \\
WTL $(\%)$ & 2.23 & 1.70 & 1.03 & 1.03 & 2.23 & 3.43 & 3.43 \\
WAT $(\%)$ & 2.32 & 3.14 & 0.10 & 0.10 & 2.32 & 4.54 & 4.54 \\
OPN $(\%)$ & 0.06 & 0.06 & 0.02 & 0.02 & 0.06 & 0.10 & 0.10 \\
TN $(\mathrm{mg} / \mathrm{L})$ & 0.29 & 0.41 & 0.00 & 0.00 & 0.29 & 0.58 & 0.58 \\
TP $(\mathrm{mg} / \mathrm{L})$ & 0.05 & 0.05 & 0.02 & 0.02 & 0.05 & 0.08 & 0.08 \\
TW $\left({ }^{\circ} \mathrm{C}\right)$ & 12.56 & 0.48 & 12.22 & 12.22 & 12.57 & 12.91 & 12.91 \\
SC $(\mu \mathrm{S} / \mathrm{cm})$ & 240.57 & 11.62 & 232.36 & 232.36 & 240.58 & 248.79 & 248.79 \\
pH & 7.65 & 0.07 & 7.60 & 7.60 & 7.65 & 7.70 & 7.70 \\
AP $(\mathrm{mbar})$ & 1014.37 & 0.60 & 1013.94 & 1013.94 & 1014.37 & 1014.80 & 1014.80 \\
SR $\left(\mathrm{W} / \mathrm{m}^{2}\right)$ & 602.63 & 22.65 & 586.61 & 586.61 & 602.63 & 618.64 & 618.64 \\
DO $(\mathrm{mg} / \mathrm{L})$ & 8.94 & 0.65 & 8.48 & 8.48 & 8.94 & 9.39 & 9.39 \\
\hline \hline
\end{tabular}

Notes: (1) A, S, I, VEG, BUL, AGR, WTL, WAT, and OPN, respectively, refer to subwatershed area, slope, imperviousness, vegetated land, built-up, agricultural land, wetlands, waterbody, and open land. (2) TN, TP, SC, pH, AP, SR, TW, and DO refers to total nitrogen, total phosphorous, specific conductance, potential of hydrogen, atmospheric pressure, solar radiation, water temperature, and dissolved oxygen respectively. 
Table A12: Summary of the stream water quality indicators and land use compositional attributes for redox dominated regime.

\begin{tabular}{llcccccc}
\hline Variables & Mean & SD & Minimum & $\begin{array}{c}25^{\text {th }} \\
\text { Percentile }\end{array}$ & $\begin{array}{c}50^{\text {th }} \\
\text { Percentile }\end{array}$ & $\begin{array}{c}75^{\text {th }} \\
\text { Percentile }\end{array}$ & Maximum \\
\hline A $\left(\mathrm{km}^{2}\right)$ & 190.50 & 170.41 & 70.00 & 70.00 & 190.50 & 311.00 & 311.00 \\
S $(\%)$ & 15.21 & 16.96 & 3.22 & 3.22 & 15.21 & 27.20 & 27.20 \\
I $(\%)$ & 31.53 & 19.55 & 17.70 & 17.70 & 31.53 & 45.35 & 45.35 \\
VEG $(\%)$ & 27.98 & 37.14 & 1.72 & 1.72 & 27.98 & 54.24 & 54.24 \\
BUL $(\%)$ & 70.09 & 35.13 & 45.25 & 45.25 & 70.09 & 94.93 & 94.93 \\
AGR $(\%)$ & 1.49 & 1.86 & 0.17 & 0.17 & 1.49 & 2.80 & 2.80 \\
WTL $(\%)$ & 0.22 & 0.31 & 0.10 & 0.10 & 0.22 & 0.44 & 0.44 \\
WAT $(\%)$ & 0.07 & 0.04 & 0.04 & 0.04 & 0.07 & 0.10 & 0.10 \\
OPN $(\%)$ & 0.16 & 0.19 & 0.02 & 0.02 & 0.16 & 0.29 & 0.29 \\
TN $(\mathrm{mg} / \mathrm{L})$ & 1.17 & 0.57 & 0.76 & 0.76 & 1.17 & 1.57 & 1.57 \\
TP $(\mathrm{mg} / \mathrm{L})$ & 0.07 & 0.05 & 0.03 & 0.03 & 0.07 & 0.11 & 0.11 \\
TW $\left({ }^{\circ} \mathrm{C}\right)$ & 17.03 & 7.49 & 11.74 & 11.74 & 17.04 & 22.33 & 22.33 \\
SC $(\mu \mathrm{S} / \mathrm{cm})$ & 459.23 & 425.74 & 158.19 & 158.19 & 459.24 & 760.28 & 760.28 \\
pH & 7.98 & 0.35 & 7.73 & 7.73 & 7.98 & 8.23 & 8.23 \\
AP $(\mathrm{mbar})$ & 959.43 & 42.98 & 929.03 & 929.03 & 959.43 & 989.82 & 989.82 \\
SR $\left(\mathrm{W} / \mathrm{m}^{2}\right)$ & 401.25 & 205.10 & 256.23 & 256.23 & 401.26 & 546.28 & 546.28 \\
DO $(\mathrm{mg} / \mathrm{L})$ & 10.19 & 0.83 & 9.60 & 9.60 & 10.19 & 10.77 & 10.77 \\
\hline \hline
\end{tabular}

Notes: (1) A, S, I, VEG, BUL, AGR, WTL, WAT, and OPN, respectively, refer to subwatershed area, slope, imperviousness, vegetated land, built-up, agricultural land, wetlands, waterbody, and open land. (2) TN, TP, SC, pH, AP, SR, TW, and DO refers to total nitrogen, total phosphorous, specific conductance, potential of hydrogen, atmospheric pressure, solar radiation, water temperature, and dissolved oxygen respectively. 


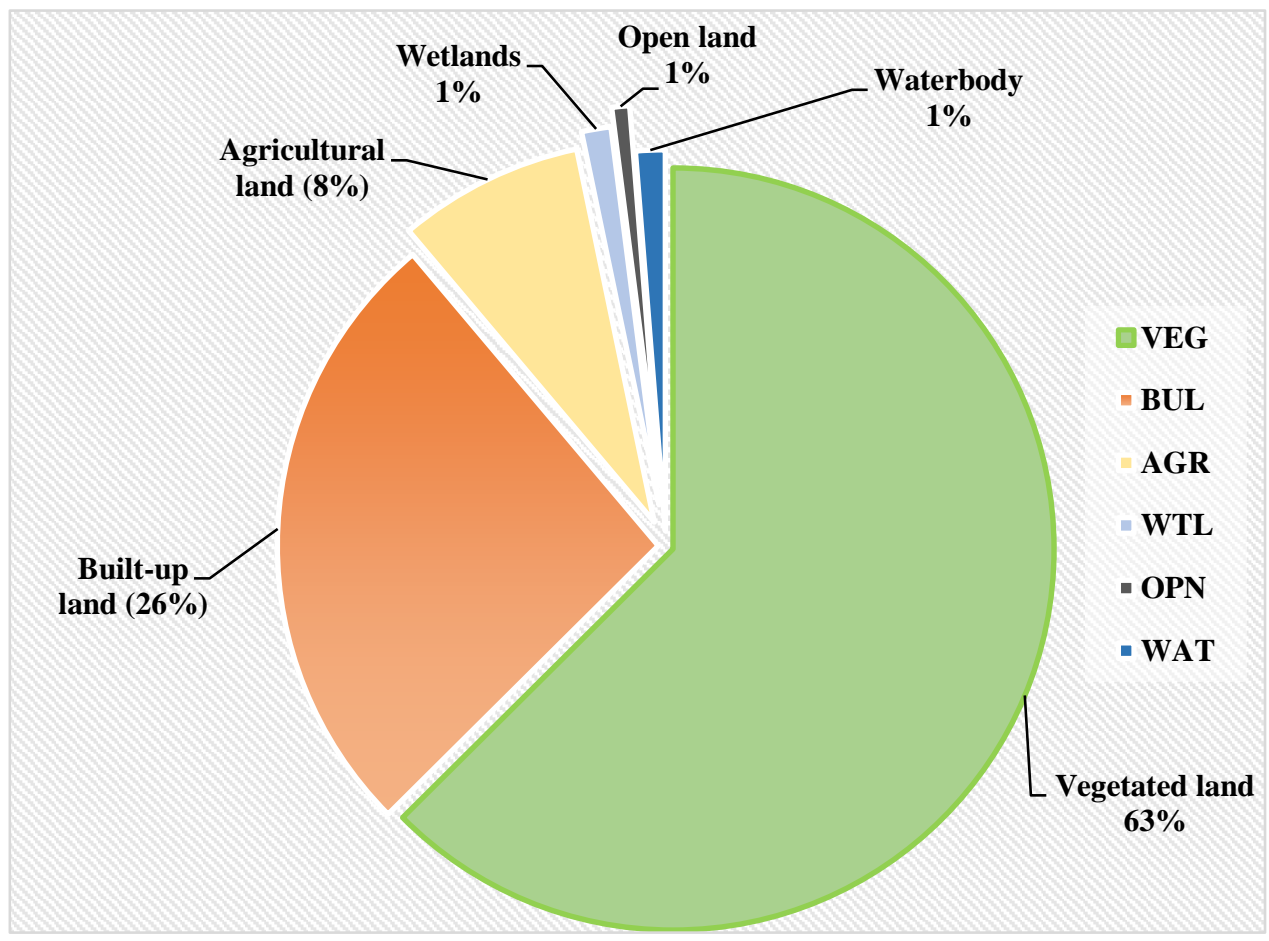

Figure A1: Compositional attribution of Land use/ Land cover (LULC) across the study area. 
(a)

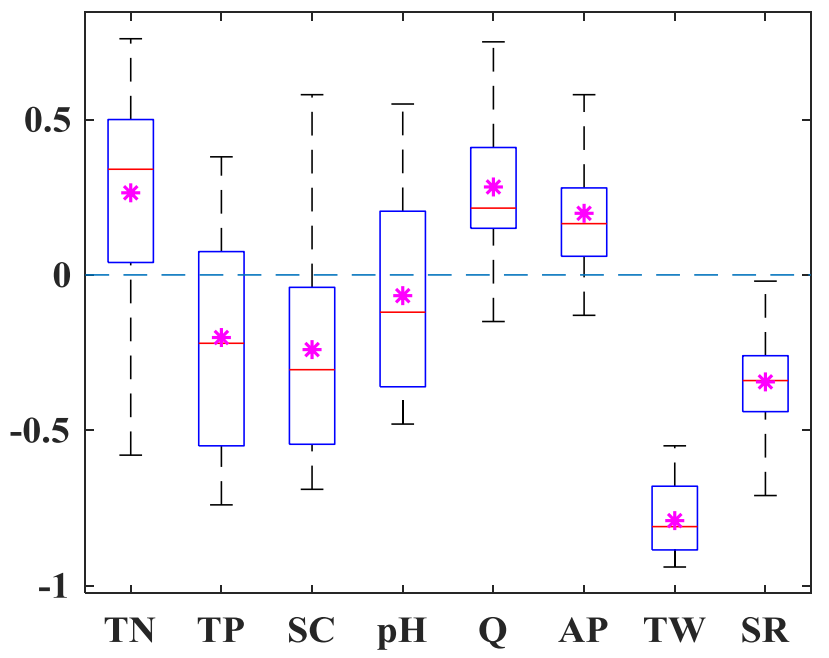

(c)

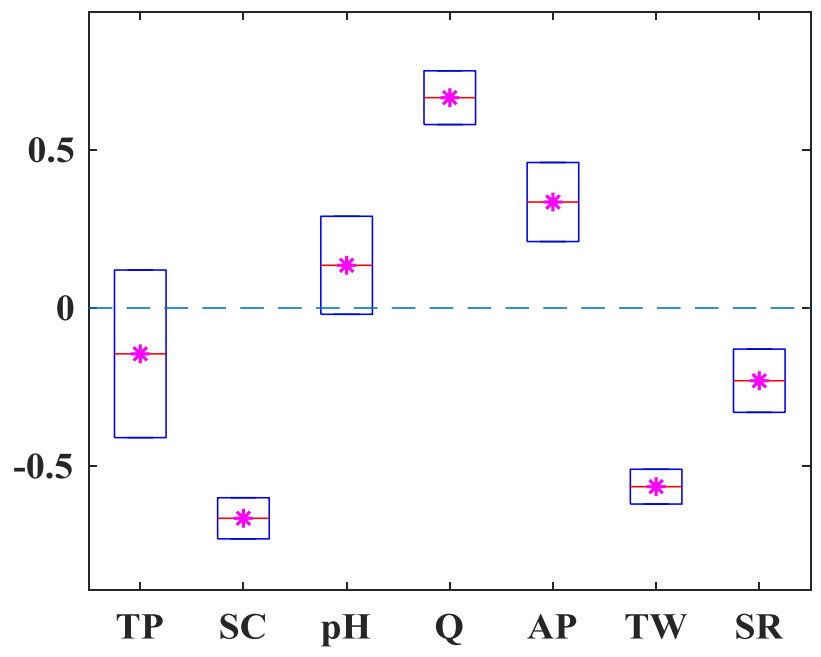

(b)

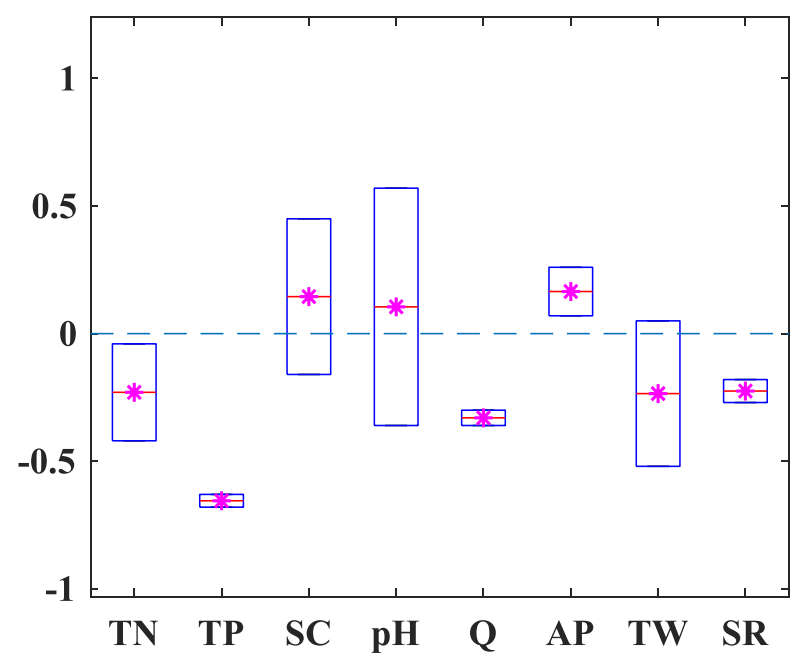

(d)

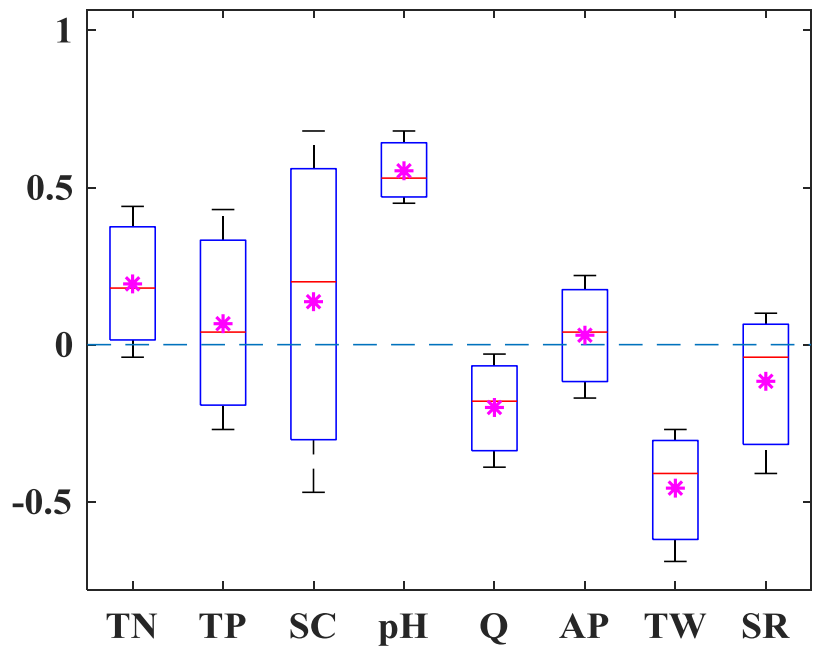

Figure A2: Box plots of correlation coefficients for each environmental regime: (a) Type I, (b) Type II, (c) Type III, and (d) Type IV. 
(a)

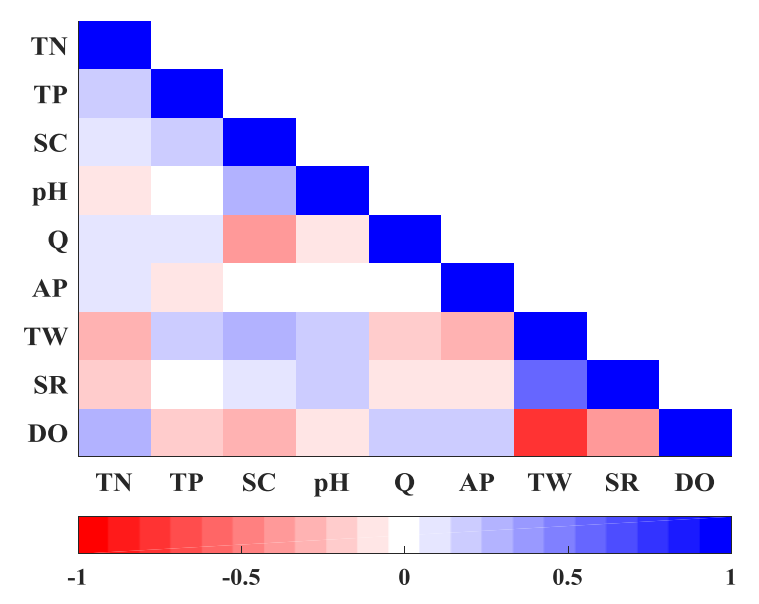

(c)

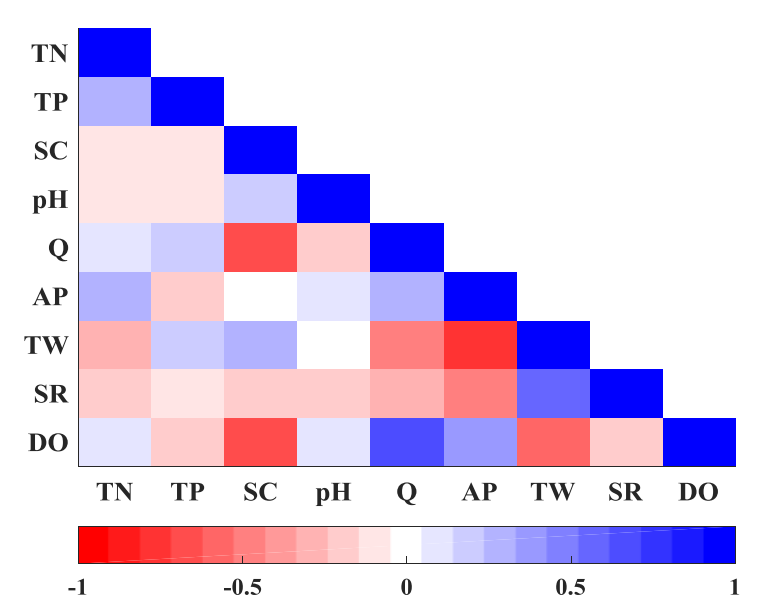

(b)

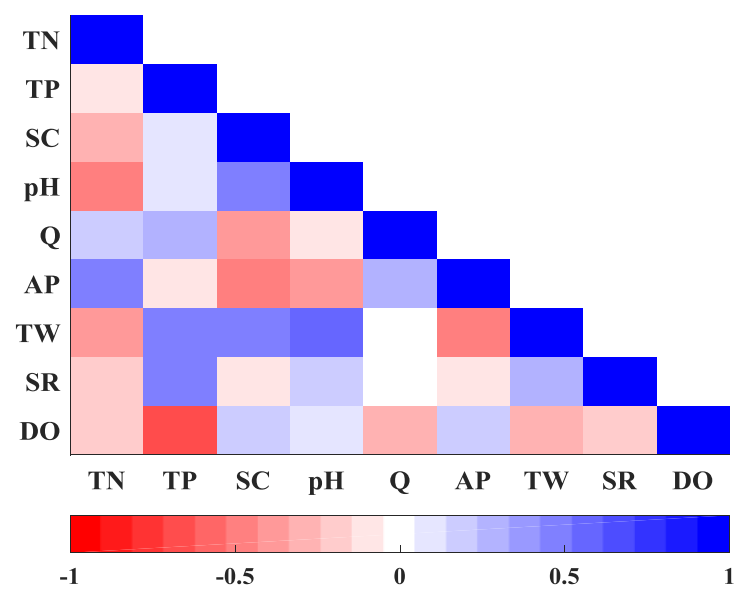

(d)

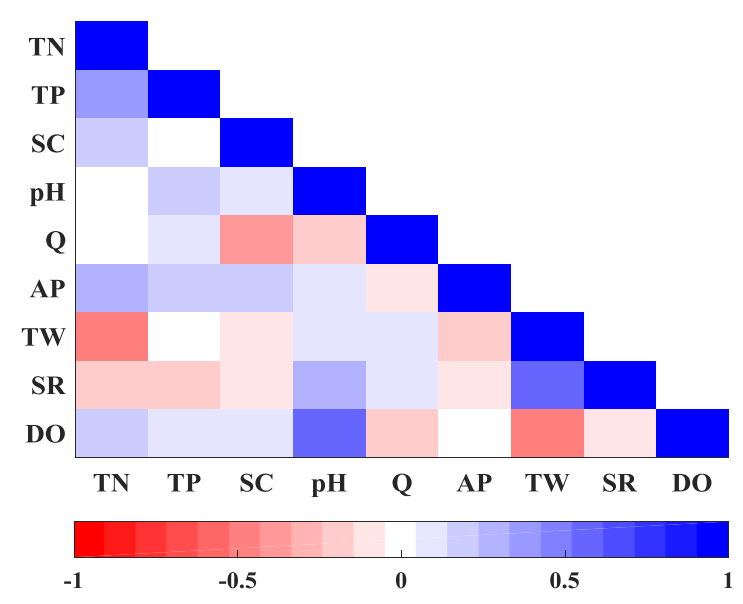

Figure A3: Triangular map representing correlation coefficients: (a) Type I, (b) Type II, (c) Type III, and (d) Type IV. 

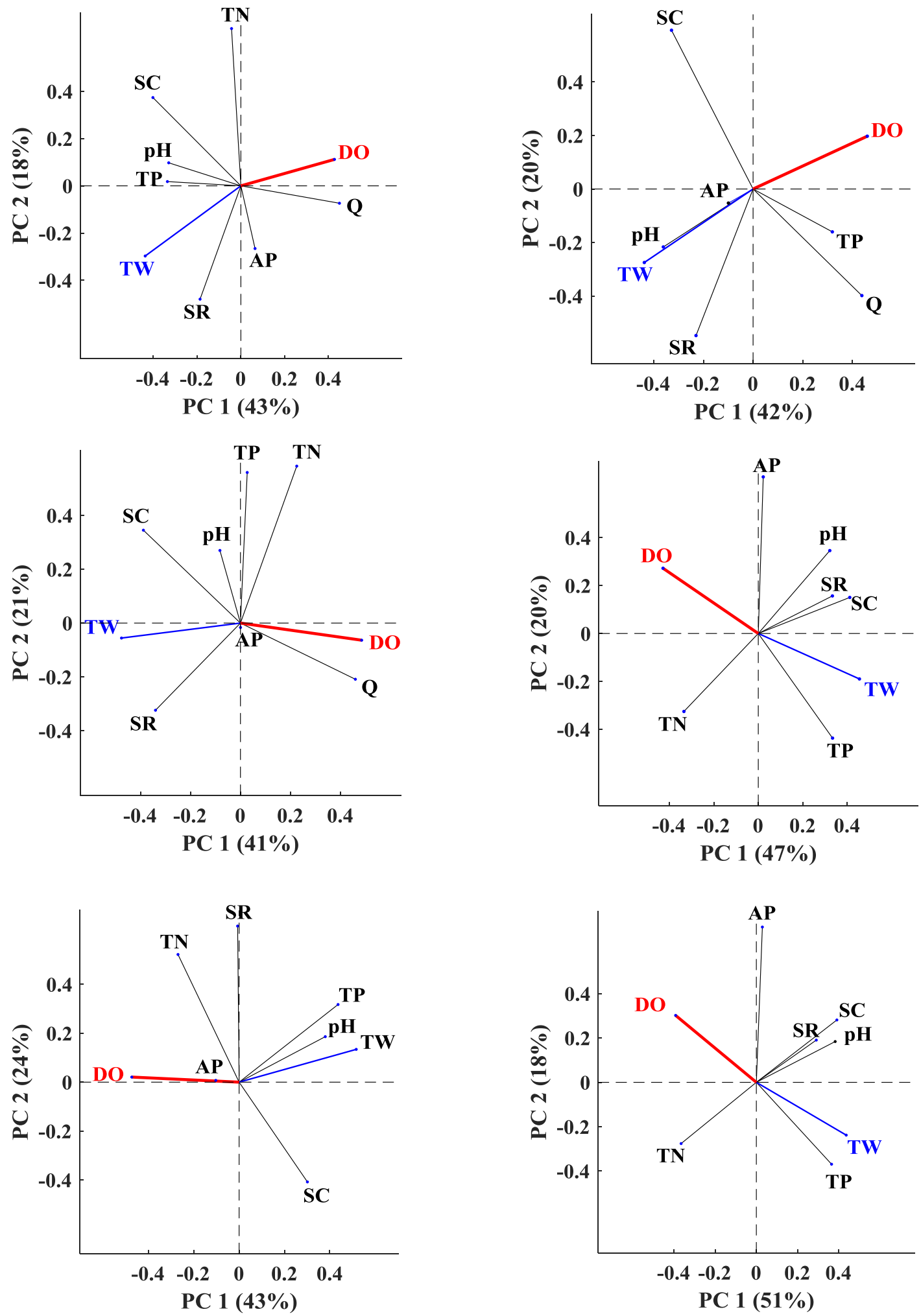

Figure A4: Biplots of Type I regime obtained from principal component analysis showing interrelation of DO with dynamic environmental drivers. 

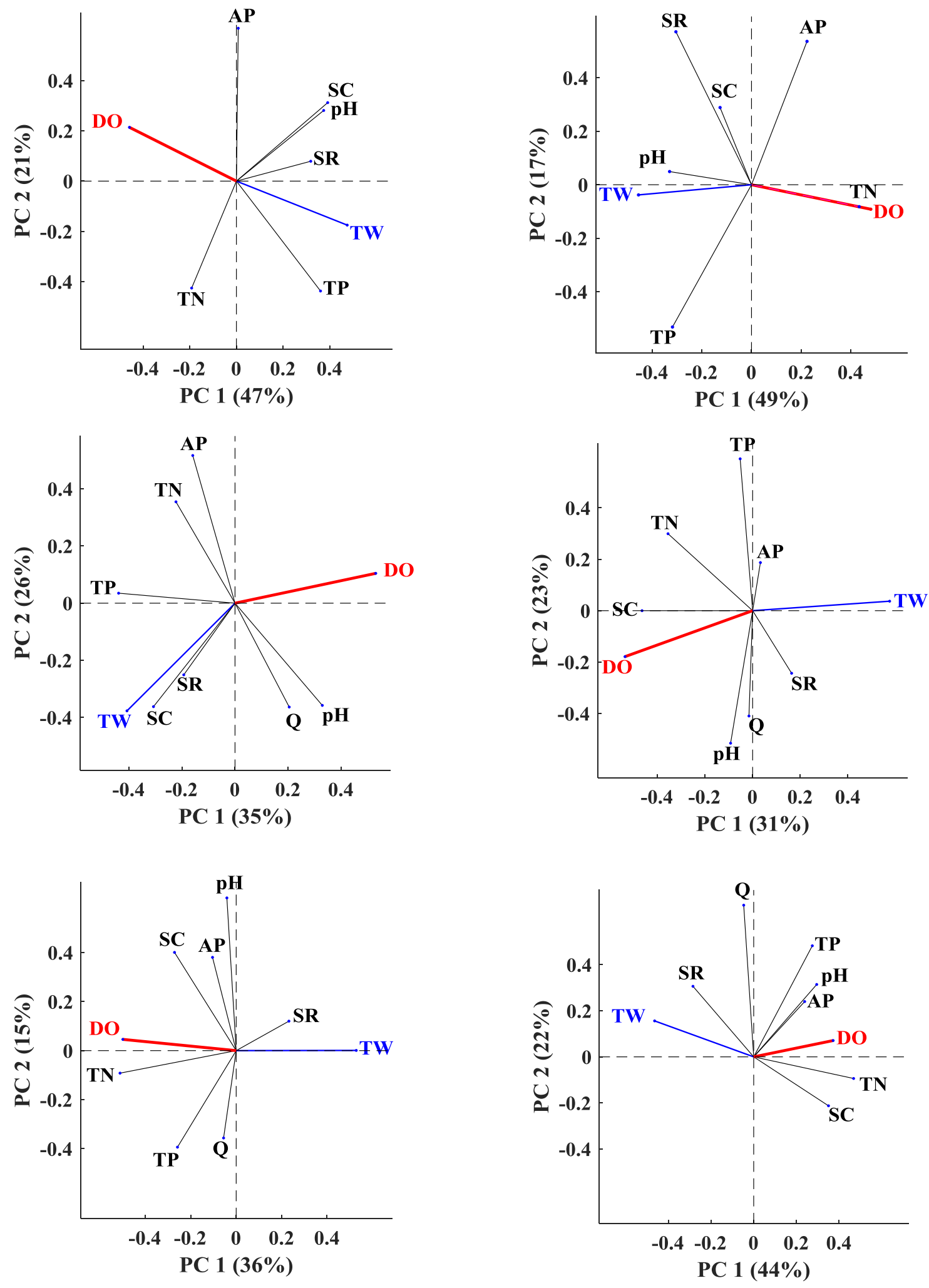

Figure A4: (continued). 

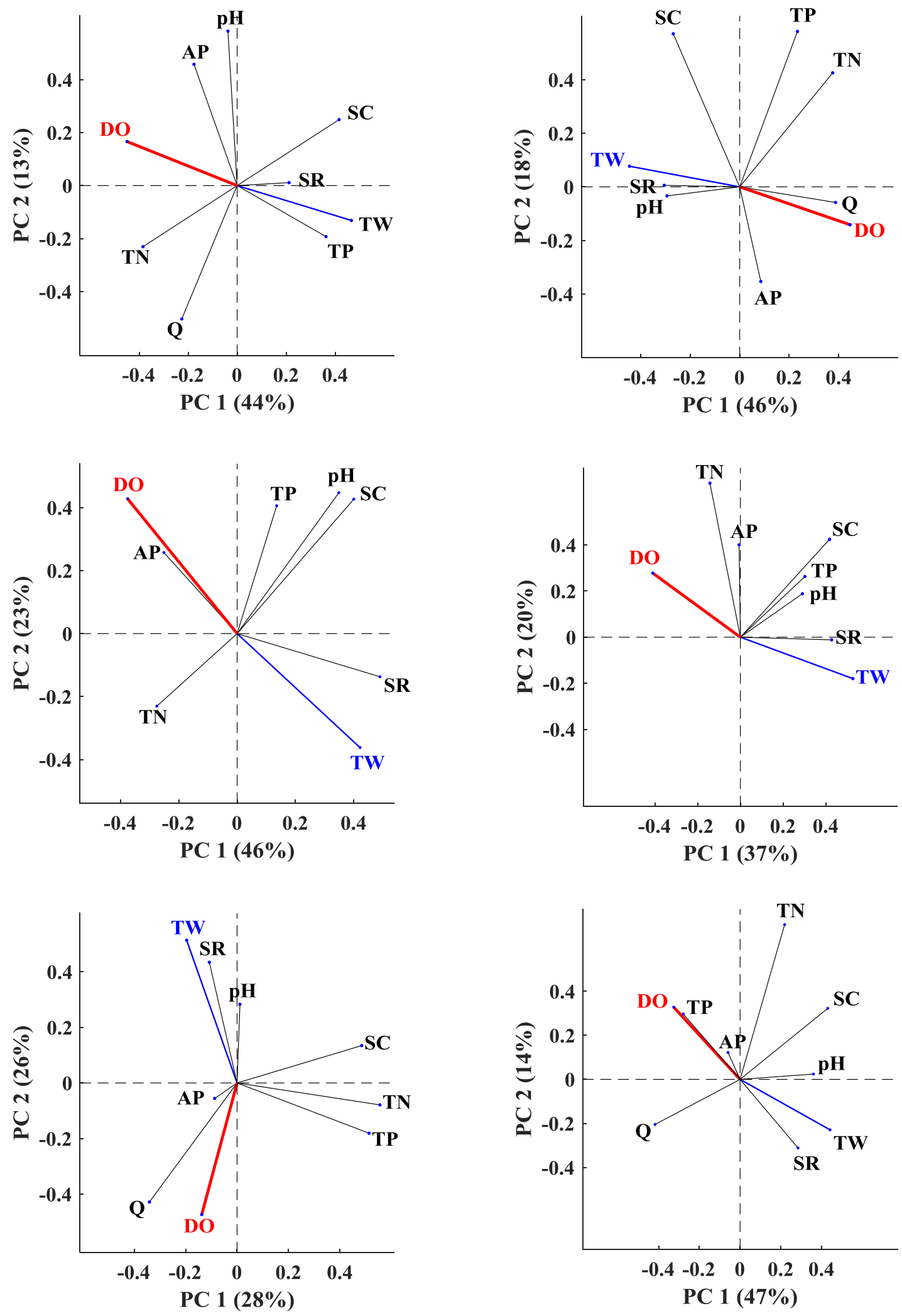

Figure A4: (continued). 

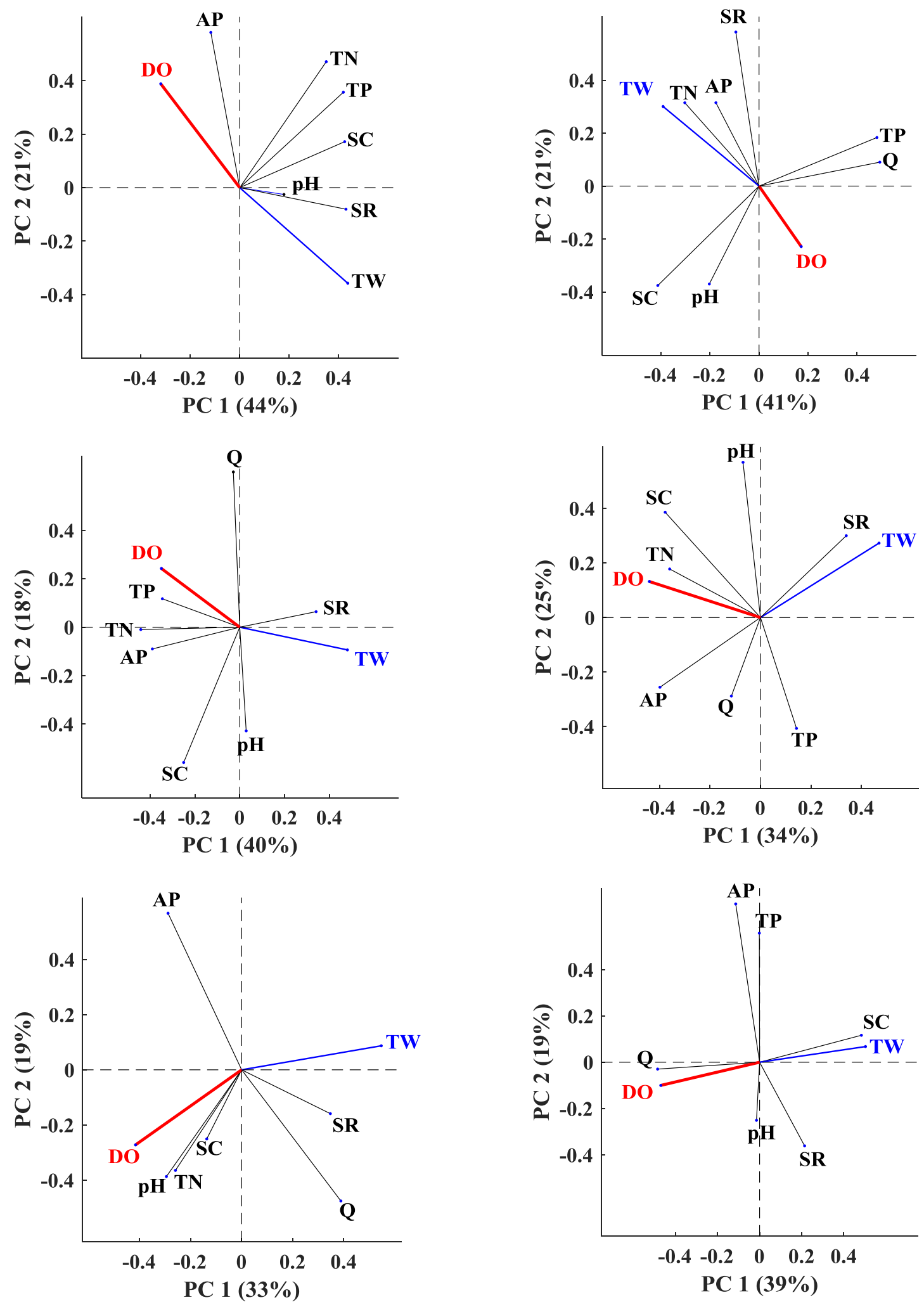

Figure A4: (continued). 

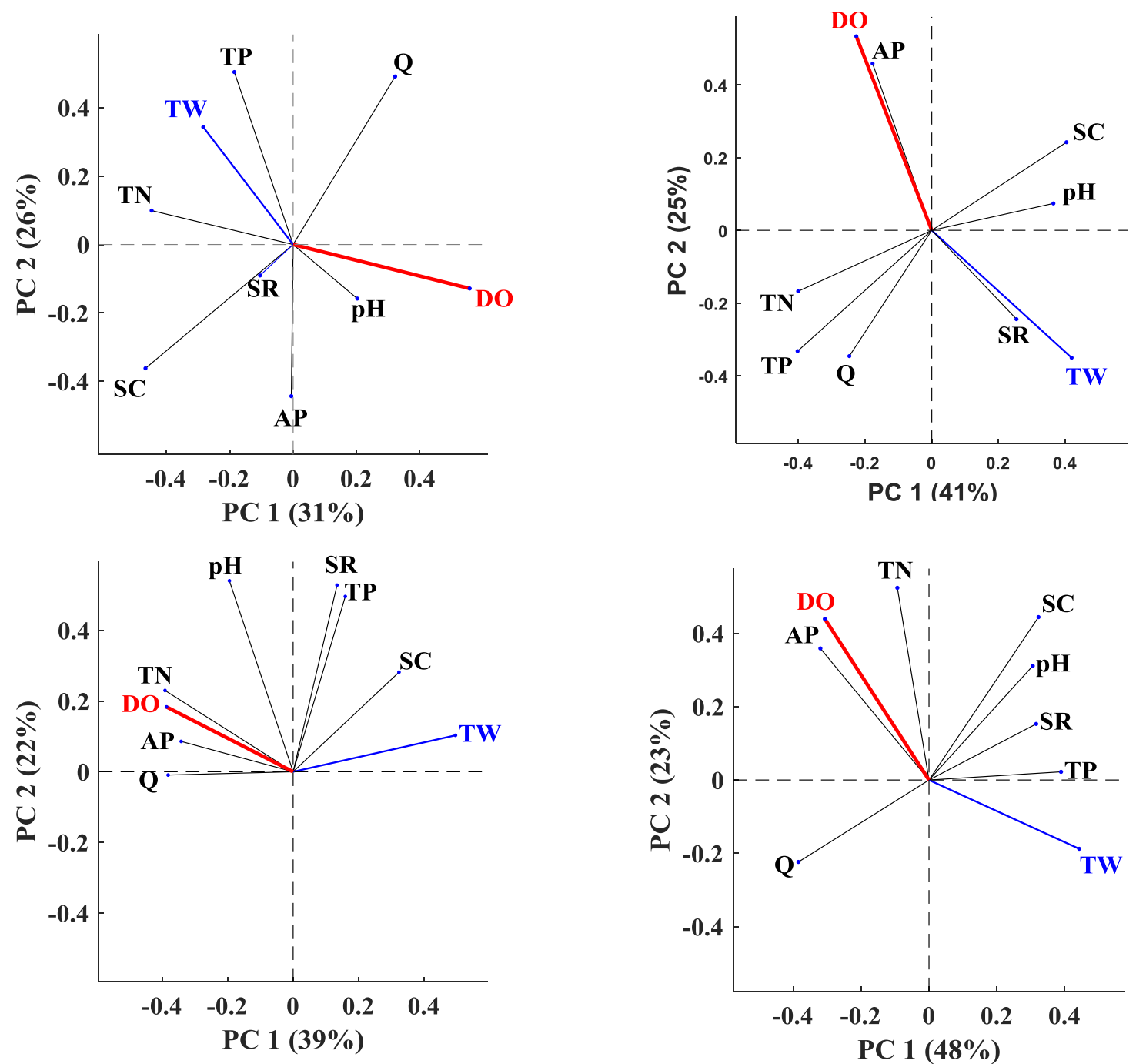

Figure A4: (continued). 

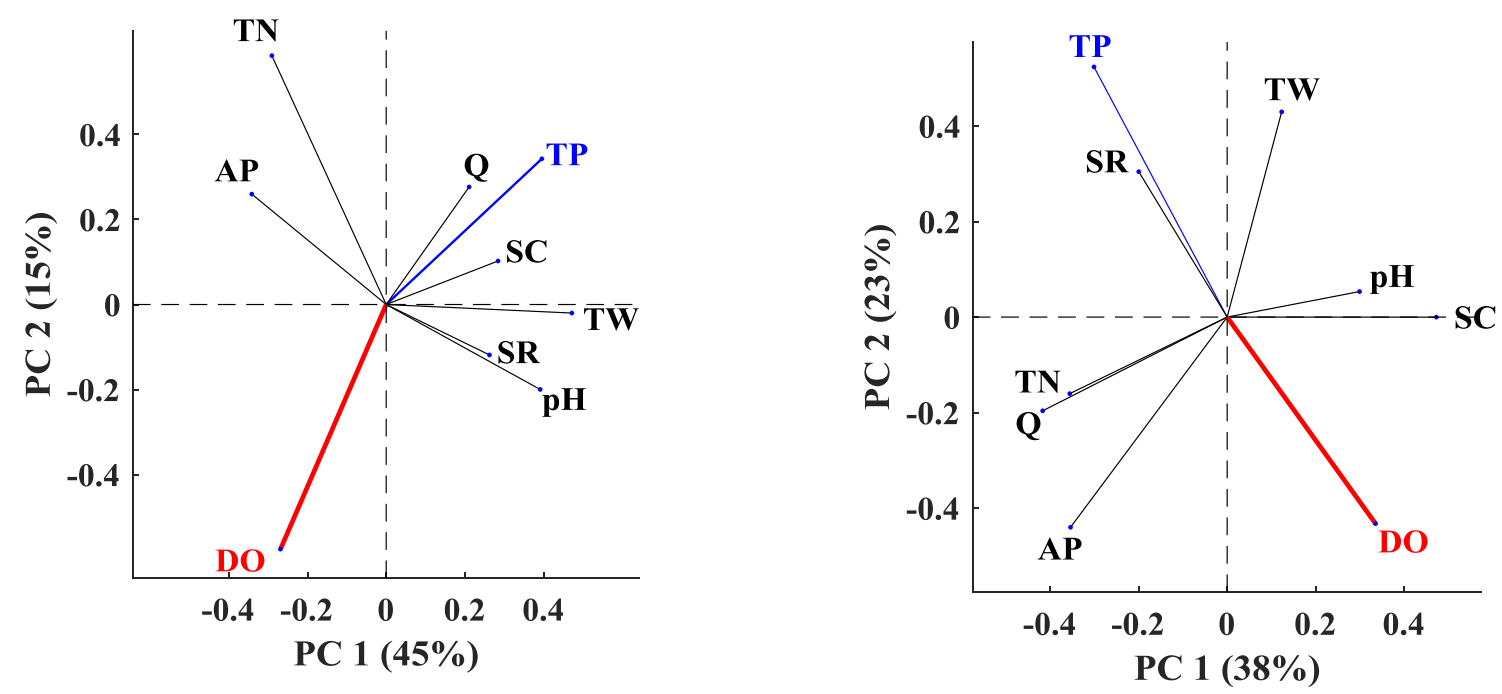

Figure A5: Biplots of Type II regime obtained from principal component analysis showing interrelation of DO with the dynamic environmental drivers.
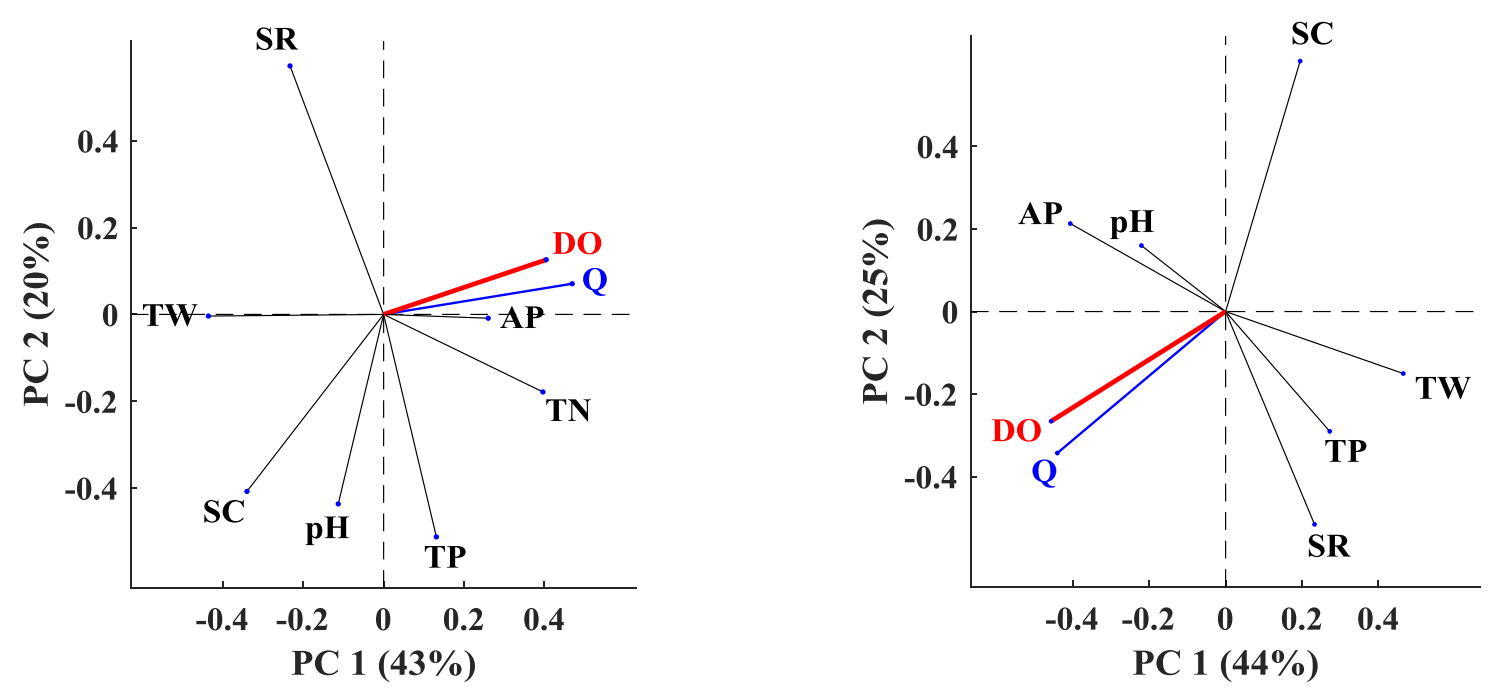

Figure A6: Biplots of Type III regime obtained from principal component analysis showing interrelation of DO with the dynamic environmental drivers. 

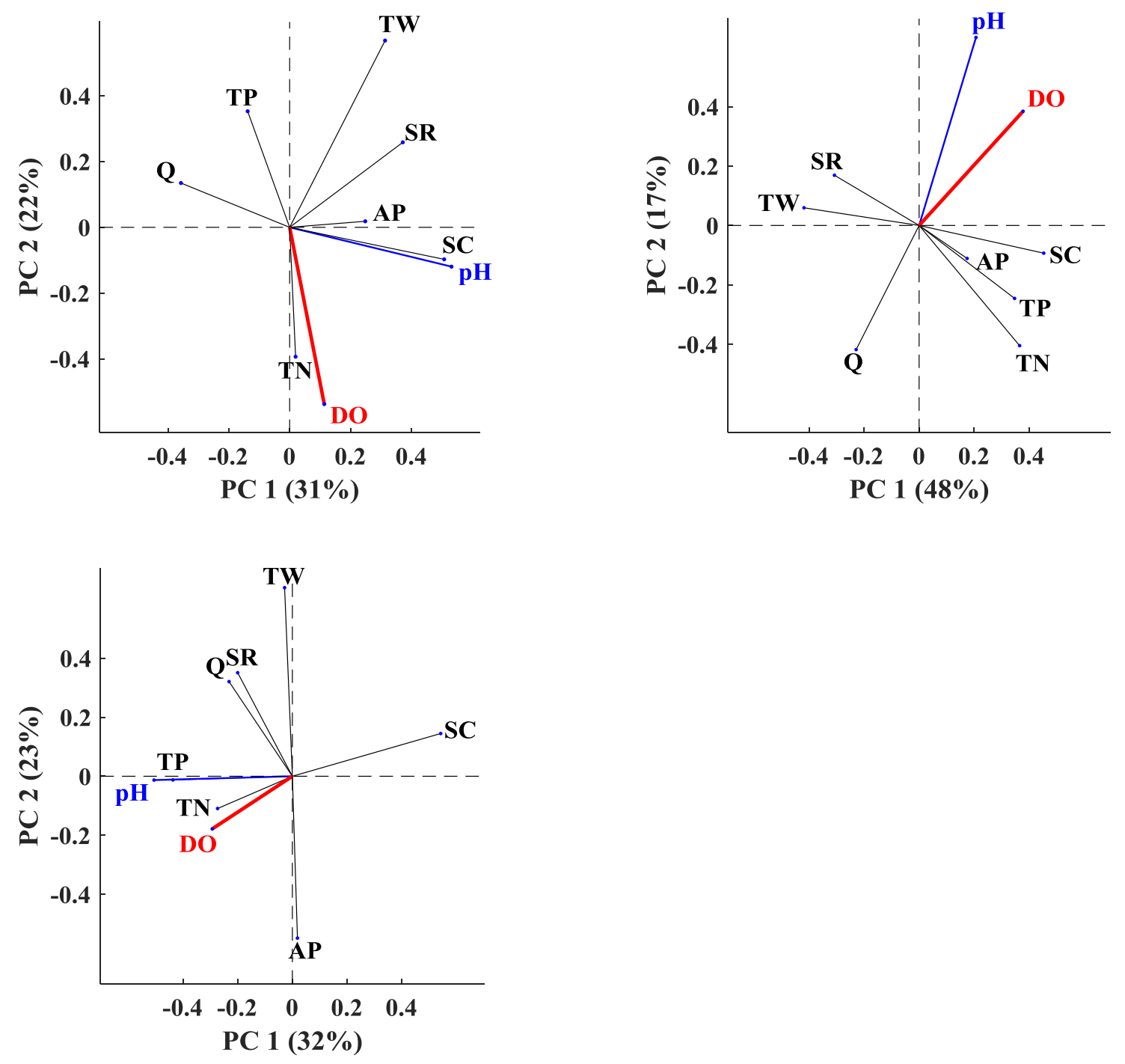

Figure A7: Biplots of Type IV regime obtained from principal component analysis showing interrelation of DO with the dynamic environmental drivers. 
(a)

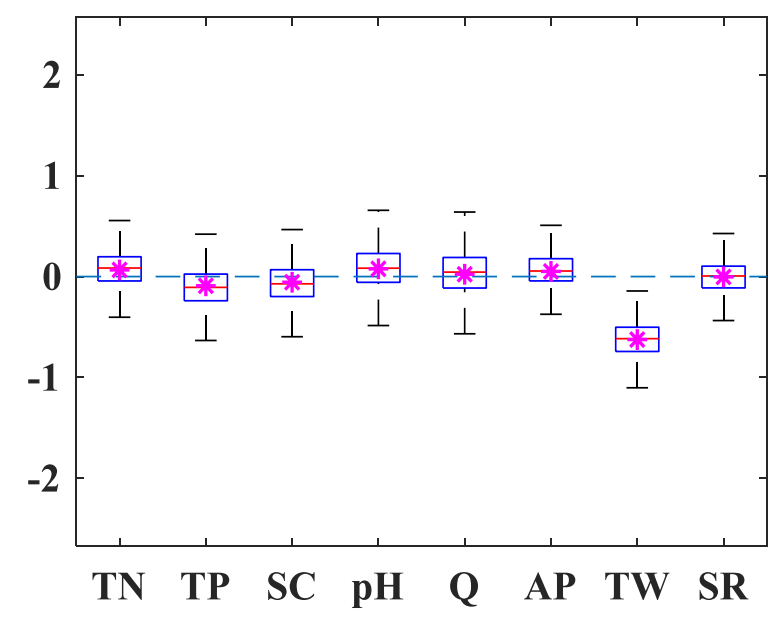

(c)

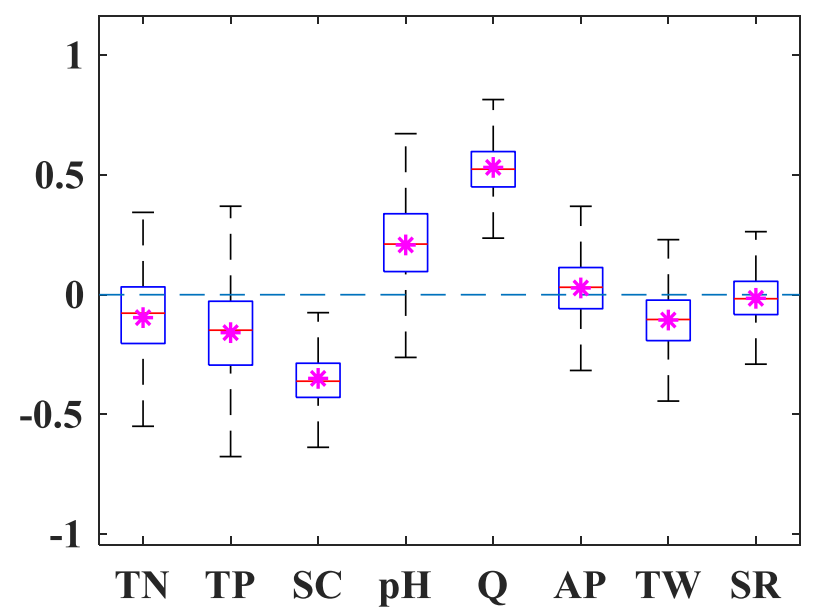

(b)

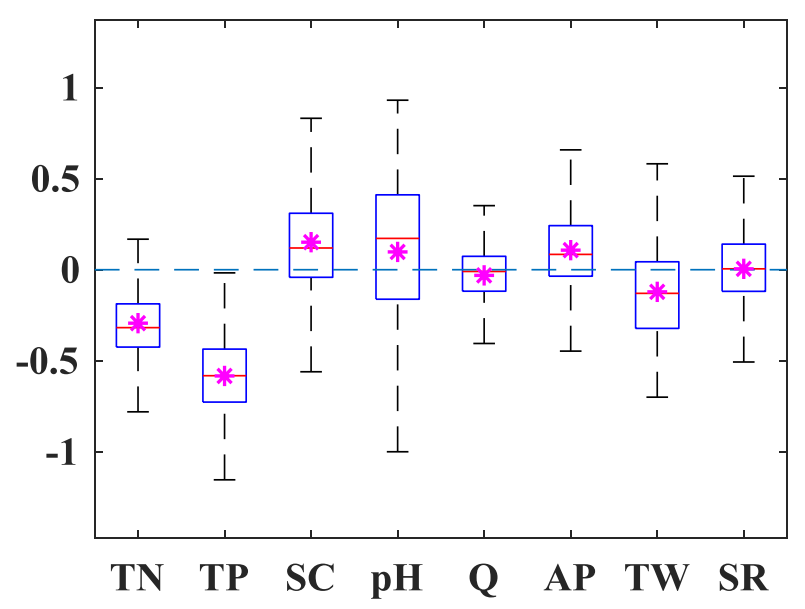

(d)

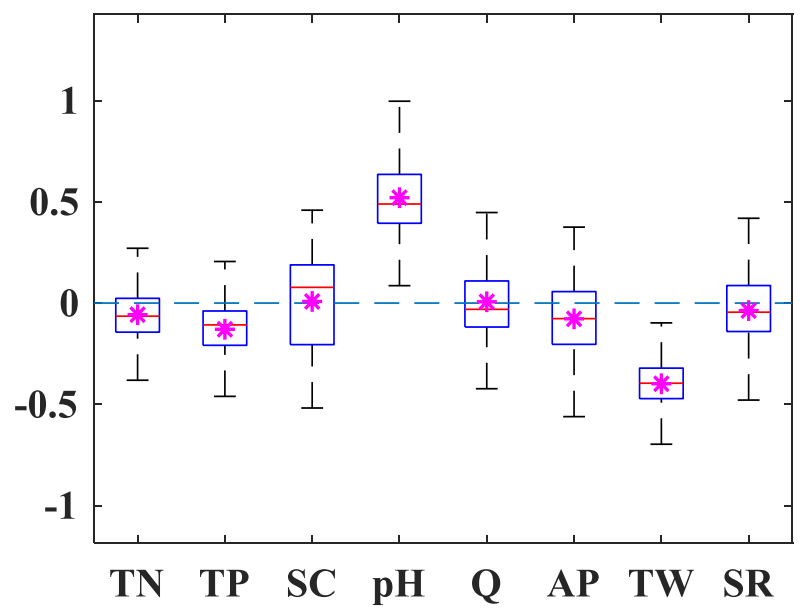

Figure A8: Box plots of beta coefficients after 1000 Monte Carlo for each environmental regime:

(a) Type I regime, (b) Type II regime, (c) Type III regime, and (d) Type IV regime. 


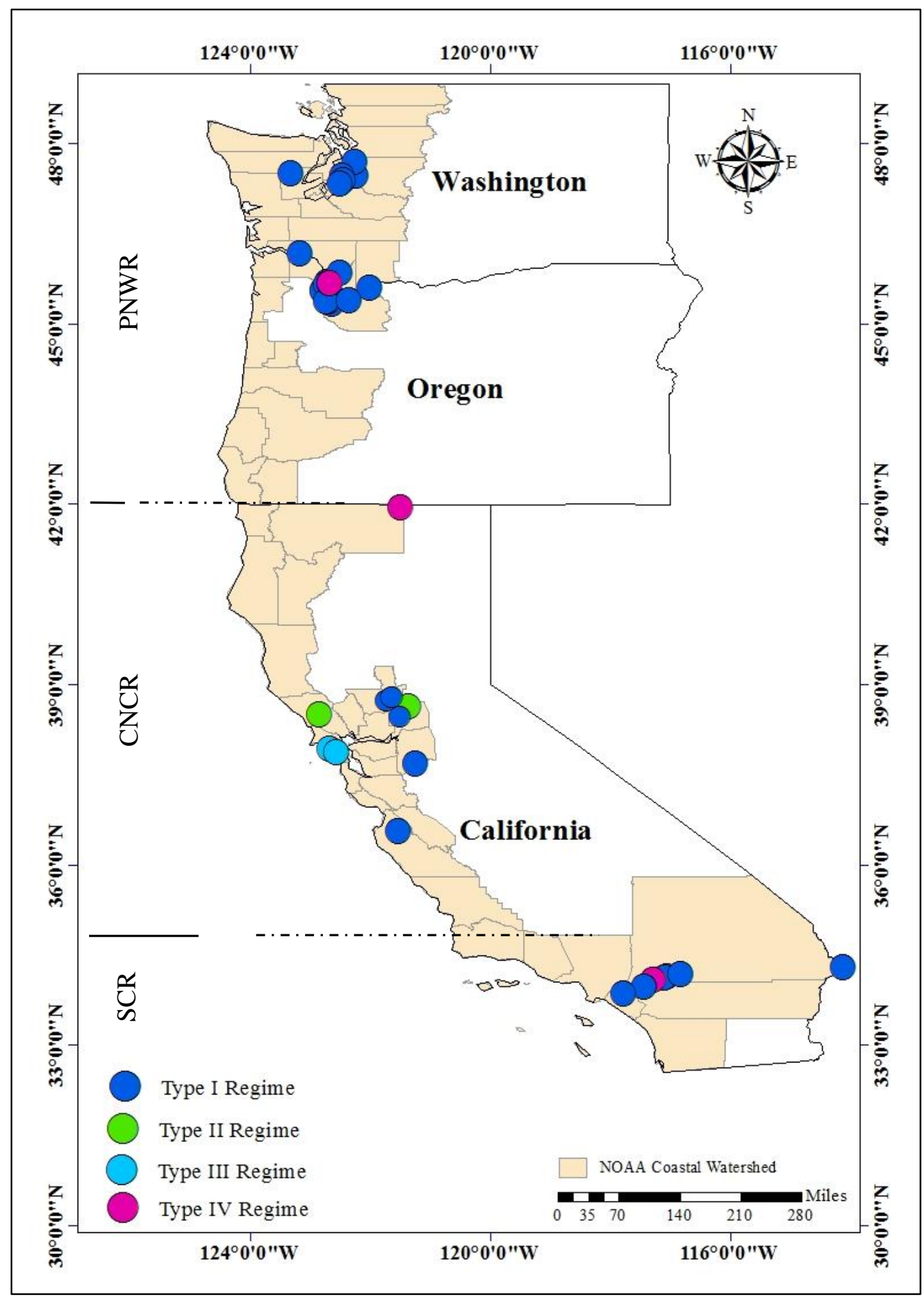

Figure A9: Locations of coastal stream water quality monitoring stations for the dominant process components in four different environmental regimes across the Pacific Coast of U.S.A. 

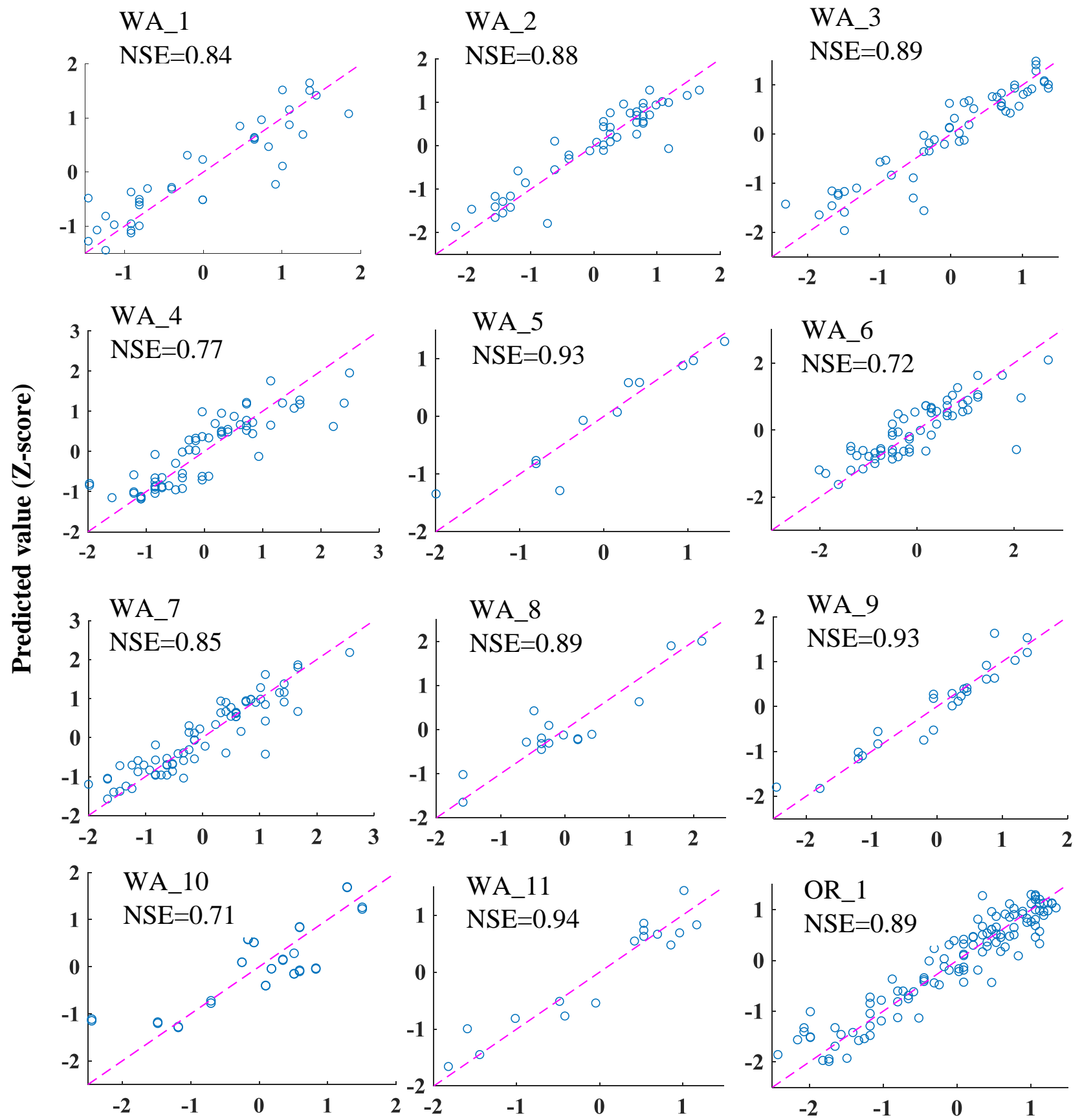

Observed value (Z-score)

Figure A10: Observed vs. predicted Z-scores of dissolved oxygen. 

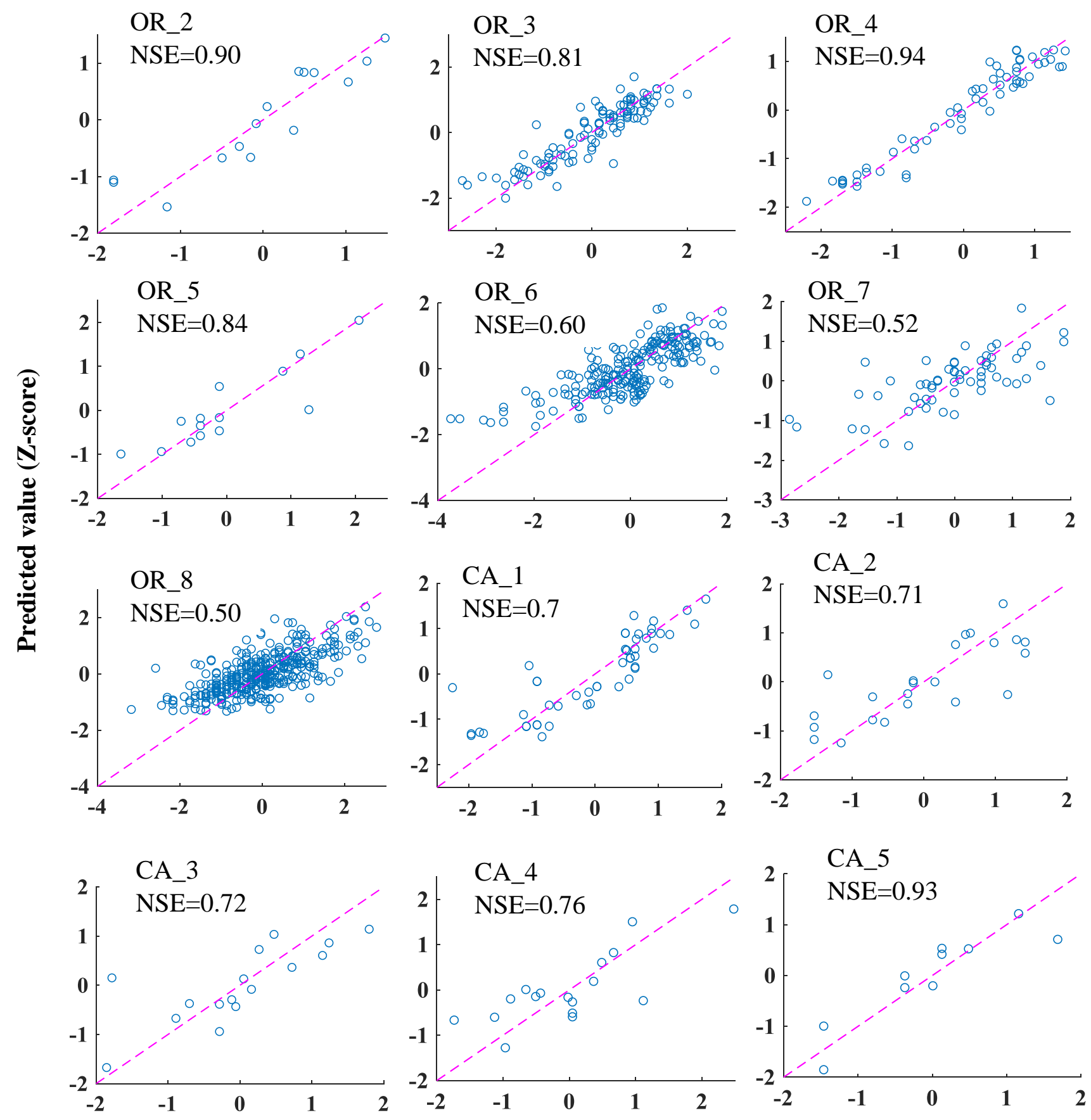

Observed value (Z-score)

Figure A10: (continued). 

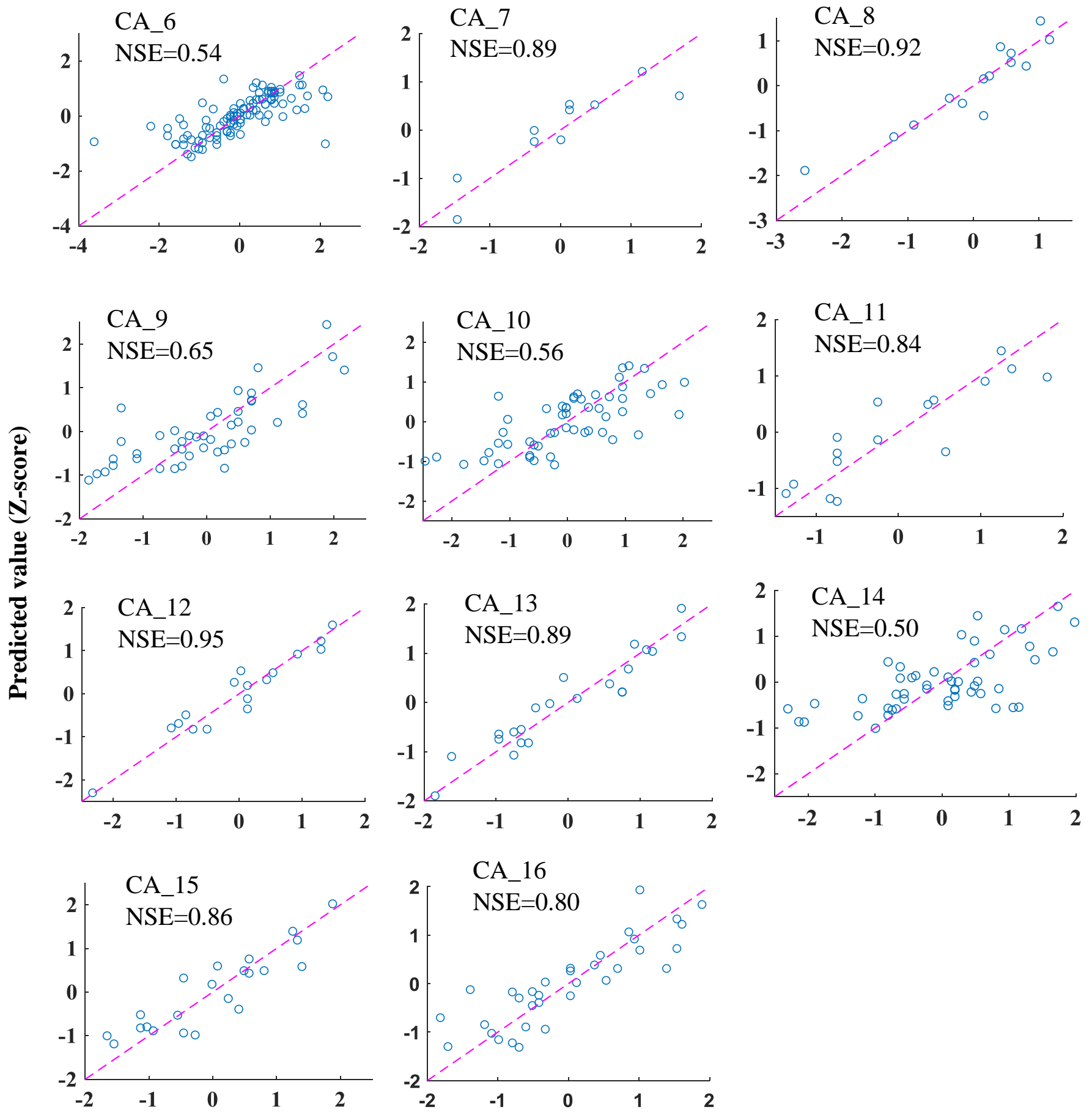

\section{Observed value (Z-score)}

Figure A10: (continued). 


\section{Appendix B}

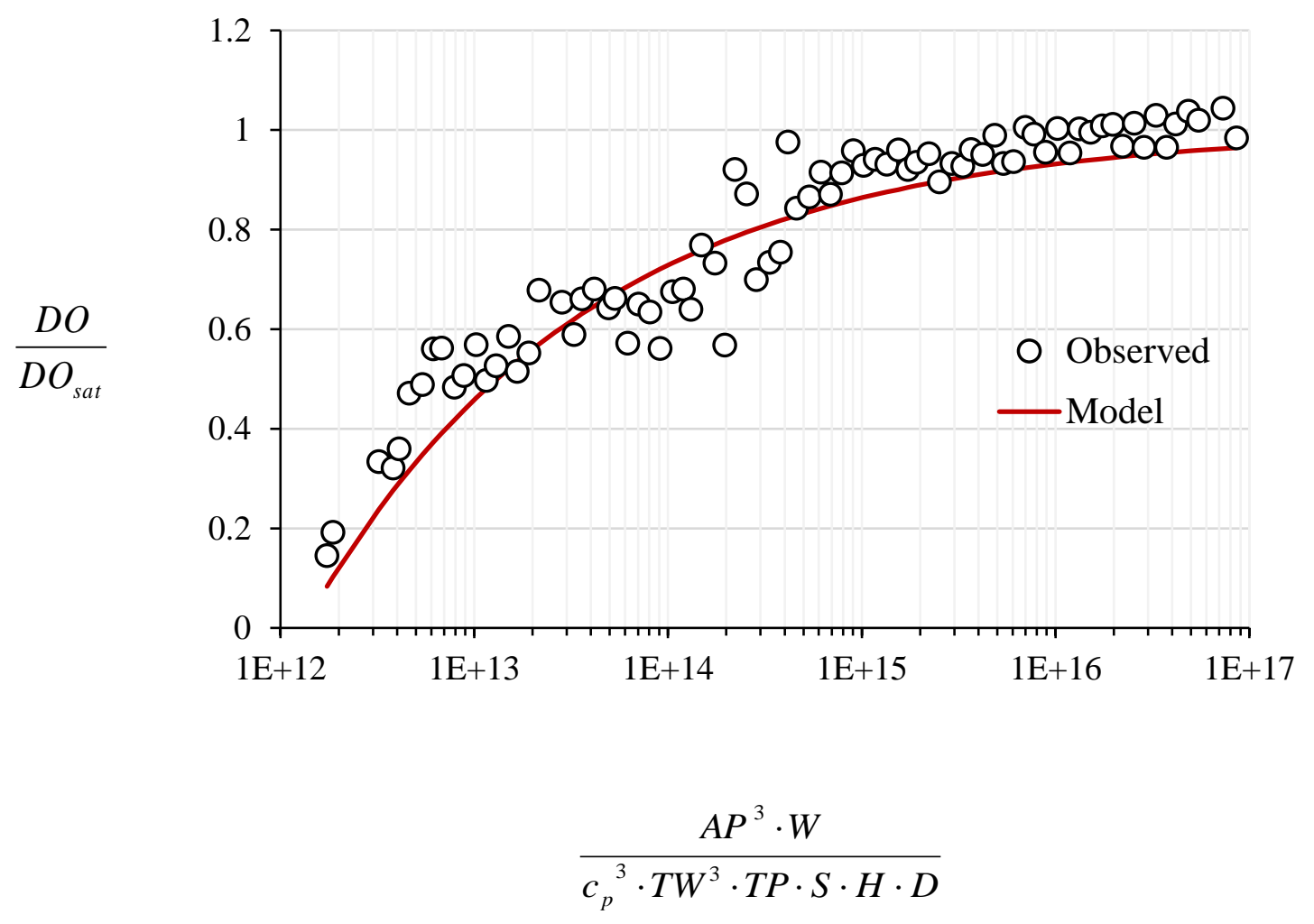

Figure B1: Plot of the bin-based average data between the predictor dimensionless group $\left(\Pi_{\mathrm{r}}\right)$ and the response dimensionless group (DO*). 

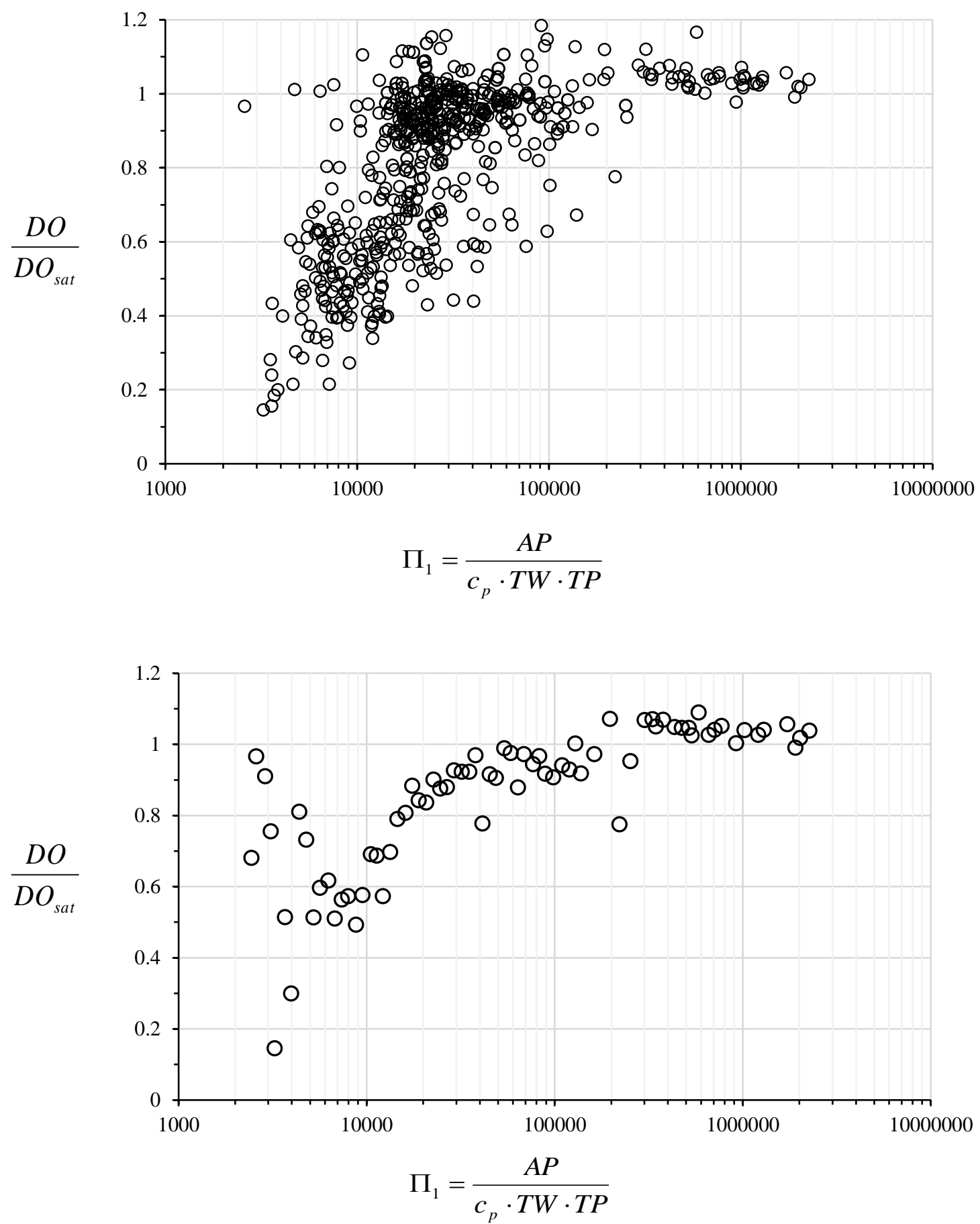

Figure B2: Plot of the predictor dimensionless group $\left(\Pi_{1}\right)$ with the response dimensionless group (DO*): collapse of (a) all original data and (b) bin-based averaged data from different streams across different environmental regimes. 

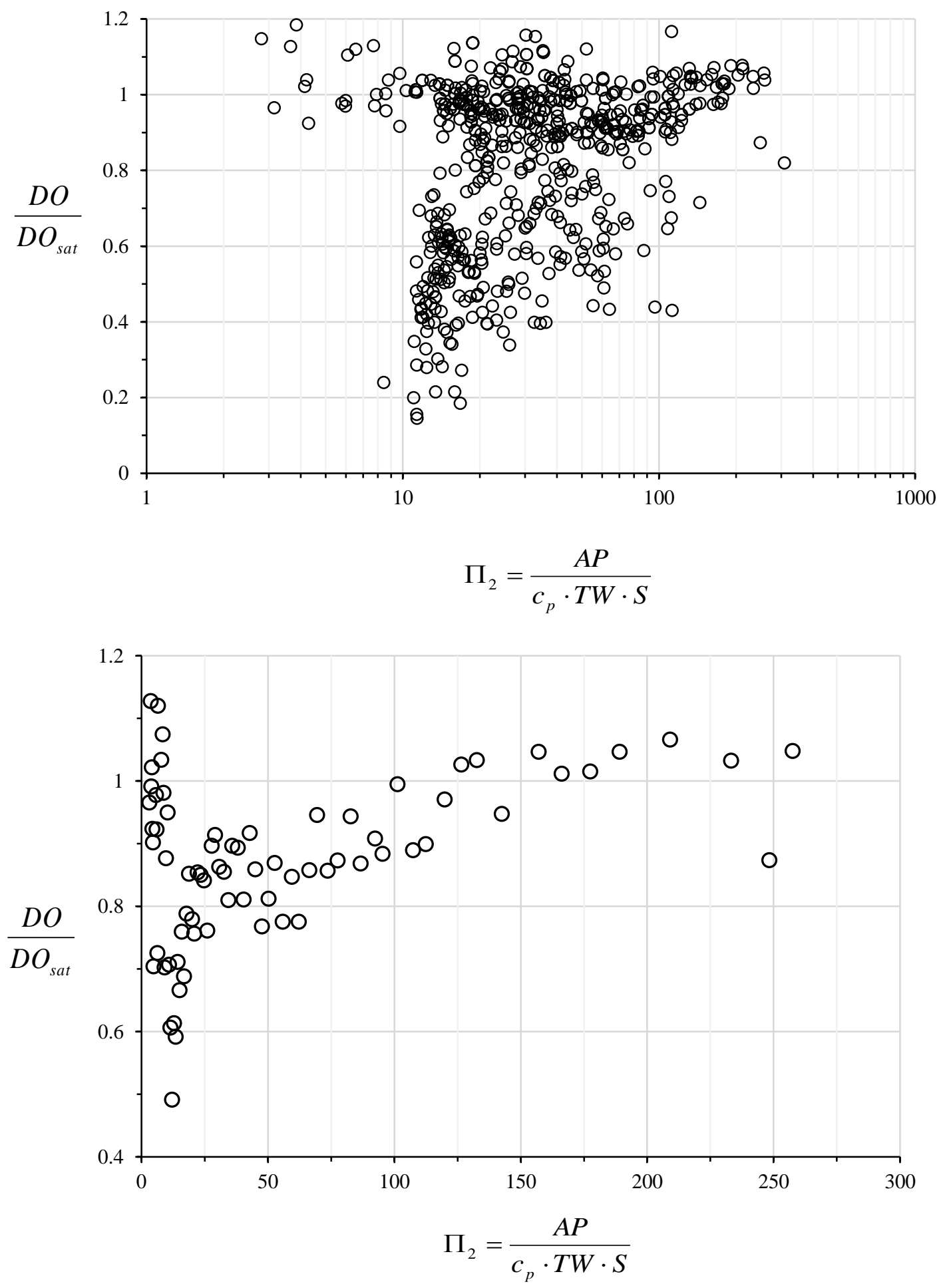

Figure B3: Plot of the predictor dimensionless group $\left(\Pi_{2}\right)$ with the response dimensionless group (DO*): collapse of (a) all original data and (b) bin-based averaged data from different streams across different environmental regimes. 


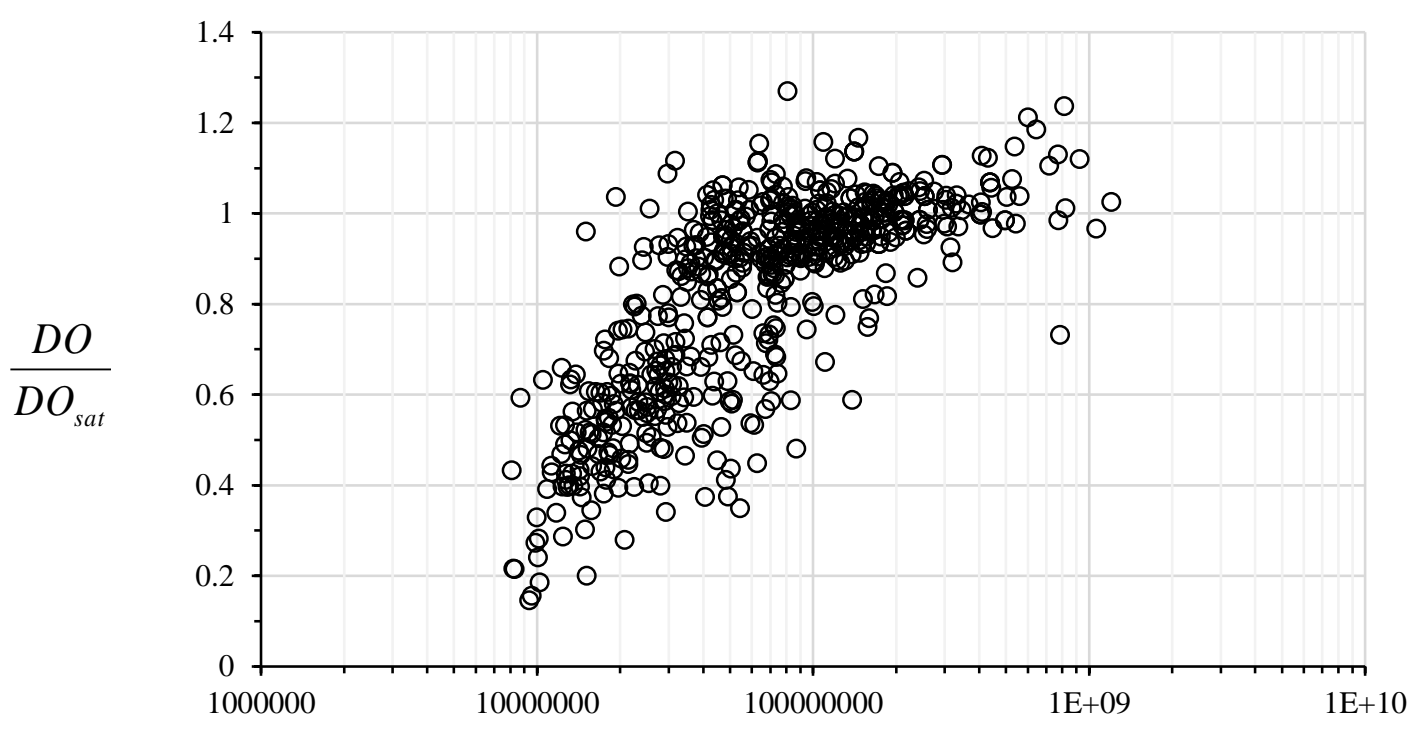

$$
\Pi_{3}=\frac{A P}{c_{p} \cdot T W \cdot H}
$$

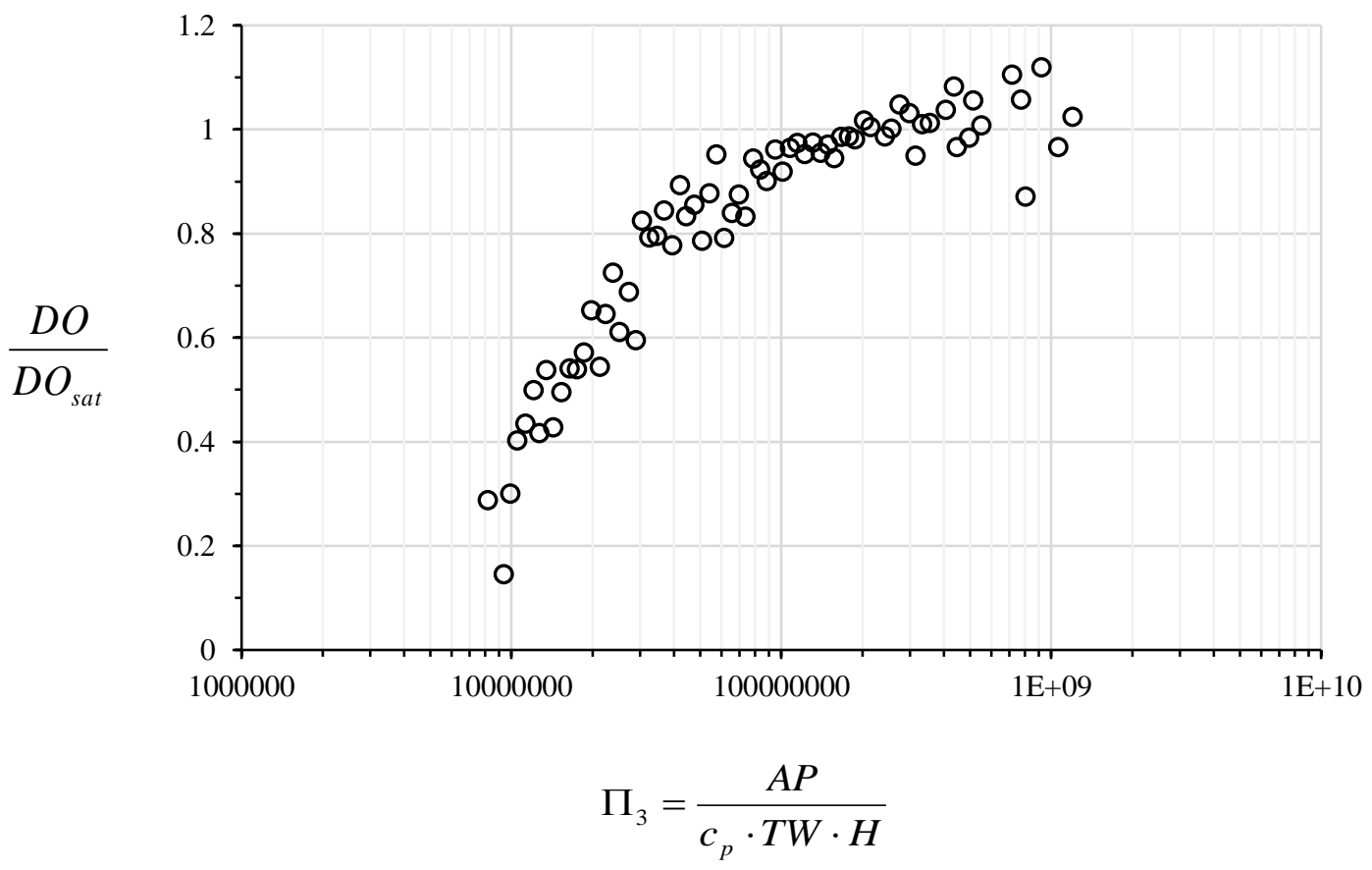

Figure B4: Plot of the predictor dimensionless group $\left(\Pi_{3}\right)$ with the response dimensionless group (DO*): collapse of (a) all original data and (b) bin-based averaged data from different streams across different environmental regimes. 